Portland State University

PDXScholar

$1-8-1993$

\title{
Second Language Use in the Workplace: A Case Study of a Dental Hygienist
}

Gina L. Crocetti

Portland State University

Follow this and additional works at: https://pdxscholar.library.pdx.edu/open_access_etds

Part of the Bilingual, Multilingual, and Multicultural Education Commons Let us know how access to this document benefits you.

\section{Recommended Citation}

Crocetti, Gina L., "Second Language Use in the Workplace: A Case Study of a Dental Hygienist" (1993). Dissertations and Theses. Paper 4578.

https://doi.org/10.15760/etd.6462

This Thesis is brought to you for free and open access. It has been accepted for inclusion in Dissertations and Theses by an authorized administrator of PDXScholar. Please contact us if we can make this document more accessible: pdxscholar@pdx.edu. 
AN ABSTRACT OF THE THESIS OF Gina L. Crocetti for the Master of Arts in TESOL presented January 8, 1993.

Title: Second Language Use in the Workplace: A Case Study of a Dental Hygienist

APPROVED BY MEMBERS OF THE THESIS COMMITTEE:

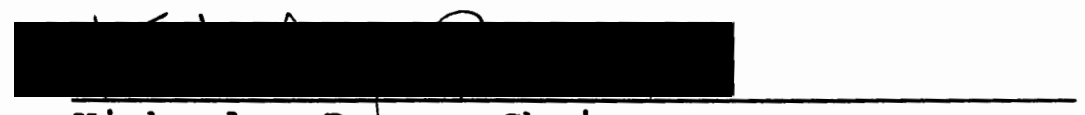

Kimberley Brown, Chair
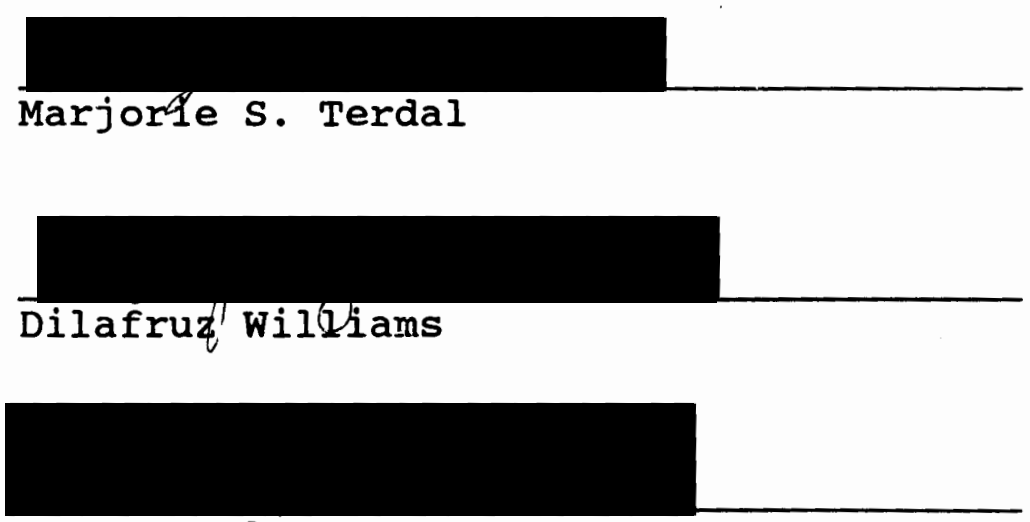

Susan Poulsen

This paper describes a case study of a non-native speaking (NNS) dental hygienist in her work environment. The subject learned English by learning to become a dental hygienist rather than through formal language education. Participant observation and discourse, event/network, and componential analyses were the methods used to analyze the 
subject's communication in her work setting.

The philosophical question as to how ESP differs from ESL is raised and elements of the work setting and the NNS workers' communication with interlocutors in that setting are identified to aid educators in teaching ESP courses. Questions ESP educators might address in designing and teaching ESP courses are given as well as suggestions for future research. 
SECOND LANGUAGE USE IN THE WORKPLACE:

A CASE STUDY OF A DENTAL HYGIENIST

by

GINA L. CROCETTI

A thesis submitted in partial fulfillment of the requirements for the degree of

MASTER OF ARTS

in

TESOL

Portland State University

1993 
TO THE OFFICE OF GRADUATE STUDIES:

The members of the Committee approve the thesis of Gina L. Crocetti presented January 8, 1993.

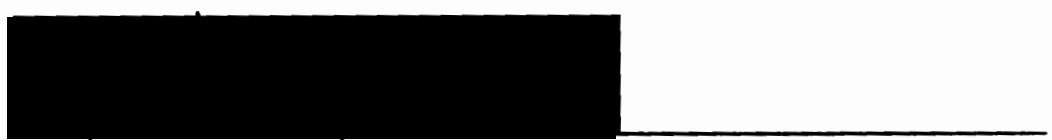

Kimberley Brown, Chair

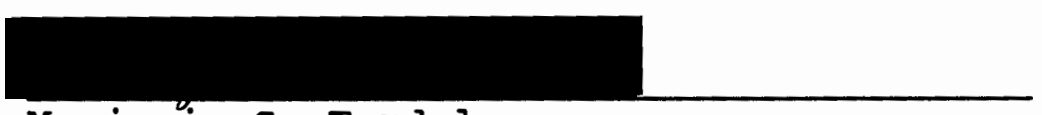

Marjorie S. Terdal

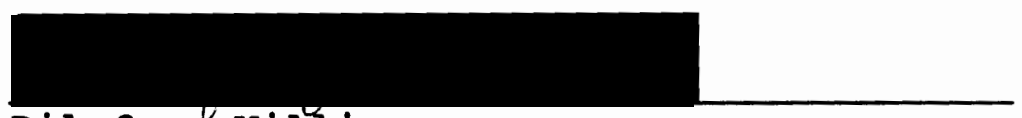

Dilafruz williams

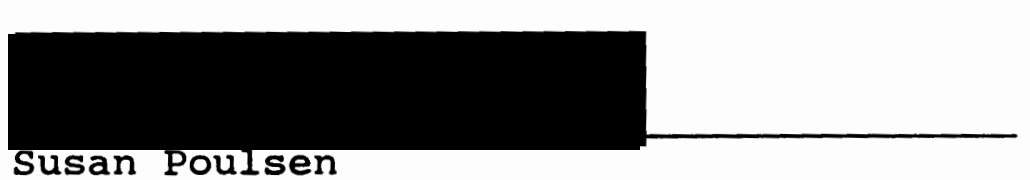

APPROVED:

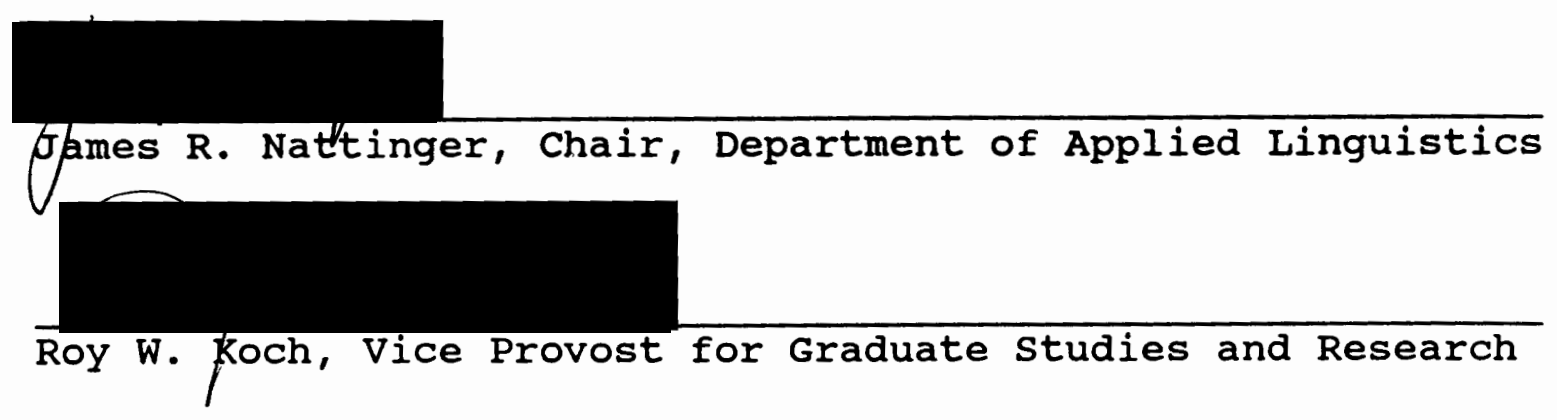


TABLE OF CONTENTS

PAGE

LIST OF TABLES . . . . . . . . . . . . . . . . . v

LIST OF FIGURES . . . . . . . . . . . . . . . . vi

CHAPTER

I INTRODUCTION . . . . . . . . . . . . . . . . I

The approach of this study . . . . . . . 3

Quantitative versus Qualitative Research

Research Questions . . . . . . . . . 8

II LITERATURE REVIEW . . . . . . . . . . . . 10

Communicative competence . . . . . . . . . 11

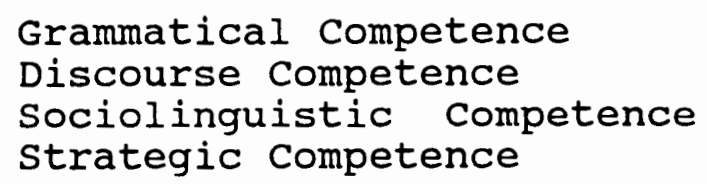

Methods of Research . . . . . . . . . . 17

III METHODS . . . . . . . . . . . . . 30

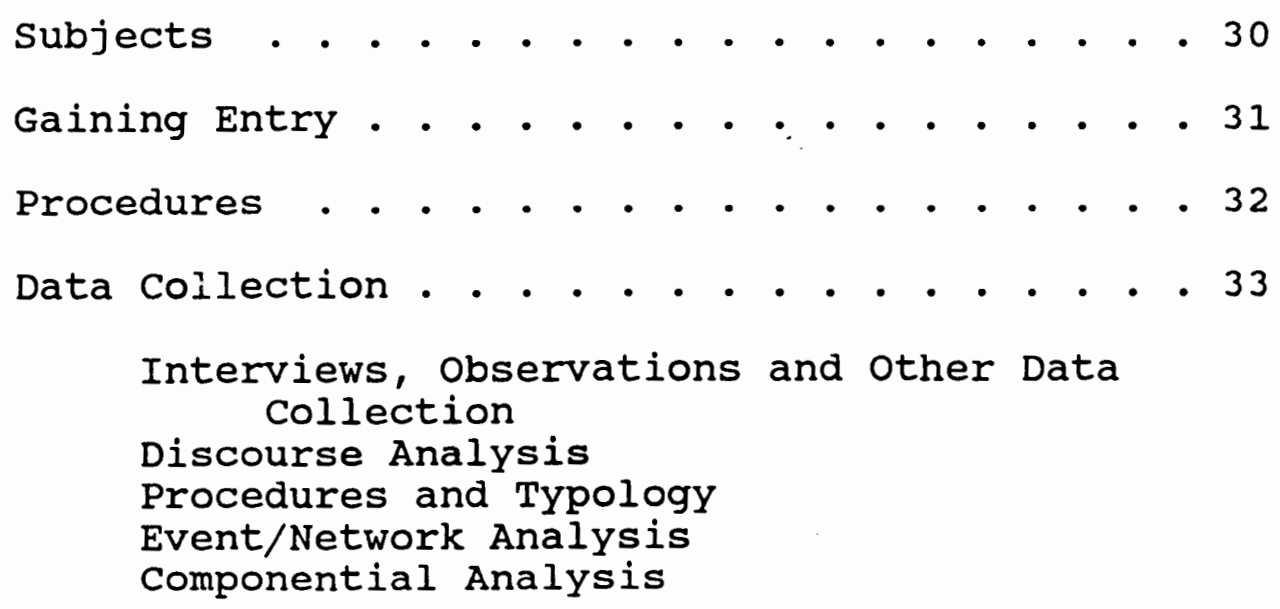


IV CONTEXT ................... . 49

Iulia's Background . . . . . . . . . . 49

Iulia's Professional Work Culture.. . . . 55

Types of Patients.............. . 63

V ANALYSIS/RESULTS . . . . . . . . . . . 68

Analyses . . . . . . . . . . . . 68

Discourse Analysis

Event/Network Analysis

Componential Analysis

Summary . . . . . . . . . . . . . 119

VI DISCUSSION . . . . . . . . . . . . . . 121

The NNS Profile............ . . 121

Profile of the Dental Culture . . . . . 126

Questions . . . . . . . . . . . 129

Question 1

Question 2

Question 3

Limitations . . . . . . . . . . 134

Summary . . . . . . . . . . . . . 136

SOURCES CONSULTED . . . . . . . . . . . . . . . . 138 APPENDICES

A SPEAK TEST . . . . . . . . . . . . . . . 143

B PATIENT CONSENT FORM . . . . . . . . . . . 145

C EVENT/NETWORK DATA . . . . . . . . . . . 147

D DISCOURSE TRANSCRIPTS . . . . . . . . . . 161

E COMPONENTIAL ANALYSIS TRANSCRIPTS . . . . . • 171 


\section{LIST OF TABLES}

TABLE

PAGE

I Communication Strategies . . . . . . . 70

II Observed Interactions . . . . . . . . . 82

III Time Breakdown . . . . . . . . . . . . 93

IV Componential Data . . . . . . . . 102

V Dentists . . . . . . . . . . . . 112

VI Dental Administration . . . . . . . . 114

VII Dental Administration II . . . . . . . 116 
LIST OF FIGURES

FIGURES

PAGE

1 Communication Network . . . . . . . 80

2 Time Breakdown Diagram . . . . . . . . 93 
CHAPTER I

\section{INTRODUCTION}

The purpose of this research is to define what it means for a non-native speaker (NNS) to be communicatively competent in a specific professional environment. This involves identifying who the NNS communicates with, the dynamics and nuances of communication, and the linguistic skills the NNS needs in order to communicate at work. The educational needs and goals of NNS learners and the obstacles they face in achieving them will also be addressed. Finally, based on this research, recommendations to aid educators in bridging the gap between business and education will be given.

Businesses have begun to realize a need for a better educated labor force as machines replace manual labor and force workers into service positions which require abilities to communicate using different mediums (spoken, written, and electronic means). Businesses are funding literacy and math courses and more frequently of late, English as a second language (ESL) classes. But who are the students attending such classes? How are they different or similar to the ESI students in a university or college classroom? What difficulties do businesses face in educating these 
employees? The financial opportunities, needs and expectations of students wanting to learn English in order to do their job or change occupations and students wanting to learn English in order to pursue higher education are different. The latter group is privileged, able to make choices to improve their Iives; the former group often faces hard work and the hope their efforts will someday benefit their children. Students in an academic setting are usually well educated in their first language; they do not necessarily intend to remain in the host country for an extended period; they frequently are not allowed to work because they do not have work visas, and many come from wealthy families who can afford to educate their children abroad. Non-native speaking immigrants in a work environment tend to have fewer advantages. This group may or may not be educated in their first language, must work to support themselves and their families, and reside permanently in their host country as many of them are immigrants. The immigrant workers' educational needs and goals and the obstacles they face in achieving them are the focus of this study.

If immigrants' second language skills are low, they are forced to take low paying, manual labor jobs. When offered English courses, immigrants' interests in taking the courses may be to improve their English so they can obtain better jobs in fields of their choice. On the other hand, 
businesses offering courses in English for specific purposes (ESP) or English for the workplace (EWP) are interested in improving their employees' ability to communicate with coworkers and clients or promote them to positions requiring language fluency since educating employees is less expensive than hiring and training new ones. Instructors, teachers, and professors are held accountable by both the students and employers. Given such different goals, the demands the employers and employees place on educators may be in conflict.

An educator familiar with students' backgrounds, work setting, and relationships in that setting will be better prepared to help students achieve their professional goals. This study looks at one NNS professional in her work environment in order to provide some insight into the needs and goals of immigrant workers and describes the relationships and dynamics of a work setting in order to facilitate language educators' transition from teaching in an academic environment to teaching in a business one.

\section{THE APPROACH OF THIS STUDY}

\section{Quantitative versus Qualitative Research}

To understand the needs of the non-native speaking workers and their employers, one must understand the students' backgrounds, their work culture, and their needs in that culture. Both quantitative and qualitative research 
have their place in gaining an understanding of the work environment and the speech participants in that environment. Quantitative measures can be used for many purposes, for example, identifying the commonalities of student and employer needs and cultures in different fields and measuring the success of one teaching technique versus another in a particular environment. Such studies are important but premature to an understanding of the environment and the speech participants being studied. Qualitative studies require that researchers attempt to put themselves in their subjects' place and understand the situation from the subjects' point of view. Spradley (1980) says the participant observer has a dual purpose, "(I) to engage in activities appropriate to the situation and (2) to observe the activities, people, and physical aspects of the situation" (p. 54). By appreciating the way subjects and/or students view their situations, researchers can identify issues of study for which the answers are important to their subjects. Teachers can base their teaching on needs the learners feel are important rather than what the teacher thinks learners might find important.

Research in second language learning has typically used quantitative methods of measurement. According to watsonGegeo (1988), quantitative methods are static in that they involve single-time observations or testing; they intercept language learning and look at the data in a cross-sectional 
manner. However, language learning is an interactive, ongoing process. In a qualitative approach to research, individual learners are studied in a holistic manner in order to provide information

about the processes and strategies that individual L2 learners use to communicate and learn, how their own personalities, attitudes, and goals interact with the learning environment, and about the precise nature of their linguistic growth. (Johnson, 1992: 76)

Qualitative research serves to identify variables for further study and measurement while quantitative research measures variables for which findings are generalizable to the population being studied; thus, quantitative research would seem to follow and complement qualitative research naturally.

The type of qualitative research used in this study is ethnographic. Data are gathered through observation and provide a description of an individual or a group studied. But research must go beyond the level of description to explanation in hopes that findings from a study might be applied to better understand how students learn and how educators will be better able to meet their needs. Spradley (1979, 1980) and Dobbert (1982) have attempted to systematize ethnographic research. Their techniques and others from the field of linguistics were borrowed to conduct this research and provide an explanation as well as 
a description of the group studied. The background for this study and further arguments in favor of using ethnographic research are provided in Chapter II.

Having identified the particular area of language education I wished to study and the type of research method I expected to use (qualitative), there remained the task of identifying a NNS individual in a specific occupation for study. I met her by chance when I went to a university to have my teeth cleaned. I was given to Iulia, a Romanian woman in her final term of a dental hygiene program. My dental profile was such that I proved to be an ideal test subject and agreed to participate in Iulia's final board (an applied exam). The entire cleaning lasted twelve hours and had to be completed in three four-hour sessions. In the first two of these visits my teeth were examined by Iulia and by at least three supervisors, my medical history was charted, 18 x-rays of my teeth were taken, and one quarter of my teeth were cleaned. The final visit was Iulia's scheduled exam during which she was given two hours to clean one half of my teeth.

The length of the entire cleaning was excessive for a graduating hygienist (12 hours as opposed to less than an hour in professional practice). However, the twelve hours proved very interesting from a linguistic and cultural perspective. I seemed to be the only person who did not have difficulty hearing Iulia when she spoke. Our faces 
were close together as she worked and her soft voice was audible to me only because of our close proximity. I recall being surprised when Iulia asked me to spell several medical terms and then I had to struggle to maintain confidence in her abilities. My confidence deteriorated as time passed and little progress in cleaning my teeth was made.

Knowing what to expect, I was extremely reluctant to return for my second visit. It proved as difficult and long as the first and Iulia was impatient with me for not bearing the pain more graciously. We were both concerned she would not be able to complete her final board because of time limitations and agreed I should be numb during the exam. However, Iulia successfully completed her exam in the allotted time.

over the next couple of weeks I reflected on the feelings, attitudes, and opinions I formed while sitting in Iulia's chair. I wondered if she would be able to find work in her field now that she was graduating. I remembered the stories she told me about herself and I was ashamed at having formed opinions because of her linguistic difficulties and lack of speed probably due to a lack of confidence rather than a lack of training or ability. Iulia presented her views, beliefs, and opinions with unwavering confidence. Her soft, uncertain voice was in sharp contrast to the secure person I came to recognize in her in a very short time. 
I observed Iulia over the next year and a half as she entered her chosen professional field. I watched as she struggled to adjust linguistically and culturally, as she gained mastery of her newly acquired dental hygiene skills, and as she adjusted between the two worlds of her personal and private lives. This thesis is in part an ethnographic story of an immigrant and her success in a professional field in a second language and culture despite her never having had the luxuries of time and money to pursue structured second language study. Qualities Iulia possesses that have contributed to her success are identified in this study as well as insights into the work culture and the conflicts at least one second language learner experienced in confronting that culture. The information is meant to help ESL instructors interested in ESP move more fluidly between the academic and business environments, and to help them realize the many issues at stake for employers and learners. Questions will then be generated for future researchers to test in order to develop better teaching methods for teachers to help immigrant learners move into professional fields should they so desire.

\section{RESEARCH QUESTIONS}

Interviews, observations, and recorded segments of speech comprise the data used in this study. Analysis of the data gathered helps answer questions regarding the 
implementation of ESP courses: 1) What characteristics of a specific setting need to be identified and taught to nonnative speakers in order for them to function and communicate in their professional fields? 2) How can professional language educators best meet the needs of the ESP learners and meet the desires of the business community simultaneously? and 3) Are the language competencies, functions, and settings so different in ESP as compared with ESL that ESP needs to be heralded as a separate discipline? 
CHAPTER II

\section{LITERATURE REVIEW}

I attempted to determine how researchers view ESP as different from ESL when I reviewed the ESP literature. I also looked at how educators have historically taught ESP so that, once my own observations and analyses were completed, I might better be able to answer my second research question: How can professional language educators best meet the needs of the ESP learners and the desires of the business community simultaneously.

Hutchinson and Waters (1987) call ESP an approach based on learner need. Essentially, ESP looks at the question: what is the learner's purpose in learning English? Drobnic (1978) says ESP is a tool for achieving another goal, that is, communicating internationally within a discipline. Further, he describes it as, "a response reflecting the shifts and changes in the world's balance of power in this century" (p. 3). Developing nations realize that in order to advance they must communicate with and learn from developed nations and English has emerged as the common, international language of communication. Learners' purposes for learning English are often to keep current with advances in their fields while practicing their profession in their 
native country and using their native language to do so. Advances in technology, professional publications, and international conferences are most frequently published or conducted in English. Learners' purposes in learning English are sometimes specific to communicating in their field rather than learning English for an aesthetic or general purpose. Thus, ESP learners are sometimes prepared to communicate at a professional level but are unable to communicate on general topics.

COMMUNICATIVE COMPETENCE

In attempting to address what the specific language of a field needed to be taught might be, it is necessary to look at what is involved in communicating competently in a second language. Communicative competence, according to Chomsky (1965), consists of both linguistic competence and linguistic performance. A linguistically competent speaker is defined by Chomsky as an ideal speaker or listener who, in a homogeneous speech community, has mastery of the abstract system of rules of the language and of the ability to produce and understand them. He defines linguistic performance as how the speaker or listener actually uses the language and how the language is affected by what the person knows to be acceptable even if not grammatically correct.

To this definition Hymes (1972) added appropriacy of language in context, "whether (and to what degree) something 
is appropriate (adequate, happy, successful) in relation to a context in which it is used and evaluated" (pp. 281-2). Hymes' definition allows us to differentiate between the knowledge of the rules and forms of a language and the knowledge needed to communicate with a variety of people in a variety of settings.

Chomsky's and Hymes' combined contributions to the definition of communicative competence comprise the meaning of communicative competence as it will be understood in this research. Communicative competence can now be broken down into four subcategories (Canale \& Swain, 1980). In looking at these subcategories individually it will be possible to see how ESP has historically handled the issue of communicative competence and to address whether or not ESP is distinct from ESL. The categories are 1) grammatical competence, 2) discourse competence, 3) sociolinguistic competence, and 4) strategic competence.

A functional/notional approach to teaching ESP was an early approach to developing learners' communicative competence (van Ek, 1975). This approach identified "the categories into which the mind and thereby language divides reality, for example, time, frequency, duration, gender, number, location, quantity, quality, etc" (Hutchinson \& Waters 1987: 31). This approach identifies possible surface forms to be used in stated contexts and creates simulated situations for their use. The danger in this approach is 
that it lacks a systematic conceptual framework and learners are not able to organize the knowledge they have of the language (Widdowson, 1983). Giving learners the forms they will use to communicate in their field will not necessarily enable them to use these forms in new situations, to interpret situations, or to call on grammatical structures to communicate. Instead, learners need to develop an underlying grammatical competence so they may interpret and create meaning on their own.

\section{Grammatical Competence}

The category grammatical competence consists of the lexical, morphological, syntactic, semantic and phonetic items and rules a speaker needs in order to master a language. These items and rules may be present at an underlying level of linguistic ability but not necessarily realized by the second language learner when speaking. Speakers' grammars are the rules they have that enable them to create surface structures. The language speakers produce is a reflection of their underlying thoughts and grammatical competence (Chomsky, 1965). Speakers' underlying competence also allows them to interpret meaning. This competence must be developed in order for second language learners to function independently from the teacher and the classroom. 


\section{Discourse Competence}

Discourse analysis seeks to describe linguistic forms as a speaker's "means of expressing intended meaning" (Brown \& Yule, 1984: 24). The interest here is not to describe something complete such as the end result of a form so much as it is to describe the context of an utterance, its purpose in a context, and how it is comprehended and processed. Discourse competence, then, is not simply the knowledge of the underlying rules of English but also the knowledge of the use of sentences in the performance of different communicative acts (Hutchinson \& Waters 1987).

Sentences can have vastly different meanings in different contexts and require speech participants to use their discourse competence to understand conversations. The second language learner must understand how an utterance relates to previous discourse, how the same utterance can have a different meaning in a different context, and when knowledge of social and cultural norms must be called upon to accurately interpret and appropriately produce language (Hymes, 1972). Sentence fragments are often produced in speech and interpreting them requires speakers to rely even more on their discourse competence. Participants must look at the discourse that came before and the discourse that will follow a fragment to understand the meaning of the fragment in context (Swales, 1984). Discussions participants have shared on a topic either through other 
sentences uttered in a current discussion or in past conversations provide participants a meaningful context.

\section{Sociolinguistic competence}

Sociolinguistic competence is the use of appropriate language in a variety of contexts with a variety of speakers. Speakers use shared presuppositions, past experiences and social and cultural norms they have in common to understand a communicative exchange (Brown, 1987: 200) - Speakers assume the world functions in a certain way. When second language learners enter another society they do not share common past experiences and knowledge with native speakers and are unable to interpret speech the same way members of the new culture or NS culture do. Brown \& Yule (1984) say "the smaller the community, the more notions of regularity will be shared since the contexts which the members of the community share will be very similar" ( $p$. 62). One such speech community is a given professional field.

Hymes (1986) says the goal of sociolinguistics is to explain the meaning of language in human life. To develop models or theories of the interaction of language and social life, Hymes believes

there must be (an) adequate description of that interaction, and such descriptions call for an approach that partly links, but partly cuts across, and partly builds between the ordinary practices of the discipline. (p. 41) 
To describe sociolinguistic competence for a non-native speaking dental hygienist, it is necessary to describe the language used in the discipline and how hygienists interact in the social environment of their professional field. Such a description may be achieved through ethnographic research. An argument favoring ethnographic research will be taken up shortly.

\section{Strategic competence}

The fourth category in the definition of communicative competence, strategic competence, consists of the ability and skills a speaker uses to repair breakdowns in communication. This competence allows a second language learner to compensate for imperfect linguistic knowledge and to sustain communication through paraphrase, circumlocution, repetition, hesitation, avoidance, guessing, and shifts in register and style (Sauvignon 1983). Further, strategic competence enables speakers to use their grammatical, discourse, and sociolinguistic competencies to negotiate meaning.

Faerch and Kasper (1984) are concerned with the way in which communication strategies are defined. They refer to Tarone's (1980) definition of communication strategies as the interactional definition whose central function is the negotiation of meaning. Faerch and Kasper list this definition as a subset of the psycholinguistic definition they propose where the language user is confronted with a 
communication "'problem,' whose solution requires the activation of a particular strategic plan" (p. 47). They further state that since consciousness is not a permanent psychological state, the communication strategies a learner uses are related to problems and solutions they have successfully pursued in the past.

Canale (1983) discusses the nature of communication. He characterizes it as a form of social interaction and therefore claims social interaction is necessary for language acquisition to occur. He further states that communication has a purpose such as establishing social relations or promising. Its success depends on the actual outcome. Canale discusses the four part definition of communicative competence according to canale and Swain (1980): grammatical competence, sociolinguistic competence, discourse competence, and strategic competence. All of these are necessary and relied upon to varying degrees to ensure the successful outcome of communication.

\section{METHODS OF RESEARCH}

The concept of communicative competence has led to three ways of doing research in ESP: discourse analysis, register analysis, and needs analysis. The use of the first of these, discourse analysis, has been to analyze texts used in courses or samples of speech common to a discipline to determine learner needs. The proponents of this type of 
research believe the analyzed discourse of a speaker can give a clearer picture of how sentences are combined to form meaning. This approach emphasizes characterizing varieties of ESP as separate. As with the functional/notional approach, care must be taken not simply to establish grammatical patterns or set phrases but to enable learners to use, adapt, and create language to communicate (selinker, Trimble, \& Trimble, 1976). It does not follow that because learners can recognize a pattern of discourse, they are able to create and produce that pattern on their own in an appropriate context.

Selinker, Trimble, and Trimble (1976) found this to be true when they studied the inability of a group of learners to comprehend the total discourse in a paragraph even when they understood all the words in the paragraph. They say native readers use implicit knowledge to analyze English for science and technology (EST) discourse. The non-native learners may not use knowledge in the same implicit way native English speakers do. When the non-native learners do not understand the relationship between the individual clauses making up the supporting information of the text or the function of the style of the text, they will not understand the discourse (Selinker, Trimble, and Trimble, 1976: 285-6). Further, non-native learners are not always able to identify information when it is implicitly stated. selinker et. al., suggest first teaching students to 
recognize explicit definition and classification where it is obscured by writing style. Once this is done, teaching implicit information becomes easier and can be done in two steps: 1) extract the information, and 2) reorder the information into functional, explicit form. Learning to deduce implicitly stated information may be more common in the American system of education than it is in many other educational systems. NNS learners may need to develop this skill in order to read and learn when they come to the United States.

Kachru (1985) has looked at the role conventional socio-cultural knowledge and rules of discourse play in interpreting texts. He examined texts written by native and non-native speakers of English to demonstrate that the linear progression of thought is not solely a characteristic of native speaker writing but that interpretation of texts depends on general background knowledge about the world (i.e., cultural knowledge). Kachru believes further research in the area of culture-specific thought patterns will show that different languages and cultures have different preferences for structuring discourse. Conventions of language use and knowledge of the social and cultural context in which the text originates are necessary for the non-native speaker. Educators, aware of their learners culture-specific thought patterns, will be able to 
identify their learners' difficulties and explicitly teach the American patterns.

In the area of register analysis, Dubois (1988) examined some of the rules of register in writing in the field of biomedics. Her study looked at the frequency of direct quotation, paraphrasing, summary, and generalization in 49 biomedical journal articles. She also surveyed seven biomedical scientists for their opinions of what constitutes plagiarism. Findings showed direct quotation is seldom used in biomedical professional writing. Paraphrasing, generalization, and summary are more common. Researchers are cited in bibliographies but not in the body of the texts. Scrutiny of the 49 articles revealed a quantity of material which would be considered plagiarism in other fields. Attitudes of the scientists surveyed were that, "a certain amount of borrowing... is acceptable...the justification is that essential intellectual property resides... in science [rather] than in wording" (p. 188). Dubois' study shows the practice of using the published work of others in writing journal articles differs among disciplines. Selinker, Trimble, and Trimble demonstrated deducing inductively stated information may be culture specific. Kachru's work suggests writing practices differ among cultures. Together, these studies suggest that teaching accountability and knowledge of the rules of the discipline/culture are necessary. 
In the area of needs analysis, Munby (1978) developed a model to specify the needs of learners in target situations. He defines his model as a fully operational instrument for the purpose of constructing a profile of communication needs to the specific category proposed (Munby, 1978: 30-32). Once done, this needs analysis provides the content of the syllabus. The analysis identifies communication needs at eight levels: participant, purposive domain, setting, interaction, instrumentality, dialect, social class, target level, communicative event, and communicative key. The results are then converted into a taxonomy of 54 skill areas to be learned, which becomes the syllabus of the course. However, the syllabus may be static because it is too specific. According to Widdowson (1983):

the more specific you become in identifying what language will be used for, the more you restrict competence and assume you can assign a formulae to a problem thereby conflating the purpose to which language will be put and the intentions to be achieved in the course (p. 16).

Widdowson (1983) thinks methodology, not the goals, should be placed at the center of ESP. He suggests using a methodology that will stimulate problem solving activities congruent with the students' specialist preoccupations. He recommends language be required in solving these activities. In this way, methodology is serviced by course design.

In defining the end goals in his needs analysis, Widdowson suggests that in his needs analysis model, Munby has not provided a means for achieving the end goals. A 
theory of education is needed in order to implement the taxonomy Munby suggests. For this very reason, Widdowson claims the kinds of ESP presented by Munby and other researchers make up an observational list and are not backed by theory. In lacking theory, ESP circumvents issues of education and resembles training rather than learning. If ESP is training then the answer to my third research question is that ESP is different from ESL. However, the answer raises a fourth question: who should be teaching NNSs studying a specific discipline, language educators or professionals in the specified field?

Concerning the relationship between ESP and training, Richards (1989) argues that an attack (specifically the one made by Widdowson) on ESP as a training concept is misconceived. He believes there is a strong case for looking at training and occupational environments in implementing ESP courses because one is bound up with the other. Richards suggests ESP and training or occupational environments are mutually beneficial.

Widdowson's argument is that ESP theory has not accounted for appropriate methodology. Richards does not believe ESP should be treated as a distinct discipline but rather as a bridge between education and training. Widdowson argues that ESP is goal-oriented rather than process oriented (business versus education). Richards thinks the issue is more complicated. He sees the 
strategies and skills students will be learning as the specified objectives in a course and the ones students will be expected to apply at the end of a course. Richards recommends setting short and long term goals, the short-term goals being training in basic skills required to carry out a task and the long-term goals relating to the student's functional development. The latter would be more gradual and less clear since language development is not so easy to measure as the acquisition of a skill which could be demonstrated by the successful completion of a task.

Richards cites the current view of training as bringing the individual into the focus of attention (not unlike current views of learner-centered language teaching) with a primary objective of improving individual and organizational performance. Training centered environments are designed to create learning opportunities:

We need instead to think more carefully about the relationship between our discipline and the environment in which it operates: that, after all, is the central concern of both training and education. (Richards 1989: 214)

ESP involves a responsibility to a student's occupational aspirations. This responsibility is a training concept and can be exploited by shifting the focus of attention to the environment in which it operates (Richards 1989). This focus would enhance a similarity between ESP and ESL in that both "seek to develop the ability to cope with language as a means of conceptualization and 
communication" (Widdowson 1983: 108). At the same time, the focus would distinguish between ESP and ESL by focusing specifically on the setting and the personal and organizational goals specific to a group of learners.

The focus on the ESP environment brings me to an argument for using ethnographic methods of research. These methods help researchers illustrate the ESP situation and participants' communicative competence in that situation. Brown (1987) calls communicative competence:

a dynamic, interpersonal construct that can only be examined by means of the overt performance of two or more individuals in the process of negotiating meaning. (p. 199)

Brown is referring to other factors in the communicative situation in addition to the communicative competence of the speakers. These are social situation, speech acts, culture, and native speaker attitudes towards non-native speech.

The social situation is comprised of the setting (the time and place), the medium of discourse (spoken or written), and the social constraints on activities and communication in a particular setting at a particular time (Blom \& Gumperz, 1986). Often the setting remains the same, but the social constraints vary according to who the participants in the discourse are in relation to each other. Blom \& Gumperz say, "a speaker cannot identify the social situation without first having made some decision as to the nature of the setting" (p. 423). Elements of time, and 
place and whether the message is written or spoken impose constraints on communication as well.

The social situation provides the context for analyzing non-verbal communication: "systematic body movements in their social context" (Birdwhistell, 1955: 12). These movements (or facial expressions) "have only the social meaning of their performance in context" (p. 17). Nonverbal communication conveys as much meaning (if not more) than spoken words. I refer to non-verbal communication in this study when it supports or defines descriptions given.

A speech act is the uttering of a sentence and can serve as the act of apologizing, betting, excusing, turntaking, name calling, etc. (Tripp, 1986). The function of a speech act is determined by the social situation. The utterance: "God bless you" could be uttered by a queen to her executioner asking that God forgive him for the atrocity he is about to commit or it could be uttered by a wife taking her turn in the course of conversing with her husband after he has sneezed. Recognizing when to use particular speech acts depends in part on social and cultural knowledge.

Work by van Naerssen $(1978,1979,1981)$ raises cultural issues in the teaching of English for medical purposes (EMP). Early work by van Naerssen, in which she looked at U.S. guidelines for foreign medical graduates (FMGS), revealed that when FMGs passed their exams, they were 
unprepared to work safely in American health environments. This work indicates that being able to read in English is not sufficient. The FMGs still needed to be versed in attitudes towards pain, sickness and death. These attitudes are bound up with the culture. Van Naerssen identifies other areas where FMGs lack cultural knowledge: state laws on malpractice; differences between medical English and lay English; American educational, political, and health systems; ethical and legal responsibilities; and public accountability of physicians. Assumptions or philosophies about the nature of the world are reinforced by the items identified and are different between each culture. When these are not understood by the FMGs, the consequences can be detrimental to the well-being of the physicians or their patients, according to van Naerssen (1978), "a matter of life and death" (p. 193).

An example van Naerssen uses to demonstrate culture operating adversely for the FMGs is of medical audits conducted for hospitals to maintain their accreditation. She says these audits cause FMGs who already feel insecure about their communicative ability to feel less secure and even threatened. The FMGs understand the audits and their use but not the importance of evaluation in American culture. They believe they are being singled out. Frelick and van Naerssen (1982) conclude that learning a language involves learning about the related culture. 
Howard (1988) offers comments relevant to van Naerssen's work. He says in the American culture the patient and doctor are equal in the medical consultation. This view of equality is different in other cultures and needs to be taught to NNS doctors. Doctors practicing in America need to ensure this equality since a patient may be intimidated by professional authority and therefore may not offer clarification or explanations. When problems are minor they are easily overlooked. The dental hygienist, dentist, or doctor must be able to solicit or encourage the patient to volunteer information. Further, when language is outside the NNS professional's field of expertise and must be explained, the professional's credibility is diminished. Van Naerssen (1981) warns that patients may react to a NNS student's or professional's speech by forming negative opinions of intelligence and professional ability.

So far the focus of this literature review has been on the competence and social and cultural knowledge a NNS must have. Another factor in successful communication is the attitudes native speakers have towards speakers of nonstandard English. Trudgill (1983) says,

Because language as a social phenomenon is closely tied up with the social structure and value systems of society, different dialects and accents are evaluated in different ways...non-standard, non-prestige varieties are often held to be 'wrong,' 'ugly,' 'corrupt,' or 'lazy'. (p. 19)

Judgements are made on how closely the individual's appearance and dress as well as speech approximate those of 
other members of the culture. An accent marks a speaker as different from the group and judgements about the person are made regarding anything from the person's intelligence to suitability for a job (Dreger, 1991).

Rey (1977) studied the effect of accent on employability. He played tape-recorded samples of speech of white Americans (WA), black Americans (BA), and Canadian nationals (CN) to potential employers. Employers answered questions regarding the speakers' social status and employability. Results of the study showed employers would be more inclined to hire a person with a standard accent and least likely to higher a person with a distinctly foreign accent. Rey concluded that the employers who participated in his study displayed a significant amount of stereotyped attitudes toward various speech types and, subsequently, job discrimination. Language attitude and discrimination may be evident in an analysis of a non-native speaker's communicative competence conducted in a natural environment. Ethnographic studies rarely focus on the relation between social role and language features (Hymes, 1986: 43). Gumperz and Hymes say adequate descriptions and taxonomies of speaking are needed to provide an adequate classification of languages in order to place languages in terms of their common features and differences. Further, of this body of research they say the interaction of social role and features of languages are the most neglected areas. 
Adequate descriptions and classifications of the language roles and features in a specific situation will begin to provide the basis for an analysis of what it means to be communicatively competent in one specific setting. Eventually, as other descriptive and quantitative data are gathered, generalizations about how best to bridge the gap between learner needs and employer expectations can be developed.

This study provides a description of the culture of Iulia's work environment. The description is then classified according to the language roles and features in specific situations in Iulia's environment. Analysis of the classification helps to define what it means for Iulia to be communicatively competent in her specific environment. The description may be useful for developing teaching strategies for learners with similar needs and expectations. 
CHAPTER III

METHODS

In order to learn more about the culture of a work environment and a non-native speaking employee's adjustment to it, I observed and interviewed participants in the culture. I tape recorded and analyzed segments of discourse to learn about communication strategies and Iinguistic needs of the NNS employee. I recorded events and interactions to explain behaviors and the language used. This chapter will describe in detail the means by which I gathered and analyzed my data. Procedures/techniques used were interview, observation, discourse analysis, event/network analysis, and componential analysis. The methods were taken from two different disciplines, linguistics and anthropology, in order to validate the data and support my conclusions.

\section{SUBJECTS}

Iulia was selected as the primary subject in this study because of her intention to become a professional in a field requiring specialized training and education. Two other important criteria for selecting her were that she had achieved a near fluent level of proficiency (as judged by 
her ability to gain employment and her score on the SPEAK test, Appendix A) in English and that she did not formally study the language. A native speaking hygienist was also selected for the study on the basis that she is female, holds the same position as Iulia, and works at the same clinic. other observed subjects in this study included over a hundred patients and at least thirty clinic staff members. The patients were notified of the researcher's presence prior to their dental visit and were given the opportunity to request the researcher not be present (Appendix B). Coworkers are discussed in greater detail in the event/network analysis in which I recorded interactions, interaction participant, nature of address (such as a request, rebuke, demand, question, etc...), and equality of participants (Appendix C) .

\section{GAINING ENTRY}

Gaining access to the work situation required attaining permission from the clinic manager. However, my presence was not immediately accepted. Regarding accessibility, spradley (1980) says,

You can enter some settings easily, participate freely in the activities, and record your observations. Others offer easy access the first time and then become difficult or impossible to enter again. (p. 47)

Iulia was initially nervous with my presence and I felt a lack of distrust from her co-workers (the doctors in 
particular). By my third or fourth observation, the employees at the clinic were better acclimated to my presence. The situation was accessible to me then and continued to be so until I had almost finished collecting data. Towards the end of my observations, the clinic's employees and Iulia were becoming weary of my presence. I took my cue from their less enthusiastic greetings and questions about how soon I expected to finish and brought my observations to a close. Interestingly enough, accessibility to patients was easy and constant. No patients requested I leave the room during their dental visits.

\section{PROCEDURES}

I observed Iulia six to eight hours a day, two days a week for six months. Which day of the week I conducted my observations depended on Iulia's schedule but one of these days usually was a Saturday. I interviewed Iulia several times in her home. All but two of these interviews were informal. The two more formal interviews were recorded. In the first one, the researcher administered the SPEAK test and questioned Iulia about her educational background. This tape was transcribed, the SPEAK test scored by a trained rater, and part of the transcription was used in the discourse analysis (Appendix D, segment A). Data gathered in the second of these more formal interviews were divided 
into two parts: in the first half, Iulia responded to questions based on generalizations and hypotheses the researcher was beginning to formulate (Appendix E), in the second half: she was asked to sort types of discourse (speech acts identified by researcher through observations) according to who she would be likely to use the discourse with. These data are discussed in the componential analysis. In addition, Iulia and I held numerous telephone conversations. These were often useful for quickly clarifying uncertain points.

\section{DATA COLLECTION}

Interviews, Observations and Other Data Collection

Questions asked in the informal and semi-formal interviews conducted with Iulia were intended to reveal Iulia's perspective and feelings about her job and herself as a non-native speaker of English. I asked open-ended questions in the informal interviews in order to refrain from leading Iulia in her responses. In the semi-formal interviews, I asked open-ended questions to some extent, but guided Iulia back to a desired topic and restated some questions several times in more than one way so as to gain greater understanding and validation of a response.

I conducted an interview with the supervisor from Iulia's dental assistant program. Questions asked in this interview related to 1 ) the supervisor's connection with and 
knowledge of Iulia; 2) knowledge of Iulia's difficulty in understanding and making herself understood by her colleagues; and 3) the communication difficulties the supervisor is aware of with non-native students in general. This interview lasted twenty minutes and was conducted near the end of the data collection. The interview was not taped.

Observational instruments used in gathering field data were note taking, researcher journal entries, and taped recordings. Data were analyzed to discover patterns about the communication processes of the NNS dental hygienist. These patterns were then used to guide questions asked in the componential analysis. Data also provided information for describing how Iulia communicates in her work setting, a source for identifying problems she has with communication, and a source for identifying language and cultural needs of NNS hygienists in general.

\section{Discourse Analysis}

The discourse analysis was undertaken to determine how the communication strategy use of a non-native speaking dental hygienist varied when communicating in different settings. When a speaker is unable to carry out a communicative goal as planned, the speaker "is forced to reduce the goal or to locate alternative means to express it" (Ellis, $1985 \mathrm{p}$. 165). The alternative means the speaker employs are referred to as communication strategies. 
Definitions of the communication strategies used to code the data are discussed below. The results of the study are discussed in terms of the subject's strategy use and learning English for a specific purpose in Chapters $V$ and VI.

Tarone (1980) discusses the necessary criteria for defining communication strategies in second language learning and language use. She believes approaches to studying strategy use have confused strategies used for learning with those used for communicating and have implied "a primary intention to learn, not to communicate a meaning" (p. 421). She claims that strategy use may result in learning but it does not have to. She cites three ways of analyzing data, each of which will produce widely different results and concludes that all three types of research are necessary.

1. Communication strategies: a focus on both interlocutors' attempts to use alternative strategies to agree on one interlocutor's intended meaning.

2. Foreigner talk: a focus on the linguistic and discoursal structure of the native speaker's input to the learner, with a view to eventually determining the influence of that structure on second language learning.

3. Repair: a focus on (a) the discoursal rules for who corrects whom, when, and (b) the correction of linguistic form as well as negotiation of intended meaning ( $p$. 427)

Due to space and time limitations, the data in this study will be analyzed from the first perspective listed with one modification: only the communication strategies used by the 
non-native speaker will be analyzed, but this will be done in light of all interlocutors' attempts to agree on intended meaning

\section{Procedures and Typology}

Three thirty minute segments of speech were recorded and transcribed. The first segment (segment A) is an interview between the researcher and Iulia. The interview was recorded in Iulia's home. Only the researcher and Iulia were present. The topic of conversation was Iulia's English language and dental hygiene education. The second segment (segment $\mathrm{B}$ ), was recorded at the clinic. Participants in the discourse are Iulia, a dentist (referred to as doctor), the researcher, and a patient. The dentist was summoned by Iulia to give the patient her annual check-up. Iulia told the doctor her findings, he examined the patient, and gave both Iulia and the patient his recommendations. The third segment (segment $C$ ) was recorded during an hour lunch break in the employee breakroom where Iulia spends every lunch hour. Other dental hygienists, dental assistants, and occasionally doctors came in and out during the lunch hour. A prescribed or structured topic of conversation was not given but the topic centered around Iulia's background history. The presence of the researcher and tape recorder probably contributed to the topic selection.

The data were transcribed by turn. A turn consists of the beginning of an interlocutor's speech and continues 
until a second interlocutor interrupts the first speaker or begins speaking after the first speaker has finished. Where Iulia switches topics in the course of a turn, the dialogue was divided but not counted as a separate turn. The occurrence of topic change is frequently marked by a Iong pause or reader difficulty in following the topic:

e.g. Iulia: so she was the one who / (breathes out) uh give me a list what can I do / become a nurse, become a technician dental technician, become a hygienist

I didn't know what hygiene at that time anything / or dental assistant

and I thought of this one is the easiest...

Eight minutes of each of the thirty minute transcribed samples were selected for analysis. Middle portions of segments $A$ and $C$ were selected because the tape had been on long enough to give the speech participants time to become accustomed to being taped. As the researcher was present during each of these recordings, comments on perceived comfort levels achieved are relevant. In segment A, Iulia achieved a high comfort level because the interview followed a stressful taped SPEAK test and, in comparison, the informal interview was much less threatening. An optimal comfort level was not achieved in segment $C$ because new participants in the discourse did not have time to forget they were being recorded and Iulia was not comfortable with the proceedings. The portion of tape with the greatest 
amount of communication was selected for analysis. Since there are many fewer doctors in the clinic than there are patients and dental hygienists, the doctor's time with a patient is limited. Therefore, the entire discourse involving the doctor (segment B) is used in this study. Definitions of communication strategies (strategies used to repair a breakdown in communication) were adopted from Long's (1983) and Yamamoto's (1991) definitions to analyze the data. Those that are used in this study are Iisted below with examples to clarify them. One of the variables examined in the data is the number of communication strategies Iulia uses in different situations. According to Swain (1985), interactive natural conversations influence the use of communication strategies. Thus, segment $A$ is a sample of natural conversation, segment $B$ is a sample of work related discourse, and segment $C$ involves both the work environment and natural conversation. Finally, number of turns and words per turn were calculated to determine Iulia's willingness to communicate depending on the various participants involved in the discourse. The researcher expected the data to reveal Iulia would participate less as her subservient role increased. In other words, she would say less and use fewer strategies with an interlocutor who had high status to her than with one who had equal or low status to her. 
Following are the definitions of the strategies used for analysis of the data gathered for this study. Examples clarifying the definitions are taken from both the data in this study and examples from previous research. Comprehension Strategies (Long, 1983)

1. Expansion: a partial or full repetition which modifies some portion of an interlocutor's previous string of speech by adding syntactic or semantic information.

e.g. NNS: I wear a sweater.

NS: Yes, you're wearing a red sweater. (Long, 1983: 136)

2. Clarification Request: a request for further information from an interlocutor about a previous utterance.

e.g. H2

Iulia
(.2) And that's a hard day (laughs). Hard day for her? (segment $C$, lines 64,65 )

3. Confirmation Check: the speaker's query as to whether or not the speaker's (expressed) understanding of the interlocutor's meaning is correct, characterized by rising intonation.

e.g. NNS: I went to cinema.

NS: The cinema? (Long, 1983: 136)

Production Strategies

1. Self-expansion: a partial or full repetition which modifies some portion of the speaker's own 
previous string of speech by adding syntactic or semantic information.

e.g. Iulia: English as a second language and that exam went after / I don't know a few days I had something few days week ten days I don't remember how long... (segment A, line 26)

2. Repetition: an exact repeating of a string of speech (either partial or full, and either a selfor other-repetition) (Long, 1983: 138).

e.g. Iulia / I I have all all the time I... (segment $C$, line 15)

3. Comprehension Check: the speaker's explicit query as to whether or not the participant's understanding of the speaker's (expressed) meaning is clear. Differs from confirmation check above in that speech is without rising intonation (Long, 1983: 138).

e.g. NS: It was raining cats and dogs. Do you follow? (Long, 1983: 136)

4. Repair: an attempt by a speaker to alter or rectify an utterance which was in some way lacking in clarity or correctness (either self- or otherdirected) (Long, 1983: 138).

e.g. Iulia (.) but / part partly... (segment A, line 41)

5. Indication of Difficulty: explicit appeal for assistance by verbalizing difficulty (Yamamoto, 1991: 55). 
e.g. Iulia how you call that test?

(segment $A$, line 37 ).

6. Verification Request: implicit appeal for assistance with requests for affirmation or verification of an uncertain item using rising intonation (Yamamoto, 1991: 55).

e.g. Iulia you know*? (segment $A$, line 4)

7. Avoidance: reduction strategies to avoid taking risk in communicating in $\mathrm{L} 2$ including the following:

a. non-verbal (silence): the learner remains silent in an obligatory turn. b. incompletion: the learner begins to talk but stops in mid-utterance and does not take it up again in the current or next speech turn.

c. declining to respond: the learner simply tries not to talk about a topic (Yamamoto, 1991: 56). Differs from nonverbal avoidance strategy in that the speaker changes topics or states their desire not to address the topic.

8. Long Initial Pauses: nonlinguistic fillers or pauses lasting more than two seconds (Yamamoto, 1991: 56).

e.g. Iulia they told us (3) and was like... (segment $A$, line 12) 
In examining the data, communication strategies were broken down into two groups: comprehension strategies, those the non-native speaker used when she was addressed, and production strategies, those the non-native speaker used when she was addressing her audience. Emphasis was placed on analyzing production strategies since the potential for Iulia's fossilizing in her second language is likely. Fossilization is a stage where second language learners' grammatical structures and vocabulary are stabilized and relatively permanent even though they may continue to make mistakes. Language learners cease developing linguistically in their second language at this stage. Ellis (1985) says "fossilization occurs in most language learners and cannot be remedied by further instruction" (p. 48). It was hoped that use of production strategies identified in the study would reveal whether Iulia's work environment has a beneficial or negative effect on her language learning.

\section{Event/Network Analysis}

An event/network analysis was used to determine the structural aspects of Iulia's social situation: "the social form of an ongoing set of interactions that [are] observable by any uninvolved outside viewer" (Dobbert, 1982: 157). Dobbert states that the structural aspects of a social situation will be seen in constantly repeated behavioral patterns and that these patterns will be so prevalent they will give form to the social entity. The patterns are 
documented and analyzed for frequency and centrality from which an observer can define the social situation by looking at it in operation. The composition and arrangement of a group is revealed by "tracing the interactive behaviors of an individual" (p. 160). In analyzing the data, particular attention is paid to prestige and power aspects of interactions. In some situations, power and prestige relations are obvious, but, according to Dobbert, "an ideology of equality tends to hide both the existence of separate groups and the qualities of their interactions" (p. 160). The event/network analysis revealed groups in Iulia's work setting and their interactions.

Data were again collected, this time over an eight and a half hour period. The researcher kept a log of Iulia's actions and interactions during this time beginning from the moment Iulia arrived at the clinic. Each action, interaction, and participants in the interaction that took place in Iulia's room were recorded in minutes along with relevant details. These details included the length of interaction in minutes; the nature of address; researcher determined level of equality discerned; territory (whose room or area the interaction took place in) and the relevance of territory to the status of the participants. A record was then made of the number of people in Iulia's network and of the types and qualities of the interactions with those interlocutors. Iulia was not comfortable having 
the researcher follow her around the clinic so the bulk of the data was collected in her room while events and interactions that took place outside of the room were revealed when the researcher questioned Iulia or overheard her conversations.

\section{Componential Analysis}

Data up to this point were collected mainly through direct observation, informal interviews, and recorded conversations in work settings. This section covers data gathered through a more structured interview process based on generalizations and formulated hypotheses to understand how Iulia sees and defines herself in her work situation. The purpose for doing the structured interviews was to go beyond a level of description to a level of explanation. These formal interviews tested hypotheses through specific elicitation techniques, for example, asking Iulia to describe her job, the people she interacts with, the types of interactions she has with the people identified, her feelings about what happens and what is said in her work environment, and to provide answers to other questions raised in data collection. Previous observations served to raise questions for these formal interviews about the structure of the clinic and Iulia's position in it. Researcher's questions and subject's responses are found in Appendix E. Answers to the questions formulated are designed to elicit information about what questions 
hygienists at the clinic are responding to and what questions are taken for granted because they are common knowledge and do not need explicating. Patterns are sought that represent Iulia's cognitive repertoire and, combined with behavioral acts discussed in previous sections, complement information given regarding Iulia's work culture. The technique used in analyzing the data is derived from ethnoscience, a Darwinian method specifically following four successive levels: description, classification, comparison, and explanation (Dobbert, 1982: 129) and provides a cognitive perspective for defining the shared knowledge dental hygienists use to guide and explain their behavior. This technique is "used to gather depth data in a general study" (Dobbert, 1982: 128). The technique is not entirely scientific but adapted from scientific conventions to discover taxonomies. The technique and its adaptation require a creative approach to the design of taxonomies with discussions of difficulties in defining the complex relationships at the clinic and the cultural interpretations derived. You Owe Yourself a Drunk (Spradley, 1970) was useful in guiding the interpretation of the results especially as those interpretations applied to an overall understanding of the culture in question.

The main goal of ethnographic research is to discover, describe, and explain culture: "to describe and explain the regularities and variations in social behavior" (spradley, 
1980: 13). The focus is on patterns that relate ideas to each other, to people and to material objects, people to people, groups to groups and jobs and tools to all of these (Hymes, 1986: 70-1). The interest is in the organization behind the patterns. The organization of these patterns is complicated by the cultural values and beliefs Iulia brings to her environment as a non-native speaker.

Questions were developed for an initial interview to solicit Iulia's description of her job and the interactions she has at work: "Tell me what it's like to be a hygienist at-" and "Are there some doctors who are easier to talk to than others?" One question requested that Iulia identify the people she interacts with at work. Her responses were written on individual $3 \times 5$ notecards and set aside. Comparison questions were included in the interview to uncover definitions of categories and relationships between categories. These were generally in the form of ' $w y^{\prime}$ ' and 'what kind of' questions meant to give dimensions and boundaries to categories through inclusion and exclusion principles. Spradley (1979) says these questions will "elicit attributes and dimensions of contrast...[to] reveal the kinds of information needed from informants" (p. 182). The interview was taped and transcribed (Appendix E). The notecards with the names of types of people Iulia identified in her network above were laid in view on a table. The researcher asked prepared questions based on 
generalizations and hypotheses made in the event and network analyses. Iulia was asked to match the questions asked to groups in her network as she felt they applied. The researcher made notes of Iulia's responses. This categorization process was also taped and parts (comments made by Iulia) were transcribed and included in Table IV. This table forms a taxonomy of the questions asked and Iulia's responses on the nature and quality of those interactions and the identification of participants. The taxonomy is given in table form and not stratified since the nature of interactions varies and is not always hierarchically straightforward. The questions asked were grouped in the table according to type, i.e., 'ask,' 'tell,' 'respond,' each being considered a type. It was hoped results of these groupings would illustrate hierarchies of meaning from general to more restricted cultural classification. However, only one hierarchical taxonomy was uncovered illustrating the official structure at the clinic and it is minimally stratified from Iulia's verbalized point of view.

To identify status relations, parts of speech central to Iulia's description of situations and central to my research questions were underlined in the transcripts and category terms selected that divided people into groups, indicated the status of interactants to each other, and described the types and qualities of interactions. This 
examination of the transcripts revealed Iulia's situation from her point of view to understand how she organizes the information she needs to know to do her job.

In looking at the taxonomies derived from the data, explanatory principles common to them were identified and discussed to provide a picture of Iulia's cognitive orientation within the clinic. Results answer research questions at the cultural level by placing them in their context. The results from the interviews, observations, data collection, discourse analysis, event/network analysis, and componential analysis are found in chapters $\mathrm{V}$ and VI. 


\section{CHAPTER IV}

\section{CONTEXT}

In this chapter, I describe my informant, her work setting, and the people she communicates with both at work and at home. This information provides the context for the detailed analyses discussed in chapter $V$.

\section{IULIA'S BACKGROUND}

Iulia celebrated her seventh year in America in April, 1992. She successfully completed a one-year dental assistant program in 1988, but was unable to find a job in her field because her English was poor. She worked at odd jobs in factories and as a cleaning lady in a hotel for a year while trying independently to improve her English. After a year she was hired at a large medical institution as a dental assistant and worked there until she decided to further her education. Iulia has not had formal English language training while in the United States. Difficulties she continues to have with the language will be discussed in Chapters V and VI.

Although Iulia has adjusted to her life in the U.S. in many ways, she retains parts of her Romanian culture and society either through desire to maintain them or inability 
to discard them. One case in point was her excessive nervousness at the outset of my observations. Iulia assured me repeatedly that my presence did not bother her. In reading about Romanian culture, I learned that prior to the most recent revolution, old people were denied health care in order to keep the population young. I checked the validity of this information with Iulia. She verified it saying that indeed it was no different now and added that married women are checked by a doctor monthly to ensure they are not using any means of birth control until they have had six children. Further, pregnancy is cause for dismissal from employment and women hide their pregnancy as long as possible in order to maintain their income. still, several weeks passed before Iulia told me she was six months pregnant; thus, the cause of her nervousness was revealed. Iulia had not yet informed her supervisor and even though she saw how positively her pregnant co-workers were treated, she was afraid of being dismissed and of being made to feel ashamed of her condition. She knew her fears were removed from the reality of the situation but was unable to announce her pregnancy before the end of her seventh month when she was forced to do so by scheduling needs. Hygienist schedules are made 6-8 weeks in advance and Iulia did not think she should be on the regular schedule during her ninth month. 
Feeling ashamed of pregnancy was something Iulia

learned when her mother was pregnant with her sister. She remembered a doctor making Iulia's mother feel dirty about being pregnant. Iulia liked the American approach to regarding her pregnancy with joy but was not convinced she could regard it this way. Her husband has a 21-year-old son by a previous marriage. He did not take part in raising his son and does not want to do so with this baby either. He blames Iulia for getting pregnant against his wishes and she agrees. However, she told him if he had said he didn't want children in the beginning when she asked, she never would have married him. This response is characteristic of Iulia, who approaches life realistically and with a good deal of humor. She is not shy about carrying on such arguments with her husband in front of me though frequently these are in Romanian because her husband's English language proficiency is quite low.

Iulia does not talk much about daily life in Romania unless I ask her specific questions. She assumes I have read accounts of communist life in Russia in the papers and can make the connection with Romania, which is also under communist rule (i.e., long food lines, scarce commodities, constantly being watched by the government, etc...). She feels these are so obvious as to not be worth mentioning. Iulia remembers better times when she was little and the Communist government was not in power. Her father was a 
government official then and her family lived well. They had a big house, beautiful furniture, frequent guests, and outings to the country. When the communists came into power, they imprisoned Iulia's father. Iulia was in the first grade. She remembers offering the soldiers candy when they came to take her father; she did not know why they were there. Her mother gave away all the furniture so it would not be confiscated and was denied employment so relatives had to support the family.

Iulia's father was released for a brief time when Iulia was in junior high school. He was appalled at the poor education his children were receiving and began teaching Iulia and her brother how to read and write. When Iulia entered high school, her father was imprisoned again without explanation. Shortly after this second imprisonment, Iulia's sister was born. Iulia's sister had a more difficult time in school because her classmates had not lived through the Communist takeover, did not understand as Iulia's classmates had, and were cruel to her because her father was in prison.

Iulia recalls how difficult high school was. Students learned Latin, French, higher mathematics, and studied Leninist writings extensively. once forty pages of reading on Lenin had been assigned. The teacher quizzed each student on the assigned reading but no one had read the material and she gave the entire class an ' $F$ ' for the day. 
The mark stayed with Iulia throughout high school because the Communists keep such extensive records on everyone. This mark looked very bad. of the difficulties Iulia faced in Romania, the one she is most bitter about, is the poor education she received.

Despite what Iulia terms a poor education, she was accepted into a dental assistant program of study. When she entered the program she did not have any knowledge of English and was accompanied by an interpreter. I interviewed the director of this dental assistant program for 15 minutes informally in her office. The director of the program said she accepted Iulia because she had a background in the German language. The director has found through experience that NNS students with a Germanic background do have success in the program as many of the medical terms in the dental field are Germanic based. She will not accept NNS students without it. Further, the director stated in our interview that the NNS students must take advantage of language tutoring offered at the school and spend a great deal of out-of-class time getting individual attention from their professors. The dental assistant program of study is small and able to meet the NNS students' special needs. The director remembered Iulia even though three years had passed since Iulia graduated. The director recalled Iulia did very well in the program. 
Iulia's father sent the family unsigned postcards every few months to let them know he was alive and well. Once when he was moved from one prison to another, his train passed through their town. He used charcoal to write on pieces of his underwear and dropped the pieces onto the train track. He wrote his name and that his health was good. Two of them were found and delivered to Iulia's family. They symbolized the family's hope and Iulia's mother still has them.

When Iulia's father was released from prison again three years later, the family applied for immigration to the U.S. They could not have recovered financially in Romania unless Iulia's father joined the Communist party and this he refused to do. The U.S. granted the family permission to emigrate but four more years passed before the communist government in Romania would allow the family to leave. During this time, Iulia worked in an office processing paperwork for a canal stalin had ordered built for strategic purposes. The canal was begun in the 1950 s and finished in 1984. Iulia reports the canal was useless, but for her it was a good job as it was close to her family.

Iulia has many responsibilities to her family and the Romanian community here in the U.S.; many of these are financial. She earns more money than anyone else in her family and is expected to shoulder the financial burdens. Earlier this year she paid for her brother's wedding, 
including the rental of the reception hall, food for a hundred guests, and her brother's tuxedo. Iulia pays for and ships care packages to her relatives still in Romania and helps with her sister's education. About a year ago, Iulia put $\$ 5,000$ down on a house a Romanian woman was selling. The woman changed her mind about selling and used the money to put a new roof on her house. The Romanian community has since put pressure on Iulia not to demand the money back. More than anything Iulia wants to own a house but no longer has the money for a down payment. Other members of the community expect Iulia to clean their teeth for free. Iulia avoids doing so as much as possible or she would find herself doing nothing but cleaning Romanian teeth free of charge.

Iulia's personal characteristics and her success (given her age, 38, and educational background) are admirable. A study of success predictors might begin by looking at these characteristics. Iulia is a survivor, one who weathers any situation, an immigrant, willing to work hard and struggle for a better life.

\section{IULIA'S PROFESSIONAL WORK CULTURE}

Iulia has responsibilities at the clinic where she works too; not only must she follow the patient schedule and do her work according to company standards, but also, she is liable for the dental work she does perform. When patients 
first sit in the dentist chair, the hygienist immediately questions them about any recent changes in their medical history. The hygienist also questions patients about the status of existing medical conditions and whether or not they are under the care of a physician. Patients are asked to sign and date their medical charts when the hygienist is satisfied with their answers. When patients sign their charts, the hygienist is released from medical liability or issues the patient failed to report. Patients younger than 15 must have a parent sign their chart. When dentists give the patients annual check-ups, they verify the hygienist's work, add recommendations and also sign the charts. This procedure and order of events never varies and thus leaves a clear trail of responsibility. The procedure also provides future hygienists, dentists, and supervisors with clear and easy reference.

The state in which Iulia works has strict guidelines for procedures a certified hygienist can and cannot perform. Primarily, hygienists can clean teeth and give shots to prepare patients for surgery. They must hold additional certification, called EFDA (Expanded Functions Dental Assistant), to assist in surgery. Requirements vary from state to state.

Hygienists and dentists at the clinic have code numbers for easy identification and record keeping. There are also code numbers for dental procedures, problems and conditions. 
These are used for billing purposes. From time Iulia records a code incorrectly. Sometimes th receptionists/billing clerks tell Iulia she has .. However, they can complain to her supervisor. Iulia said this happened once and it made her so nervous she was sure she was recording all codes incorrectly.

Hygienists educate patients about home health care, showing them proper techniques for brushing and flossing their teeth. Iulia tries to scare patients into taking better care of their teeth by implying their teeth are close to decaying. Iulia asks patients, "You don't want to lose them do you?" She says they are taught in school to scare patients into caring for their teeth and the dentists I have observed seem to participate in this practice as well. One told a patient, "Believe me, dentures are not comfortable no matter what they say on $t . v . "$

Hygienists know a lot about patients' habits by looking at their teeth and x-rays. Patients who drank fluoridated water when their teeth were developing did not grow up locally as the city does not fluoridate its water. They know what patients usually eat and drink, what vitamin deficiencies they might have, whether or not a patient has had braces, and if the patient is or has experienced physical, mental, or emotional trauma. Chart histories reveal whether or not patients have been taking care of their teeth between dental visits or not by improvement or 
lack of improvement in amount of calculous, plaque, or decay a patient has. Hygienists must be sensitive to what the patients want as well as to what they need. For example, one of the first patients I watched Iulia work on was a teenage boy. She spent little time on cleaning the patient's teeth and more on polishing them. When in school, Iulia took twelve hours to clean my teeth and I was amazed she spent so little time on the patients at the clinic and this one in particular. When I questioned her about this she said she knew the boy only cared about his teeth looking good for the girls. She knew this because he expressed concern about how his teeth looked but didn't bother to keep them clean between dental visits.

I have noticed differences between procedures at the clinic and those I observed when Iulia was in school. Iulia has told me about how procedures also differ between the clinic and private practice. Little time is spent with each patient at the clinic, seldom more than an hour, and even less in private practice. In private practice, Iulia has observed dentists recommending unnecessary procedures for the business/money. She doesn't believe they care much about servicing the patients, something she values highly. At the clinic, patient dental work is legally and consistently charted, but this is not the case in private practice though in both cases the hygienists are liable for their work. 
There are some things Iulia finds difficult about her work at the clinic. The main one is her lack of seniority and the ensuing instability. She works a total of four days a week for the company. This is full time employment and makes her eligible for benefits. Two of those days are spent at the clinic where I observe and two at a second clinic. Iulia does not have a permanent room and must use the room of a hygienist who has the day off. Because she is a fairly new employee, Iulia does not have regular patients and is given many of the first time patients. Complete medical and dental histories must be written for these new patients. These histories lengthen patient visits. Thus, Iulia sees fewer patients in a day and her patient quota is low. Further, Iulia finds reading and writing in English difficult; though she is capable, these skills require a great deal of effort on her part.

In addition to expressing her difficulties, Iulia has clear opinions of issues she observes. She is disgusted with dental procedures that are done for aesthetic purposes, such as extracting teeth. She thinks the procedure is 'messy' and may cause more serious problems later. Most patients who have worn braces have a bone problem where the upper and lower jaw bones do not align. Patients who have suffered a trauma often suffer from this malady as well. Iulia refers to such poor bone alignments as 'TMJ': temporal mandibular joint. Unless teeth positions are preventing a 
patient from chewing or causing other medical problems, Iulia does not believe patients should wear braces. She often cleans patients' teeth just before they get braces but never mentions the problems that go along with them. She assumes dentists will inform patients and does not believe the patients would take her advice anyway. Iulia feels disgust for patients who come in dirty and/or on drugs. She believes medical personnel should be shown more respect. This belief comes from her own childhood, when she would wash and put on her best clothes before going to see the doctor out of respect for his position.

Another difficulty Iulia has at work is that she does not have her own room and must keep patient charts on the floor during the day. She must also use precious counter space to store her trays and instruments. She keeps her lunch in her car and tucks her purse into a corner, hiding it as best she can. When she forgets to stock items such as dental floss, rubber gloves, or toothbrushes, the hygienist whose room she is in will leave Iulia a post-it note the next time Iulia is in to remind her to properly stock the room. In the beginning, these notes made Iulia feel bad, but more recently she has begun to joke about them, "I'Il have to put some floss or another sticky Monday." Hygienists are supposed to help dental assistants take patient dental $x$-rays and blood pressure when they have time between patients. This is not possible when there is one 
patient per dental assistant. When dental assistants are new to their job they are slow. Iulia must wait for them to finish before she sees the patient and this wait puts her behind schedule.

I have observed Iulia make progress over time. Before I began my observations, Iulia was reviewed at work by her supervisor. She was very pleased with her evaluation, except when her supervisor commented she asks the patients "Are you okay?" too much. My subsequent evaluations confirmed the supervisors'; however, four months later Iulia's use of this phrase dropped-off noticeably. At the beginning of my observations, Iulia flossed patients' teeth during their visit. She no longer does so now. Instead, she shows patients how to floss and watches as they demonstrate for her. She believes the patients are responsible for brushing and flossing their own teeth. When I first began observing Iulia, she told me she would prefer to have me observe her at the other clinic where she works; she liked that clinic better because her co-workers were friendlier. The hygienists at the other clinic didn't leave her sticky notes and the receptionists/billing clerks didn't report her to her supervisor when she used the wrong code. Initially, I thought this might be an issue of her being a non-native speaker, but over time it has become clear there is an initial probationary period before new employees are 
accepted at the clinic where I observe. This was confirmed in an interview by the native-speaking (NS) hygienist recently observed and may have been a contributing factor in Iulia's unwillingness to reveal her pregnancy. Iulia commented to me that her co-workers were curious about my research and asked her questions. Iulia was pleased with the attention and my presence as I inadvertently provided her with a topic of conversation with the hygienists. Iulia is now included in gossip, a sign the other hygienists accept her. These hygienists gave Iulia a baby shower shortly after she announced her pregnancy. Iulia thought the idea of a baby shower was a little silly but was extremely pleased at having been given one.

Now Iulia says she prefers working at the clinic where I observe and describes the group as a family. One hygienist at the clinic is not liked and not accepted by the group although she has worked at the clinic for several years. Iulia feels bad for this hygienist because she thinks the hygienist brings it on herself and Iulia sees membership in the group as a 'wonderful thing'. In blaming the hygienist for not integrating into the group, Iulia seems to have forgotten her own difficult probationary period. 


\section{TYPES OF PATIENTS}

Iulia is kept from becoming bored with her work by the wide variety of patients she sees. She claims no two are alike though I have observed that many of their questions and comments are. For instance, after Iulia asked me why so many Americans have allergies, I began noticing most patients complain of allergies. Many patients explain to Iulia they do not floss their teeth because their gums bleed when they do. Iulia always tells them their gums bleed precisely because they do not floss regularly and advises them to try flossing for a few days to see that the bleeding does cease. Patients frequently ask about the quality and purpose of dental care products on the market. Iulia asks patients who complain they are experiencing sensitivity in their teeth if they have recently begun using a tartar control toothpaste. She tells them this toothpaste contains more abrasive materials than regular toothpaste and advises they stop using it. Patients often promise to take care of their teeth from now on, and then just as often they break their promise.

Some patients are more willing to participate in conversation than others, and Iulia must adjust to each one. She communicates well with patients who are employees for the same company she works for. This may be due to the background information she shares with these patients. These patients laugh rather than complain about the length 
of time required to make a dental appointment (this establishes comraderie rather than blame). Iulia says teenagers are the most difficult patients to work with because they are surly and impossible to engage in conversation. Iulia simplifies her language, uses repetition and a lilt in her voice when working on children. Her use of motherese (i.e., simplified language used when speaking to young children) comforts the children and prevents their visits from being frightening experiences.

Each patient is new and interesting. However, those that are most interesting seem to cluster around one another. Iulia's first patient one morning was a tense, pale thirteen-year-old boy. His hands were clenched in tight fists and he kept his eyes shut and his mouth open during the entire visit--even when Iulia left the room. Iulia told the patient she needed to talk to his parent so the parent could sign the chart and schedule the patient's next appointment. The boy told Iulia his father was next door at the restaurant. The boy had TMJ and most of his baby teeth. When the dentist examined the boy he mentioned to Iulia they might want to pull the baby teeth to give the adult teeth a chance to come in. Later Iulia told me the boy had more serious problems than his teeth: his father had already had several drinks and it was not yet nine in the morning. Iulia spoke very little to this patient as he was non-talkative. 
Her next patient was a talkative, single man in his thirties who claimed to have been a spy in Italy during the Vietnam war. Iulia had to use a water pick instrument called a cavitron to clean his teeth because they were so dirty. This procedure is quite painful but the patient refused a numbing agent. Iulia wore two pairs of gloves while working on the patient because his chart revealed a history of drug abuse and the patient had mentioned he'd been to Brindisi, Italy. Iulia had also been to Brindisi and found it to be an unsavory place. This patient spoke a lot, and laughed and joked with Iulia. Iulia responded in kind.

Iulia's third patient was also a man in his thirties. During his visit Iulia repeatedly placed the back of her hand over her mouth (which was already covered by the customary mask) apparently because the patient had been drinking and the smell was unpleasant. This patient left about 11:30 a.m. This patient was also talkative and so was Iulia.

In the afternoon, a mother and her three young children were in to have their teeth cleaned. They were drop in patients meaning they did not have a scheduled appointment. Several hygienists were available to take the patients but none wanted to as the children were screaming and needed their diapers changed but the mother was ignoring their needs and their screams. The hygienists were joking in a 
half serious way about the disruptive situation and trying to appear busy in order not to get the group as their patients. The family was finally awarded to Iulia. Finding Iulia's office overcrowded at this point, I left. Later that evening, Iulia told me over the phone that her coworkers complimented her the rest of the day on how well she handled those patients. Iulia reported she kept the children busy by giving them toys and comforted them while she cleaned their teeth. She handles all her patients with tact and professionalism, adjusting to their communicative needs as necessary.

Iulia's success in her field is remarkable given the poor education she received in Romania, her lack of English language skills when she first entered her field, her limited economic resources throughout her education, and her on-going financial responsibilities. She clearly fits the description of the disadvantaged English for specific purposes (ESP)/English in the workplace (EWP) student discussed previously yet she has progressed from a laborer with limited language skills to a linguistically competent and professional dental hygienist.

In this study, I attempt to identify those characteristics she possesses that contribute to her linguistic and professional success. In order to do this, I have analyzed actual communication, identified her communication network, documented the social relationships 
she has with the kinds of people identified, and questioned Iulia and her co-workers and supervisors to corroborate my observations. 
CHAPTER V

ANALYSIS/RESULTS

Despite the differences between Iulia's native culture and language and her second culture and language, she has managed to adjust and find success in her profession in America. Data gathered in the field was analyzed in three ways in order to understand and identify the qualities of the work setting and the learning strategies Iulia used that have contributed to her success as a language and culture learner.

In this chapter, the results of these analyses are presented. These results contain overlapping information and serve to triangulate and corroborate findings. The first section contains the results of the discourse analysis; the second, the results of the event/network analysis; and the third, the results of the componential analysis.

\section{ANALYSES}

\section{Discourse Analysis}

The strategies listed under 'Typology' were recorded in each of the transcripts next to the segment in which they occurred (see Appendix D for coding key). Three eight- 
minute segments of dialogue were transcribed for analysis. Segment $A$ is a dialogue between the researcher and subject regarding the subject's English language learning. Segment B is a doctor consultation. Iulia, a doctor, and a patient were the participants in this segment. Segment $C$ is a transcription of a conversation held in the clinic's employee break room during a lunch hour. Participants were Iulia, the researcher, hygienists, and dental assistants. The data were compiled in table form (Table I below) to show the frequency and type of strategy Iulia used in each of the three conversations. Strategies analyzed were those Iulia used for comprehending speech and those she used for producing speech. The strategies were totaled for each conversation and for the number of times each strategy was used in the transcripts. Also listed in Table I are the number of turns, total number of words, average number of words per turn, number of unintelligible segments, and number of strategies per turn Iulia used in each of the conversations.

The results of the data in terms of the total numbers of communication strategies used suggested to me that Iulia is more willing to take risks in communicating meaning in non-work environments. Of the specific strategies used, avoidance occurred less frequently than self-expansion and long initial pauses occurred less frequently than repetitionin segment $A$, but the reverse was true for the 
TABLE I

COMMUNICATION STRATEGIES

\begin{tabular}{|c|c|c|c|c|}
\hline STRATEGY & $\begin{array}{l}\text { SEGMENT A } \\
\text { Researcher/ Iulia } \\
\text { Interview }\end{array}$ & $\begin{array}{l}\text { SEGMENT B } \\
\text { Doctor, Iulia, } \\
\text { Patient } \\
\text { Consultation }\end{array}$ & $\begin{array}{l}\text { SEGMENT C } \\
\text { Hygienists in lunch } \\
\text { room }\end{array}$ & TOTALS \\
\hline $\begin{array}{l}\text { Comprehension } \\
\text { expansion } \\
\text { clarification request } \\
\text { confirmation check }\end{array}$ & $\begin{array}{l}3 \\
1 \\
0 \\
\end{array}$ & $\begin{array}{l}0 \\
0 \\
0 \\
\end{array}$ & $\begin{array}{l}1 \\
1 \\
0 \\
\end{array}$ & $\begin{array}{l}4 \\
2 \\
0\end{array}$ \\
\hline $\begin{array}{l}\text { Production } \\
\text { self-expansion } \\
\text { repetition } \\
\text { comprehension check } \\
\text { repair } \\
\text { indication of difficulty } \\
\text { verification } \\
\text { avoidance } \\
\text { long initial pause }\end{array}$ & $\begin{array}{r}13 \\
19 \\
0 \\
4 \\
2 \\
2 \\
6 \\
9 \\
\end{array}$ & $\begin{array}{l}0 \\
0 \\
0 \\
0 \\
0 \\
0 \\
8 \\
3 \\
\end{array}$ & $\begin{array}{l}3 \\
3 \\
0 \\
1 \\
0 \\
0 \\
4 \\
4 \\
\end{array}$ & $\begin{array}{r}16 \\
22 \\
0 \\
5 \\
2 \\
2 \\
18 \\
16 \\
\end{array}$ \\
\hline TOTALS & 59 & 11 & 17 & 87 \\
\hline $\begin{array}{l}\text { \# of turns } \\
\text { \# of words } \\
\text { avg \# of words per turn } \\
\text { \# unintelligible segments } \\
\text { \# strategies per turn }\end{array}$ & $\begin{array}{r}29 \\
999 \\
34.45 \\
4 \\
2.03\end{array}$ & $\begin{array}{r}27 \\
161 \\
5.96 \\
8 \\
.41\end{array}$ & $\begin{array}{r}29 \\
258 \\
8.90 \\
9 \\
.59\end{array}$ & $\begin{array}{r}85 \\
1418 \\
N / A \\
21 \\
N / A\end{array}$ \\
\hline
\end{tabular}


other two discourse segments. Iulia used three times as many strategies in segment $A$ than in segment $C$ and over five times as many as in segment B. Her participation in the interview as opposed to the other two conversations is highly marked in production strategy use but not in comprehension check strategy use. Although comprehension check strategies overall were used most often in segment A and not at all in segment $B$, they may not be significant since doctor consultations are routine and little about them needs to be clarified for Iulia. The frequent occurrence and nature of doctor consultations probably make comprehension clear.

The third set of variables looked at in this study were number of turns taken, total number of words, and average number of words per turn. Iulia took the same number of turns, 29, in segments $A$ and $C$ and only two fewer turns in segment $B$. In relation to these figures, the number of words and average number of words per turn show that although Iulia was actively participating in all three conversations, she was a less active participant when in her work environment. Iulia used 3.87 times as many words and 3.87 times as many average words per turn in segment $A$ than in segment $c$. The figures cover a greater span when compared with segment B: 6.2 times as many words and 5.78 times as many words per turn on the average. This is due in part to her job routine. Iulia cleans ten patients' teeth a 
day, four days a week. The teeth cleaning procedure is structured, as mentioned before, and patients have similar concerns and complaints. The volume of patients does not allow hygienists much time to communicate with each other on general topics so Iulia is rarely challenged to expand her cognitive repertoire. Small talk with patients is about current events and is introduced by Iulia with each new patient. The current event is discussed ten times, once with each patient, and more if it is brought up in lunch room conversation. Verb tenses are limited by the present, recent past, or near future context of current events. On the other hand, when I questioned Iulia in our interview (segment A), the topic of conversation was one she rarely discussed, that occurred in the remote past, and that required great detail.

In analyzing the data (Appendix D), expansion was initially difficult to assess in terms of other- or selfexpansion. For example (the asterisk indicates stress):

Iulia No*, Romanian.

Researcher Romanian.

Iulia She was a Romanian but she... (segment $A$, lines $2,3,4)$

I decided to call this example expansion and include it under comprehension check strategy since it immediately followed the researcher's (other's) utterance.

There were only two instances of clarification request. In both, Iulia clearly requested more information from the 
interlocutor in order for her to understand the interlocutor's intended meaning:

$\begin{array}{ll}\text { Researcher } & \text { Three months six months? } \\ \text { Iulia } & \text { For dental assistant? } \\ & \text { (segment A, lines 16, 17) }\end{array}$

Confirmation check was not listed since Iulia never checked verbally whether or not her meaning was clear to the interactants. Another strategy Iulia never used was comprehension check, a production strategy. She never checked with her interactants to determine if they understood her intended meaning before answering.

$\begin{array}{ll}\text { Iulia } & \begin{array}{l}\text { Uhm and I ask if they will } \\ \text { change my mind (.2) if } \\ \text { (.1) soon but (.3) if you } \\ \text { don't come-- }\end{array} \\ \text { Patient } & \begin{array}{l}\text { (.2) Did you do you normally } \\ \text { have Saturdays? (segment B, }\end{array} \\ \text { Iulia } & \text { lines 108, 109) } \\ \text { Yeah. }\end{array}$

The patient's initial pause in the example above indicates an attempt to process the information or a wait for clarification. When clarification is not forthcoming, the patient adopts a different approach to the topic of discussion, in this example, scheduling a future appointment. Iulia's frequent pauses indicate she is having difficulty communicating her meaning to the patient and opts for an avoidance strategy rather than a comprehension check which would enlist the patient's aid in the discourse. The data analyzed here comprise only 24 minutes of transcribed speech. For the most part, data corroborate months of 
observations. However, Iulia's use of confirmation check has been observed more frequently than these data suggest and is discussed as one of the language learning strategies she uses in the results of the event/network analysis.

Self-expansion was a difficult category to assess since it includes a repeated word or words and was difficult to distinguish from the category of repetition. In general, I looked for the addition of semantic information when coding a strategy as self-expansion:

$\begin{array}{ll}\text { Iulia } & \text { become a nurse, become a } \\ & \text { technician dental } \\ & \text { technician... (segment A, } \\ & \text { line 8). }\end{array}$

and

Iulia and I was working nother place / nother assisting--

In coding repetition, I looked for repeated segments that occurred next to each other and determined that additional information was for the purpose of completing the utterance rather than clarifying meaning:

$\begin{array}{ll}\text { Iulia } & \text { No I didn't I I-- } \\ \text { Researcher } & \text { You you-- } \\ \text { Iulia } & \text { I started-- (segment A, } \\ & \text { lines 19, 20, 19a) }\end{array}$

In the examples of repetition, information is not being added when a word is repeated; rather, Iulia is gaining time, filling pauses, and making her speech more fluid. In the self-expansion examples, Iulia is repeating a word but is also adding other words to make her intended meaning more clear. 
Following are two more examples to clarify expansion versus repetition. In the first, self-expansion, Iulia has repeated "few days" not to search for words to successfully communicate her meaning but in an effort to remember the length of time. This is not a problem of communication but an effort to remember.

Iulia I don't know a few days I had something few days week ten days... (segment A, line 26)

The frequent pauses in the second example helped identify the strategy category as repetition. Iulia seemed to be stalling for time to search for words to communicate.

Iulia (.2) Let's start it / like that and if you can (.) if you can (.) uhm (.2) keep (.) with / you... (segment A, line 26)

Repair consisted of a word Iulia did not say correctly the first time:

Iulia

ever everything...

(segment A, line 26a).

Iulia is correcting herself as she speaks. She can hear her mistakes and is making an effort to make her speech grammatically correct. These mistakes do not often impede understanding of her intended meaning.

Iulia explicitly indicated difficulty in finding a word and asked for assistance by saying, "how you call that?" (segment A, lines $26 \mathrm{a}$ and 37 ). She also used verification twice, once signaled by rising intonation: 
Iulia give me a initial impulse, you know*? (segment $A$, line 4)

The second time, the indirect appeal followed a direct appeal for assistance:

Iulia how you call that test?

Scan*tron test or--

(segment $A$, line 37).

I would have coded the strategy as repair since she found the word to clarify her meaning but chose to call it verification since she used rising intonation thereby signaling an appeal for assistance.

Most instances of avoidance were incompletions where Iulia began to talk but stopped in mid-utterance. She frequently continued her turn but began a new utterance:

Iulia

$$
\begin{aligned}
& \text { we went there / they told } \\
& \text { us (.3) and was like a... } \\
& \text { (segment } A \text {, line 12) }
\end{aligned}
$$

Often when Iulia thinks her interlocutor understands her meaning, she does not finish her thought. Thus, her speech is marked by fragments, not unlike native speaker speech.

only one instance of a no-verbal avoidance strategy was used:

$\begin{array}{ll}\text { Researcher } & \text { So Iulia will you have } \\ \text { Monday off? You work six } \\ \text { days this week? } \\ \text { (She held up one hand in } \\ \text { response to researcher's } \\ \text { query). } \\ \text { Researcher } \begin{array}{l}\text { Five. Oh. (segment } c, \\ \text { lines } 1,2,3)\end{array}\end{array}$


Iulia was aware the tape was on, may have suspected the researcher was trying to engage her in conversation, and been adverse to participating.

Iulia used long initial pauses sixteen times and over half of these were used in the interview with the researcher. These might have been more evenly distributed had the interlocutor been a participant other than the researcher. The researcher is a second language educator and accustomed to allowing learners a lengthy response time. The primary limitations in this study involve the data. Data involving only Iulia and patients were not available at the time this analysis was conducted. Evidence of more frequent strategy use in the workplace may exist. A second problem with the data is the number of unintelligible segments of speech. These untranscribed segments occurred most often in the two pieces of discourse with the least number of observed strategies. The data could be slightly skewed as these segments may have contained a significant number of strategies. Finally, the least number of strategies occurred when the doctor was a participant in the discourse. Since both the conversation situations and the interlocutor's in each conversation differed, it is difficult to determine whether the lower overall instances of strategy use in the available data were due to Iulia's increasingly subservient role or to the communicative event. 
The number of avoidance and long initial pause strategies used in all three of the transcribed segments support the part of Faerch and Kasper's claim that strategies that have worked when learners have confronted communication difficulties in the past will most likely be employed again.

As noted previously, Swain (1985) maintains that strategy use contributes to language learning. This study attempted to look at whether or not meaning was being negotiated at work and though it is to some extent, it remains to be seen how limiting those instances of negotiated meaning are. Further, Faerch and Kasper (1984) say "learners who are exposed to L2 teaching usually develop a higher metalingual awareness than those who acquire L2s outside of a formal program" (p. 47). The findings in this study support Canale's (1983) claim that learners would benefit from instruction in strategy use. Iulia would probably benefit from formal strategy training at this point in her language development (primarily, clarification request and confirmation check strategies) both professionally and personally.

\section{Event/Network Analysis}

Johnson (1992) believes case-study type research is flexible and should be formulated to suit the purpose of the study even when researchers go beyond describing phenomena to making contextual or cultural interpretations. She says 
variation in writing appeals to more than one way of knowing and enables the writers vicarious experience to be integrated into a reader's existing experience. In the following discussion of the results of the event/network analysis, I have combined descriptive and interpretive writing in order to provide examples to support my interpretations of the communicative relationship between Iulia and her discourse participants.

Over the course of an eight and a half hour work day, Iulia spoke to seven patients, two patient parents, dentists on six separate occasions, and dental hygienists and assistants on eight occasions (Appendix C). Other people Iulia likely interacted with were the receptionist, her supervisor, and the person who sterilizes instruments. The people I observed Iulia communicate with are diagrammed in a network (Figure 1 ).

In interactions with patients, Iulia tended to have higher status. Patients deferred to her greater knowledge of dental hygiene when they asked her advice about uneven surfaces on their teeth, toothaches, and what toothpaste they should use. Another factor relating to status in these patient interactions is that Iulia asks most of the questions. These questions have to do with the patients' home health care. Iulia informs patients of the actions she is going to take before she performs them, such as probing their gum line, polishing their teeth, and moving their 


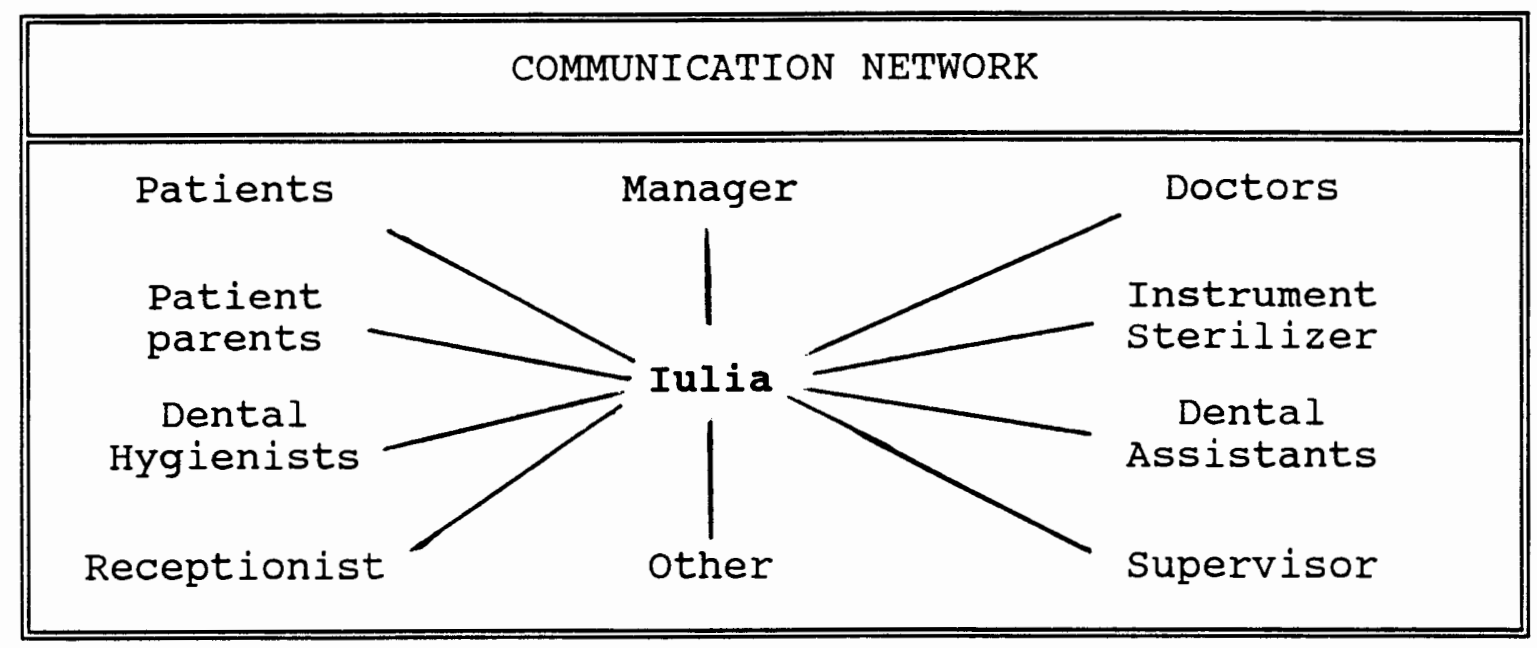

Figure 1. Communication network. 
chair. She tells almost every patient they are not flossing enough (reprimand) and has told me she tries to scare patients into taking better care of their teeth. Finally, Iulia attempts to engage patients in small talk by asking them about current events. Her efforts may indicate she is the more comfortable speech participant. For this reason, she may feel comfortable taking responsibility for the conversation. The current event Iulia used on the day the data were collected had to do with the Blazers (the city's basketball team who were competing in the championships at the time). Iulia questioned three patients about what they thought of the Blazers.

A summary of the 24 interactions recorded is given in Table II. The time of the interaction, the participants in the interaction, the nature of the address, researcher's opinion as to the status of the interactants to each other, and whether or not territory affected the interlocutors' statuses to each other is given for ease of reference.

Patients who tend to have more equal status to Iulia are those who are older and those who tease or joke with her. Iulia's first patient of the day was a middle aged man who did not always respond to Iulia's queries. Iulia restated a question about the Blazers when she did not get a response and finally asked him if he followed them at all. The man told her she would have to speak louder and Iulia ceased her efforts at engaging him in conversation. Iulia 
TABLE II

OBSERVED INTERACTIONS

\begin{tabular}{|c|c|c|c|c|c|}
\hline & TIME & INTERACTANTS & $\begin{array}{l}\text { NATURE OF } \\
\text { ADDRESS }\end{array}$ & EQUAL & TERRITORY \\
\hline 1 & $\begin{array}{l}7: 32- \\
7: 33\end{array}$ & Iulia, hygienist & request & yes & hygienists' \\
\hline 2 & $\begin{array}{l}7: 37- \\
7: 38\end{array}$ & $\begin{array}{l}\text { Iulia, hygienist (or } \\
\text { dental assistant) }\end{array}$ & rebuke & no & Iulias' \\
\hline 3 & $\begin{array}{l}7: 44- \\
7: 45\end{array}$ & Iulia, hygienist & question & yes & Iulias' \\
\hline 4 & $\begin{array}{l}\text { 8:01- } \\
8: 02\end{array}$ & Iulia, dental assistant & $\begin{array}{l}\text { information } \\
\text { exchange }\end{array}$ & yes & Iulias' \\
\hline 5 & $\begin{array}{l}7: 49- \\
8: 12\end{array}$ & Iulia, patient & $\begin{array}{l}\text { question and } \\
\text { answer (Q/A), } \\
\text { compliment, } \\
\text { information } \\
\text { exchange, } \\
\text { reprimand, small } \\
\text { talk }\end{array}$ & no & Iulias' \\
\hline 6 & $\begin{array}{l}8: 08- \\
8: 12\end{array}$ & Iulia, patient, doctor & advising, thanking & no & Iulias' \\
\hline 7 & $\begin{array}{l}8: 13- \\
8: 18\end{array}$ & Iulia, patient & informing & no & Iulias' \\
\hline 8 & $\begin{array}{l}9: 20- \\
9: 38\end{array}$ & Iulia, two hygienists & gossiping & yes & hygienists' \\
\hline 9 & $\begin{array}{l}9: 55- \\
10: 15\end{array}$ & $\begin{array}{l}\text { Iulia, patient, younger } \\
\text { brother, parent, dental } \\
\text { assistant }\end{array}$ & $\begin{array}{l}\mathrm{Q} / \mathrm{A} \text {, comforting, } \\
\text { informing }\end{array}$ & no & Iulias' \\
\hline 10 & $\begin{array}{l}10: 15 \\
10: 20\end{array}$ & $\begin{array}{l}\text { Iulia, patient, younger } \\
\text { brother, parent, doctor }\end{array}$ & $\begin{array}{l}\text { informing, joking, } \\
\text { prescribing, } \\
\text { recommending }\end{array}$ & no & Iulias' \\
\hline 11 & $\begin{array}{l}10: 31- \\
10: 37\end{array}$ & Iulia, patient & $\mathrm{Q} / \mathrm{A}$ & no & Iulias' \\
\hline 12 & $\begin{array}{l}10: 50- \\
10: 58\end{array}$ & Iulia, patient, doctor & $\begin{array}{l}\mathrm{Q} / \mathrm{A}, \text { advising, } \\
\text { directing, } \\
\text { recommending, } \\
\text { requesting, retelling }\end{array}$ & no & Iulias' \\
\hline
\end{tabular}


OBSERVED INTERACTIONS

(continued)

\begin{tabular}{|c|c|c|c|c|c|}
\hline & TIME & INTERACTANTS & $\begin{array}{l}\text { NATURE OF } \\
\text { ADDRESS }\end{array}$ & EQUAL & TERRITORY \\
\hline 13 & $\begin{array}{l}11: 04- \\
11: 05\end{array}$ & Iulia, patient & $\begin{array}{l}\text { Q/A, advising, } \\
\text { informing, } \\
\text { instructing, } \\
\text { responding }\end{array}$ & no & Iulias' \\
\hline 14 & $\begin{array}{l}11: 23 \\
11: 43 \\
\end{array}$ & $\begin{array}{l}\text { Iulia, patient, dental } \\
\text { assistant }\end{array}$ & $\begin{array}{l}\text { Q/A, informing, } \\
\text { joking, small talk }\end{array}$ & no & Iulias' \\
\hline 15 & $\begin{array}{l}11: 43- \\
11: 49\end{array}$ & Iulia, patient, doctor & $\begin{array}{l}\text { Q/A, clarifying, } \\
\text { joking, small talk }\end{array}$ & no & Iulias' \\
\hline 16 & $\begin{array}{l}11: 50- \\
11: 53\end{array}$ & Iulia, patient & $\begin{array}{l}\mathrm{Q} / \mathrm{A} \text {, instructing, } \\
\text { reprimanding }\end{array}$ & no & Iulias' \\
\hline 17 & $\begin{array}{l}12: 04- \\
12: 08\end{array}$ & Iulia, patient & $\begin{array}{l}\text { Q/A, information } \\
\text { exchange }\end{array}$ & no & Iulias' \\
\hline 18 & $\begin{array}{l}12: 22- \\
12: 26\end{array}$ & Iulia, patient & advising, reminding & no & Iulias' \\
\hline 19 & $\begin{array}{l}1: 40- \\
1: 45\end{array}$ & $\begin{array}{l}\text { Iulia, patient, } \\
\text { researcher }\end{array}$ & $\begin{array}{l}\text { Q/A, information } \\
\text { exchange, } \\
\text { informing, } \\
\text { instructing, teasing }\end{array}$ & no & Iulias' \\
\hline 20 & $\begin{array}{l}1: 47- \\
1: 49\end{array}$ & Iulia, patient & $\begin{array}{l}\text { Q/A, advising, } \\
\text { explaining, } \\
\text { information } \\
\text { exchange, small } \\
\text { talk }\end{array}$ & no & Iulias' \\
\hline 21 & $\begin{array}{l}2: 40 \\
2: 43\end{array}$ & Iulia, patient & $\begin{array}{l}\text { Q/A, informing, } \\
\text { promising, } \\
\text { requesting } \\
\text { assistance }\end{array}$ & no & Iulias' \\
\hline 22 & $\begin{array}{l}3: 21- \\
3: 25\end{array}$ & Iulia, patient & $\mathrm{Q} / \mathrm{A}$ & no & Iulias' \\
\hline 23 & $\begin{array}{l}3: 34- \\
3: 38\end{array}$ & Iulia, patient, doctor & $\begin{array}{l}\text { Q/A, informing, } \\
\text { thanking }\end{array}$ & no & Iulias' \\
\hline 24 & $\begin{array}{l}3: 48- \\
3: 50\end{array}$ & Iulia, patient & small talk & yes & Iulias' \\
\hline
\end{tabular}


clearly lost power in commanding the conversation and chose to avoid communicating rather than to speak louder. But this is not due to shyness.

In general, Iulia does not appear to be a shy individual. My inference is based on observations where she has requested meaning clarification from native speakers and other observations in which she has defended her beliefs or opinion. Further, Iulia often takes charge of conversations by introducing topics, questioning patients and staff regarding their background, and soliciting their opinion on a topic. I attended the wedding and reception Iulia had organized and funded almost entirely by herself. At the reception, Iulia took care to visit with many of the guests, in particular those guests who were not members of the Romanian community (i.e., the Americans). At the wedding, Iulia was a gregarious speaker; however, in her conversation with the older, male patient discussed above, she was a shy participant. Iulia has a great deal of respect for people who are older than she is and may be reluctant to speak loudly to them since this might be a sign of disrespect. Iulia seemingly took responsibility for the patient's inability to understand her and avoided communicating rather than continuing to embarrass herself or the patient.

Iulia's respect for older people affects the way she talks to them. She is polite and shows deference to them. She tells each patient to take better care of their teeth. 
Usually this involves encouraging them to floss more often. With older patients, if she mentions flossing and more frequent brushing, she encourages rather than instructs the patients. She does not warn them they may lose their teeth, as frequently they already have. She treats their lack of teeth as normal, and in casually requesting the patients hand her their false set of upper or lower teeth, she is making the patients as comfortable as possible. Iulia's requests, polite way of educating, and soft voice with older patients indicates she sees herself as having lower status to these patients.

The patient who achieved the least formal level of communication with Iulia was a young man who mimicked her advice and said, "I know, you guys always say the same thing and I'll probably go home and be just as bad as ever." The patient repeatedly interrupted Iulia's attempts to educate him about home health care indicating he already had the knowledge she was trying to impart. From the researcher's perspective, it appeared the patient was putting himself on an equal level with Iulia by sharing her knowledge rather than acting as one who is learning from her. The patient laughed at himself and the fact that what Iulia and other dental hygienists are trying to do in terms of home health care is wasted on him. He encouraged Iulia to laugh at him as well, as though she were laughing at a mischievous child, one she could do nothing about. 
Patients who tease and joke with Iulia establish a less formal visit. When Iulia participates by teasing and joking in kind, she is allowing this more relaxed, friendlier atmosphere to happen. Rather than a fact, this is my interpretation since I have observed Iulia develop the same rapport with another patient who was a drug user. After that patient left, Iulia revealed her disrespect for the patient. Perhaps then the generalization to be made is that Iulia intentionally adjusts her speech to the discourse participants in order to make them as comfortable as possible while at the same time she may be hiding her true reaction to them.

There were two occasions in which Iulia's linguistic difficulties affected communication. The first of these occurred when Iulia asked a patient to spell the name of an anti-inflammatory drug the patient was taking. The patient looked quickly at Iulia before she spelled the word. The patient was abrupt during the entire visit, refusing to be engaged in small talk. She also left quickly and declined Iulia's assistance in making her next appointment. Iulia does not usually offer her assistance, rather she tells the patient to come up front with her so they can schedule the next appointment. The patient told Iulia she did not like having her teeth polished because she thought the gritty material used for polishing was uncomfortable. Other comments the patient made indicated she did not like dental 
visits. The patient's unwillingness to communicate could have been due to her dislike of dental visits. It is likely the patient was unhappy with the entire procedure and directed her negative attitude towards Iulia, the only person available. Rather than submitting patiently to the procedure, the patient reacted and changed the situation from a necessary procedure she was responsible for to a procedure she was being forced to undergo against her choice. The patient's attitude affected Iulia's relation to her but did not necessarily lower her status. The patient was willing to allow Iulia status for her position and direct her anger at the situation and procedure but Iulia's request fueled and supported the patient's attitude and gave her a tangible, human target for her feelings. Iulia may have been aware of the patient's feelings since she asked rather than told the patient they would go up front together.

The second instance occurred when a patient complimented Iulia on her English and Iulia downplayed her abilities. She told the patient she wasn't good at spelling, she confused words like battle/bottle and fight/faith. The patient did not understand and chose to change topics rather than ask Iulia to clarify her intended meaning. When Iulia mentioned battle/bottle, I began to understand she was confused by the spelling/meaning correspondence because of the similarity in spelling. 
However, when she said fight/faith, a brief lull in the conversation ensued in which Iulia was done speaking and the patient and I were trying to process this information. In not asking Iulia to clarify her meaning, we were employing a face-saving device to protect her. Though Iulia may not have been aware of the conversation breakdown, the patient was, and abandoned the topic.

Reaction to Iulia's non-native speech and accent have not been observed except where Iulia has admitted a lack of knowledge. Co-workers at the clinic frequently hear nonnative speech from patients and as all co-workers of equal or higher status to Iulia have been at the clinic at least as long as she has, they are accustomed to her speech. Patients are of generally lower status to Iulia since they come to her for her expertise and help. When she admits to incompetency with the language by asking patients to spell words, patients may lose confidence in her as a professional. These instances are admittedly few and their effect on the patient is possibly outside of Iulia's level of awareness since she requests assistance rather than taking a chance and making an error. Iulia is aware of her need to improve her reading and writing skills but is not motivated to work on them because she is able to do her job well enough with the skills she has. Iulia's question (Appendix C, interaction 17) as to whether the patient wanted her to accompany the patient up front revealed a 
difference of hygienist/patient relations in this visit. Iulia often instructs people of lower status to herself but conversational rules of politeness required that she make a request in a situation where the participant's status was equal or higher in relation to her. Schiffrin (1991) suggests interactional sociolinguistic strategies people use "are attuned to social differences in power and solidarity" (p. 7) .

Occasionally Iulia makes comments or asks questions that are unclear. She does not always realize when people have not understood her and seldom checks verbally whether her intended meaning was imparted (see the discussion of comprehension check strategies under discourse analysis above). I have observed her rely on nonverbal clues in interactants' facial expressions for comprehension: "talk it's okay, if not then not asking so" (Appendix E, 9f). She is usually successful which is indicative of her familiarity with her second culture. However, when her intended meaning is not understood and the interactant does not ask for clarification, the interactant may be intentionally saving her from embarrassment. On occasions when Iulia has been asked to clarify herself, she has indeed been embarrassed. Her voice gets soft and she indicates verbally that what she said was not important anyway.

With younger patients, Iulia tended to take a more dominant role. Her second patient was a three-year-old boy. 
Iulia gave him two toys and a tooth brush to play with and repeatedly told him what a good boy he was in order to alleviate his fears and discomfort. She discussed the patient's medical and dental history with his mother, answered the mother's concerns about the patient's teeth, and advised the mother regarding the patient's dental needs. In contrast to her first patient, Iulia was in charge of the conversation linguistically.

Iulia told another patient, a nine-year-old boy, that she knew from his pictures he was not taking care of his teeth. She showed him how to brush and floss properly and then gave him the brush and floss in order for him to demonstrate what he had learned. Iulia was abrupt with the patient, even telling him to wait while she finished writing in his chart. She frowned during the entire patient visit. Her frown has consistently revealed her inner feelings. I have noted her facial expressions and questioned her reactions to patients after the patients left. The frowns have indicated anger, offense, disgust, or trouble as in the case of an abused child. Following this patient's departure, Iulia told me she was disgusted with the child and his parent (with whom she talked in the waiting room) because they were dirty and smelled bad. Iulia was offended by the lack of respect she felt she was shown. In the interactions with children, Iulia used a louder voice than in her first patient visit. Iulia's louder voice; her 
directing, telling, and demanding, and her feelings of disgust show she felt she was a higher status participant in these interactions.

Iulia is in control of the linguistic interaction with children and their parents. She feels entirely comfortable with children, going so far as to boast of her ability to make them feel comfortable in the dentist chair. She uses a loud, confident voice when addressing them and simplifies her language so they will understand. Since her status is not in question and the language she is using is simple, she is not threatened in interactions with children.

In her interaction with the nine-year-old boy who was dirty, it was interesting to see Iulia's difficulty. The part of her job she likes most is working with a variety of people, but with this patient it was clear she was anxious for the visit to be over. Iulia was offended by the lack of respect she felt the patient was showing her in his lack of cleanliness, a respect she felt she deserved. Iulia allows people leeway when they follow the cultural rules of the clinic, rules which are subtle and difficult to discern. When these rules are violated (as when hygienists go through Iulia's files and when patient's are not clean), Iulia is offended. The violations of the rules and norms of the environment reveal where Iulia draws social boundaries. Iulia's interactions with doctors clearly indicate a status difference. As early as my first day of 
observations, I was amazed at how infrequently the doctors address Iulia. In observations of the NS hygienist, the doctors joked and laughed more frequently with the hygienist. This could have been due to personality factors, to the length of time the hygienist has been employed at the clinic and her familiarity with the dentist, to the hygienist's and Iulia's differing language abilities, or to doctor reaction to NNS speech. The data were too limited to make any conclusive interpretations.

Patients are seen by the hygienist twice a year for cleanings and once a year by a dentist for a check-up. If a patient is due for a dental exam, Iulia will use a control panel to call a dentist. Iulia saw eight patients over the course of this data collection and five of them were seen by a dentist. The dentist visits lasted from 5 to 8 minutes each (an average of 5.8 minutes each - see Table III and Figure 2 below).

Table III shows a breakdown of the time Iulia spent in the presence of the people in her network, the average length of time of these contacts and the percentage of total time these represented in the eight and a half hour observation period. These percentages are diagrammed in Figure 2. Seven percent of the contacts overlap. For instance, the entire time of a patient visit was recorded under time spent with patients. However, during the patient visit, a dental visit may have taken place. The length of 
TABLE III

TIME BREAKDOWN

\begin{tabular}{|l|l|l|l|l|l|l|}
\hline & $\begin{array}{l}\text { Alone or } \\
\text { Unobserved }\end{array}$ & Patients & Doctors & $\begin{array}{l}\text { Hygienists } \\
\text { and Dental } \\
\text { Assistants }\end{array}$ & Lunch & Overlap \\
\hline Time spent & $170 \mathrm{~min}$ & $262 \mathrm{~min}$ & $29 \mathrm{~min}$ & $26 \mathrm{~min}$ & $50 \mathrm{~min}$ & $34 \mathrm{~min}$ \\
\hline Average & $7.73 \mathrm{~min}$ & $32.75 \mathrm{~min}$ & $5.8 \mathrm{~min}$ & $3.86 \mathrm{~min}$ & N/A & N/A \\
\hline Percent & $33 \%$ & $51 \%$ & $6 \%$ & $5 \%$ & $10 \%$ & $7 \%$ \\
\hline
\end{tabular}

* Total time $=510$ minutes

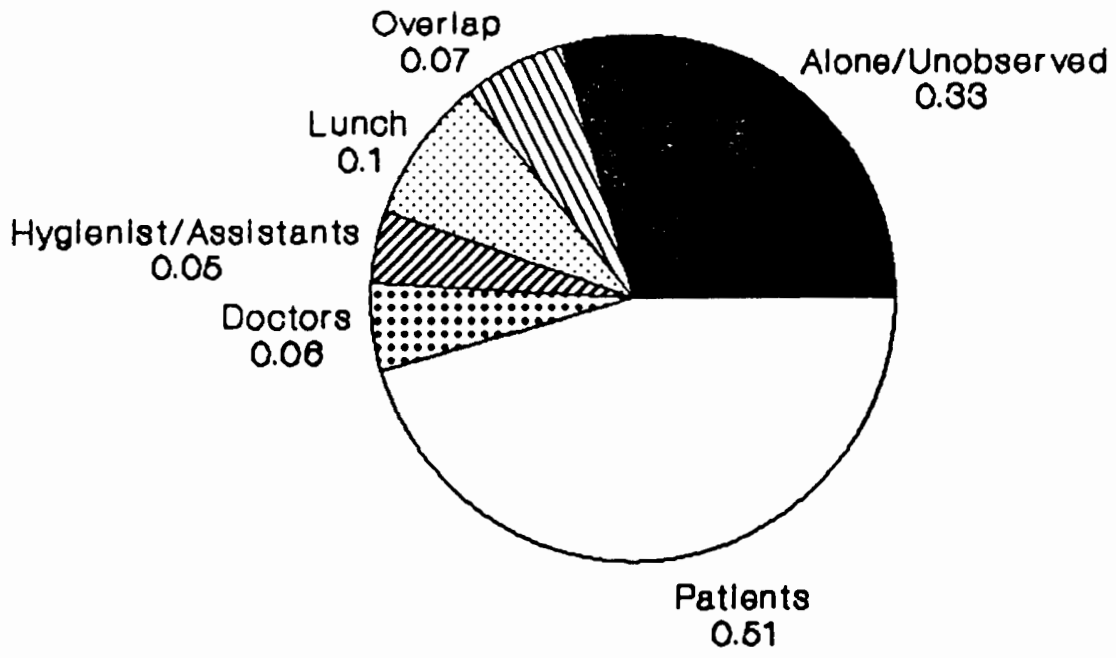

Figure 2. Time breakdown diagram. 
the dental visit was then recorded under doctor time. Thus, the length of the doctor visit was recorded twice, once under patient time and once under doctor time. The total actual time observations were recorded was 476 minutes, but, because of the overlap, the total time in the table came to 510 minutes.

The dentist addressed Iulia during only two of his visits. In the first of these two visits he asked Iulia to get a cold lotion from the central supply room, and when she returned he instructed her to chart his findings as he dictated them to her (Appendix C, interaction 12). In the second of these two visits, the dentist asked Iulia a question about the patient's medical coverage and again he told her to chart his findings (Appendix C, interaction 15). Iulia (and all other staff at the clinic) refers to the dentists as 'doctor' and is careful never to state the condition of a patient's teeth or give advice beyond a level of hygiene (such as orthodontic needs; TMJ detection; gum or periodontal disease; cavity, filling, or extraction needs). occasionally Iulia will comment on what she sees (to the patient) but will say she is uncertain and the doctor will need to tell the patient what he sees and give his advice about necessary care. The nature of Iulia-doctor interactions consistently and ritualistically demarcate Iulia's lower status to the doctors. Iulia remains largely invisible when the doctor is present during patient visits 
and serves as a tool at the doctor's disposal by performing actions when the doctor bids her to do so. She participates in promoting this status relationship by not offering her opinion of patients' dental needs and findings even though her training has taught her to recognize these needs. While Iulia's relations are subtle and change with every patient, each interaction with a dentist marks and solidifies her status to the dentist. The dentist and Iulia state their relation to each other in every interaction. Even when the dentist is not present, Iulia acknowledges his higher status by calling him 'doctor' and referring to him as 'the professional.' In addition, Iulia signals the dentist when she needs him to examine her patient and immediately interrupts her work when he arrives. Iulia's interrupting her work shows that it is not as important as the dentist's. The dentist's time is more limited since he examines as many as three times the patients Iulia sees in making rounds from one hygienist's room to another. If Iulia sees one patient in an hour, the dentist may have seen seven to twelve in the same time period given that his visits last between five and eight minutes each. one time a dentist checked to see if Iulia needed him for anything; this was an exceptional action on his part and Iulia thanked him.

In analyzing Iulia's interactions with other hygienists and dental assistants, I found it necessary, at this point 
in the observations, to combine these two groups since hygienists and dental assistants wear a variety of uniforms, all similar in color and style. Unless these interlocutors are engaged in performing their jobs, it is impossible to tell them apart. The difficulty is further compounded in that hygienists help the dental assistants by taking $x$-rays and patients' blood pressure during the hygienists' spare time. The nature of Iulia's interactions with hygienists and dental assistants tends to be equal unless territory is a factor. They gossip, exchange information and request supplies from each other. I observed one of these interlocutors overstep Iulia's territorial boundaries though, and Iulia's reaction was a sharp "No!" The interlocutor came into Iulia's room and without addressing Iulia looked through her charts. This was the only instance recorded where territory seemed to be a factor in the interlocutors' status relationship to each other, but it revealed clear expectations of respect for other peoples' territory.

Some hygienists have seniority earned by the length of time they have worked for the company. Seniority does allow privileges such as larger, permanent, and more private rooms, higher pay, and greater flexibility in work schedules but does not give any hygienist higher status over another. The NS hygienist observed had a great deal of seniority as a result of the length of time she had been employed with the 
company. This seniority allowed her flexible hours and a preferred work room. She commanded respect from her colleagues for her speed and skill in her occupation. Her speed enabled her to complete her work on patients in a shorter than allotted amount of time. She used this time to read the newspaper or chat with other hygienists in the breakroom. In contrast, Iulia tended to fall behind schedule, particularly in the first few months of my observations. When patients failed to appear for their scheduled appointment, Iulia used the time to write in patient charts; an activity that frequently kept her after work. The NS hygienist had a core of regular patients she saw at six month intervals. She did not face the writing difficulties Iulia did and rarely had to chart complete medical and dental histories for new patients. For both of these reasons, she was able to work with one to two more patients in a day than Iulia was and to complete her work in less time. Iulia will probably continue to progress in speed and skill as her job routine becomes more and more familiar to her.

Iulia has fluctuating territory rights as her assigned room changes from day to day. Within her territory on a given day, dentists have the highest status, as evidenced by Iulia's deference to their recommendations and work interruptions when a dentist enters a room. The hygienist with permanent rights to the territory has next highest 
status, since she would never be assigned to use any other room and tells Iulia via post-it notes how the room is to be kept (this indicates authority). Iulia has third highest status (except where it fluctuates with patients as noted above), and other dental hygienists and assistants have low status as evidenced by their lack of territorial rights and need to show respect for Iulia's property and territory. It is also likely that supervisors and the manager have higher status in Iulia's territory, but they have not been observed in her room. Iulia's higher status to the dental hygienists and assistants reverses itself when she is in their territory and is equal when they are in neutral territory (the lunchroom, hallways, reception area). However, it should be noted that Iulia helps the dental assistants with their work, in their territory, but the dental assistants do not, and in fact are unable to, reciprocate since they do not have hygienist training. Iulia can ask a dental assistant to break down her room after a patient visit if she is busy. Helping the dental assistants with their work is nice but optional on the part of the dental hygienists. Dental hygienists do not assist each other. They have equal power and rights within the structure of the company except where seniority (length of time on the job) affords them greater job stability (job stability is gained through length of time with the company more than with job 
performance), choice of room, and preferred schedules. However, status and work among the hygienists are equal.

Iulia spent 170 minutes alone. During 65 of these 170 minutes, she finished writing in patient charts, cleaned her room and reset it for the next patient, or picked up supplies from the central supply room. This time was observed time. The remainder of the time, 105 of 170 minutes, Iulia left her room to meet patients, checked to see what was taking them so long with the dental assistant, assisted them in making their next appointment on their way out, helped the dental assistants take x-rays and blood pressure, and gossiped, teased and joked with her coworkers.

I was unable to observe most of the interactions that took place outside of Iulia's room. Unobservable time comprised $33 \%$ of the eight and a half hour period of data collection. I was able to record the actions and interactions that took place during these times by questioning Iulia, deducing the action by the items she came and left with, or by overhearing parts of conversations. However, for 11 of the 170 unobservable minutes, I was unable to determine the event that took place and though I may have known Iulia left to get supplies or set up her tray for the next patient, I do not know whether she interacted with her co-workers during this time. 
Another problem in conducting the network analysis was that Iulia used a soft voice when speaking in English. Occasionally, I could not hear her well and I may have recorded some of the 'nature of addresses' (Table II) incorrectly. Iulia used a soft voice when she spoke to older people or people of clearly higher status to her. This could be due to ideas on how to speak respectfully to older people or to an increasing lack of confidence in addressing higher status people. Iulia frequently lacks confidence in speaking in English and as her confidence level decreases so does the volume of her voice.

Although Iulia has adjusted to American culture in many ways (such as when people continually ask her how she is without really wanting to know), she is still undecided about what to do with compliments. Thus, when she is complimented, she makes excuses for herself or disagrees with the person complimenting her. She is particularly confused by what to do with compliments on her language abilities because of her lack of confidence in this area.

\section{Componential Analysis}

Iulia identified many of the same participants in her communication network as noted by the researcher in the previous section. In addition, she identified housekeepers, mechanics, and front desk personnel. The researcher has rarely, if ever, observed Iulia interacting with supervisors, managers, housekeepers, mechanics, and front 
desk personnel and was not able to verify most occurrences of these interactions.

The transcribed interview on which the following results are based is found in Appendix E. This interview is used to explain or add information to Iulia's responses to statements. Interpretations were guided by spradley 1970 and 1980. Iulia was presented with these statements and asked to identify categories of interactants they applied to. Relevant comments Iulia made were included in the table. The researcher's interpretations of the data are guided by spradley's 1979 and 1980 guides to doing componential analyses. Statements the researcher presented to Iulia are listed under 'attribute' in Table IV. An 'O' marks Iulia's indication of a category of participant in her network with whom she would be likely to use the statement listed under 'attribute'. Researcher's actual observation of these is marked by an 'X.'

Iulia responded 'everybody' to thirteen of thirty-one statements presented. The first of these, statement \#2, "Iulia adds information to discussions with these people," did not correspond to researcher observations. The researcher has primarily observed Iulia asking questions in order to learn rather than to add information to further the discussion. The difference could be due either to Iulia's perception of herself as an active contributor in 
TABLE IV

COMPONENTIAL DATA

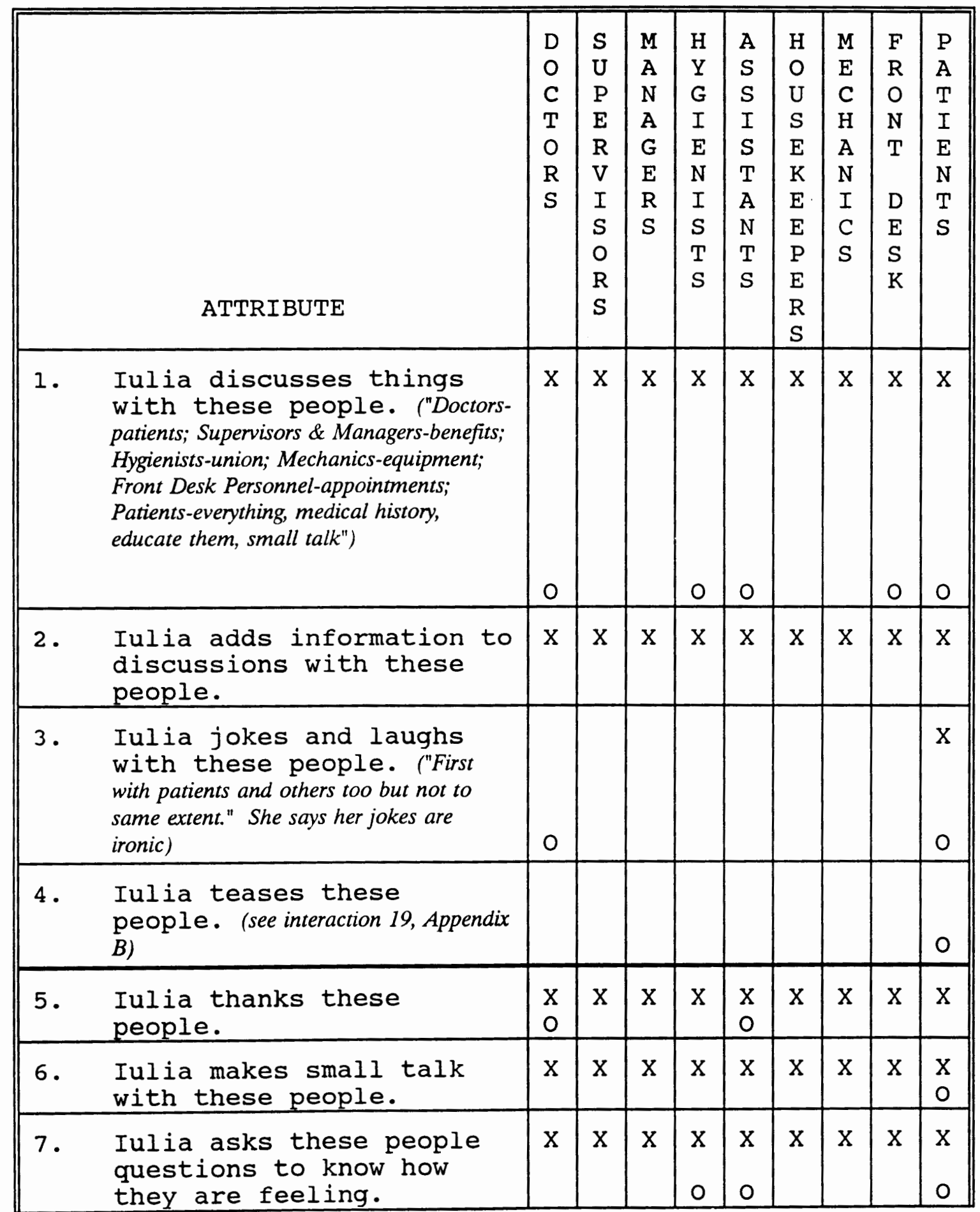


TABLE IV

COMPONENTIAL DATA

(continued)

\begin{tabular}{|c|c|c|c|c|c|c|c|c|c|c|}
\hline & ATTRIBUTE & $\begin{array}{l}D \\
O \\
C \\
T \\
O \\
R \\
S\end{array}$ & $\begin{array}{l}S \\
U \\
P \\
E \\
R \\
V \\
I \\
S \\
O \\
R \\
S\end{array}$ & $\begin{array}{l}M \\
\text { A } \\
N \\
A \\
G \\
E \\
R \\
S\end{array}$ & $\begin{array}{l}\mathrm{H} \\
\mathrm{Y} \\
\mathrm{G} \\
\mathrm{I} \\
\mathrm{E} \\
\mathrm{N} \\
\mathrm{I} \\
\mathrm{S} \\
\mathrm{T} \\
\mathrm{S}\end{array}$ & $\begin{array}{l}\mathrm{A} \\
\mathrm{S} \\
\mathrm{S} \\
\mathrm{I} \\
\mathrm{S} \\
\mathrm{T} \\
\mathrm{A} \\
\mathrm{N} \\
\mathrm{T} \\
\mathrm{S}\end{array}$ & $\begin{array}{l}H \\
O \\
U \\
S \\
E \\
K \\
E \\
E \\
P \\
E \\
R \\
S\end{array}$ & $\begin{array}{l}\mathrm{M} \\
\mathrm{E} \\
\mathrm{C} \\
\mathrm{H} \\
\mathrm{A} \\
\mathrm{N} \\
\mathrm{I} \\
\mathrm{C} \\
\mathrm{S}\end{array}$ & $\begin{array}{l}F \\
R \\
O \\
N \\
T \\
\\
D \\
E \\
S \\
K\end{array}$ & $\begin{array}{l}P \\
A \\
T \\
I \\
E \\
N \\
T \\
S\end{array}$ \\
\hline 8. & $\begin{array}{l}\text { Iulia asks these people } \\
\text { questions so she knows } \\
\text { what to do next. ("Hygienists. } \\
\text { I'm asking them after or before but not to } \\
\text { give me the sequences") (9a, Appendix } A \text { ) }\end{array}$ & & & & $X$ & & & & & $\mathrm{X}$ \\
\hline 9. & $\begin{array}{l}\text { Iulia asks for things } \\
\text { from these people. }\end{array}$ & $\mathrm{X}$ & $x$ & $\mathrm{X}$ & $\begin{array}{l}X \\
0 \\
\end{array}$ & $\mathrm{X}$ & & $\mathrm{X}$ & $\mathrm{X}$ & $\mathrm{X}$ \\
\hline 10. & $\begin{array}{l}\text { Iulia asks these people } \\
\text { to do things. }\end{array}$ & & & & & $\mathrm{X}$ & & & $\mathrm{x}$ & $\begin{array}{l}x \\
0 \\
\end{array}$ \\
\hline 11. & $\begin{array}{l}\text { Iulia asks these people } \\
\text { questions to be polite. }\end{array}$ & $\mathrm{X}$ & $\mathrm{X}$ & $\mathrm{X}$ & $\mathrm{X}$ & $\mathrm{X}$ & $\mathrm{X}$ & $\mathrm{X}$ & $\mathrm{X}$ & $\mathrm{X}$ \\
\hline 12. & $\begin{array}{l}\text { Iulia asks these people } \\
\text { for permission. ("even the } \\
\text { patient I put cold water") }\end{array}$ & $\mathrm{X}$ & $\mathrm{X}$ & $\mathrm{X}$ & $\mathrm{X}$ & $\mathrm{X}$ & $\mathrm{X}$ & $\mathrm{X}$ & $\mathrm{X}$ & $\mathrm{X}$ \\
\hline 13. & $\begin{array}{l}\text { Iulia asks these people } \\
\text { questions to help her do } \\
\text { her job. }\end{array}$ & $\mathrm{X}$ & & & $\mathrm{X}$ & & & & & \\
\hline 14. & $\begin{array}{l}\text { Iulia asks these people } \\
\text { questions because she } \\
\text { needs to know the answer. }\end{array}$ & $X$ & & & $x$ & $\mathrm{X}$ & & $\mathrm{X}$ & $\mathrm{X}$ & O \\
\hline 15. & $\begin{array}{l}\text { Iulia responds to these } \\
\text { people when they ask her } \\
\text { questions. }\end{array}$ & $\begin{array}{l}x \\
0\end{array}$ & $\mathrm{X}$ & $\mathrm{X}$ & $\mathrm{X}$ & $\mathrm{X}$ & $\mathrm{X}$ & $\mathrm{X}$ & $\mathrm{X}$ & $\begin{array}{l}x \\
0\end{array}$ \\
\hline
\end{tabular}


TABLE IV

COMPONENTIAL DATA

(continued)

\begin{tabular}{|c|c|c|c|c|c|c|c|c|c|}
\hline ATTRIBUTE & $\begin{array}{l}\mathrm{D} \\
\mathrm{O} \\
\mathrm{C} \\
\mathrm{T} \\
\mathrm{O} \\
\mathrm{R} \\
\mathrm{S}\end{array}$ & $\begin{array}{l}S \\
U \\
P \\
E \\
R \\
V \\
I \\
S \\
O \\
R \\
S\end{array}$ & $\begin{array}{l}M \\
A \\
N \\
A \\
G \\
E \\
R \\
S\end{array}$ & $\begin{array}{l}\mathrm{H} \\
\mathrm{Y} \\
\mathrm{G} \\
\mathrm{I} \\
\mathrm{E} \\
\mathrm{N} \\
\mathrm{I} \\
\mathrm{S} \\
\mathrm{T} \\
\mathrm{S}\end{array}$ & $\begin{array}{l}A \\
S \\
S \\
I \\
S \\
T \\
A \\
N \\
T \\
S\end{array}$ & $\begin{array}{l}H \\
O \\
U \\
S \\
E \\
K \\
E \\
E \\
P \\
E \\
R \\
S\end{array}$ & $\begin{array}{l}\mathrm{M} \\
\mathrm{E} \\
\mathrm{C} \\
\mathrm{H} \\
\mathrm{A} \\
\mathrm{N} \\
\mathrm{I} \\
\mathrm{C} \\
\mathrm{S}\end{array}$ & $\begin{array}{l}\mathrm{F} \\
\mathrm{R} \\
\mathrm{O} \\
\mathrm{N} \\
\mathrm{T} \\
\\
\mathrm{D} \\
\mathrm{E} \\
\mathrm{S} \\
\mathrm{K}\end{array}$ & $\begin{array}{l}\mathrm{P} \\
\mathrm{A} \\
\mathrm{T} \\
\mathrm{I} \\
\mathrm{E} \\
\mathrm{N} \\
\mathrm{T} \\
\mathrm{S}\end{array}$ \\
\hline $\begin{array}{l}\text { 16. Iulia says things to make } \\
\text { these people more } \\
\text { comfortable. ("I do this with } \\
\text { everybody, especially the patients") }\end{array}$ & $\mathrm{X}$ & $\mathrm{X}$ & $\mathrm{X}$ & $\mathrm{x}$ & $\mathrm{X}$ & $\mathrm{X}$ & $\mathrm{X}$ & $\mathrm{X}$ & 0 \\
\hline $\begin{array}{l}\text { 17. Iulia reminds these } \\
\text { people to do things. } \\
\text { (*signatures })\end{array}$ & $\begin{array}{l}X \\
\star\end{array}$ & & & & $\begin{array}{l}X \\
*\end{array}$ & & & & $\begin{array}{l}x \\
0\end{array}$ \\
\hline $\begin{array}{l}\text { 18. Iulia reminds these } \\
\text { people of upcoming } \\
\text { events. (appointments) }\end{array}$ & & & & & & & & & 0 \\
\hline $\begin{array}{l}\text { 19. Iulia rebukes these } \\
\text { people. }\end{array}$ & & & & & 0 & & & & 0 \\
\hline $\begin{array}{l}\text { 20. Iulia corrects these } \\
\text { people when they } \\
\text { misunderstand her. }\end{array}$ & $\mathrm{X}$ & $\begin{array}{l}x \\
0\end{array}$ & $\mathrm{X}$ & X & $\mathrm{X}$ & $\mathrm{X}$ & $\mathrm{X}$ & $X$ & $\begin{array}{l}x \\
0\end{array}$ \\
\hline $\begin{array}{l}\text { 21. Iulia disagrees verbally } \\
\text { with these people. ("No*, } \\
\left.N o^{*} !\right)\end{array}$ & & & & & 0 & & & & \\
\hline $\begin{array}{l}\text { 22. Iulia gives these people } \\
\text { her opinion. (limited, within the } \\
\text { confines of what is legal) }\end{array}$ & & & & & & & & & $\begin{array}{l}x \\
0\end{array}$ \\
\hline
\end{tabular}


TABLE IV

COMPONENTIAL DATA

(continued)

\begin{tabular}{|c|c|c|c|c|c|c|c|c|c|}
\hline ATTRIBUTE & $\begin{array}{l}D \\
O \\
C \\
T \\
O \\
R \\
S\end{array}$ & $\begin{array}{l}S \\
U \\
P \\
E \\
R \\
V \\
I \\
S \\
O \\
R \\
S\end{array}$ & $\begin{array}{l}M \\
A \\
N \\
A \\
G \\
E \\
R \\
S\end{array}$ & $\begin{array}{l}\mathrm{H} \\
\mathrm{Y} \\
\mathrm{G} \\
\mathrm{I} \\
\mathrm{E} \\
\mathrm{N} \\
\mathrm{I} \\
\mathrm{S} \\
\mathrm{T} \\
\mathrm{S}\end{array}$ & $\begin{array}{l}A \\
S \\
S \\
I \\
S \\
T \\
A \\
N \\
T \\
S\end{array}$ & $\begin{array}{l}H \\
O \\
U \\
S \\
E \\
K \\
E \\
E \\
P \\
E \\
R \\
S\end{array}$ & $\begin{array}{c}M \\
E \\
C \\
H \\
A \\
N \\
I \\
C \\
S\end{array}$ & $\begin{array}{l}F \\
R \\
O \\
N \\
T\end{array}$ & $\begin{array}{l}\mathrm{P} \\
\mathrm{A} \\
\mathrm{T} \\
\mathrm{I} \\
\mathrm{E} \\
\mathrm{N} \\
\mathrm{T} \\
\mathrm{S}\end{array}$ \\
\hline $\begin{array}{l}\text { 23. Iulia corrects these } \\
\text { people when she disagrees } \\
\text { with what they say. ("I try } \\
\text { to correct very gently with the patients, I try } \\
\text { to share the right information but I don't } \\
\text { try to change") }\end{array}$ & & & & & & & & & $\mathrm{X}$ \\
\hline $\begin{array}{l}\text { 24. Iulia suggests these } \\
\text { people change their } \\
\text { behavior/habits. }\end{array}$ & & & & & & & & & 0 \\
\hline $\begin{array}{l}\text { 25. Iulia tells these people } \\
\text { what she is about to do. }\end{array}$ & & & & & & & & & $\begin{array}{l}x \\
0\end{array}$ \\
\hline $\begin{array}{l}\text { 26. Iulia tells these people } \\
\text { they are not doing } \\
\text { something right or well. }\end{array}$ & & & & & & & & & $\mathrm{x}$ \\
\hline $\begin{array}{l}\text { 27. Iulia tells these people } \\
\text { things so they can do a } \\
\text { better job. }\end{array}$ & & & & & & & & & 0 \\
\hline $\begin{array}{l}\text { 28. Iulia tells these people } \\
\text { things they need to know. } \\
\text { (educating patients, adamant about not } \\
\text { telling doctors what to do) }\end{array}$ & & & & & & & & & $\mathrm{x}$ \\
\hline
\end{tabular}


TABLE IV

COMPONENTIAL DATA

(continued)

\begin{tabular}{|c|c|c|c|c|c|c|c|c|c|c|}
\hline \multicolumn{2}{|r|}{ ATTRIBUTE } & $\begin{array}{l}\mathrm{D} \\
\mathrm{O} \\
\mathrm{C} \\
\mathrm{T} \\
\mathrm{O} \\
\mathrm{R} \\
\mathrm{S}\end{array}$ & $\begin{array}{l}S \\
U \\
P \\
E \\
R \\
V \\
I \\
S \\
O \\
R \\
S\end{array}$ & $\begin{array}{l}M \\
A \\
N \\
A \\
G \\
E \\
R \\
S\end{array}$ & $\begin{array}{l}\mathrm{H} \\
\mathrm{Y} \\
\mathrm{G} \\
\mathrm{I} \\
\mathrm{E} \\
\mathrm{N} \\
\mathrm{I} \\
\mathrm{S} \\
\mathrm{T} \\
\mathrm{S}\end{array}$ & $\begin{array}{l}A \\
S \\
S \\
I \\
S \\
T \\
A \\
N \\
T \\
S\end{array}$ & $\begin{array}{l}H \\
O \\
U \\
S \\
E \\
K \\
E \\
E \\
P \\
E \\
R \\
S\end{array}$ & $\begin{array}{l}\mathrm{M} \\
\mathrm{E} \\
\mathrm{C} \\
\mathrm{H} \\
\mathrm{A} \\
\mathrm{N} \\
\mathrm{I} \\
\mathrm{C} \\
\mathrm{S}\end{array}$ & $\begin{array}{l}\mathrm{F} \\
\mathrm{R} \\
\mathrm{O} \\
\mathrm{N} \\
\mathrm{T} \\
\mathrm{D} \\
\mathrm{E} \\
\mathrm{S} \\
\mathrm{K}\end{array}$ & $\begin{array}{l}P \\
A \\
T \\
I \\
E \\
N \\
T \\
S\end{array}$ \\
\hline 29 & $\begin{array}{l}\text { Iulia tells these people } \\
\text { stories about her Iife. } \\
\text { ("whoever is asking me. They asking me, } \\
\text { so I have to answer") }\end{array}$ & $\mathrm{X}$ & $\mathrm{X}$ & $\mathrm{X}$ & $\mathrm{x}$ & $\mathrm{x}$ & $\mathrm{X}$ & $\mathrm{X}$ & $\mathrm{X}$ & $\mathrm{X}$ \\
\hline 30 & $\begin{array}{l}\text { Iulia tells these people } \\
\text { things they didn't know } \\
\text { before. }\end{array}$ & & & & & & & & & $\mathrm{X}$ \\
\hline 31. & $\begin{array}{l}\text { Iulia tells these people } \\
\text { when they are doing a } \\
\text { good job. }\end{array}$ & $\mathrm{X}$ & $\mathrm{X}$ & $\mathrm{X}$ & $\mathrm{X}$ & $\mathrm{x}$ & $\mathrm{x}$ & $X$ & $X$ & $\mathrm{X}$ \\
\hline
\end{tabular}


discussions or to the limits of the researcher's observations.

Statement \#5, "Iulia thanks these people," also did not correspond to researcher observations. In identifying issues Iulia found odd about American culture, she cited excessive thanking as one oddity but felt she was now used to it and did it herself. The researcher has primarily observed Iulia thank the doctor (in fact, after every doctor visit) and dental assistants when they deliver patient files and pictures. Thanking other hygienists and patients has not been observed and in the case of patients, it is often the case that Iulia is thanked. Iulia also had to adjust to the American custom of asking how people are without really wanting to know. She says that she now responds, "Fine, thanks," whether or not it is true but that when she asks this question she really wants to know (Appendix E, 21j). Thus, Iulia's interpretation of statement \#11, "Iulia asks these people questions to be polite," in which she answered 'everybody,' contradicts her previous comment.

For statement \#6, "Iulia makes small talk with these people," Iulia responded 'everybody.' Iulia takes responsibility for conversations with patients, introducing topics in the news and asking about a patients' weekend. With dental assistants and other hygienists, Iulia tends to take a more passive role of listener and joins in conversations when asked her opinion on a topic. Appendix 
$E$, segment $C$ is an excellent example of the quality of Iulia's participation in conversations with her peers.

Statement \#20, "Iulia corrects these people when they misunderstand her," confirmed researcher observations. When Iulia knows she has been misunderstood or misunderstands her interlocutor, she clarifies her meaning or requests clarification. When an interlocutor's misunderstanding persists, Iulia abandons her efforts at clarification but rarely is the reverse true (Appendix E, 19b). This supports findings from the discourse analysis that suggest Iulia's comprehension is higher than her spoken abilities in English (Appendix E, 17) .

Iulia has come to trust me as an interested, caring listener. She discusses her life in Romania, her work, her family life, and her experiences with me at length and in great detail. In her response to statement \#29, "Iulia tells these people stories about her life," she answered 'everybody.' Iulia's life under a communist regime, in a less developed country is difficult to comprehend when one has limited experience with other cultures. The bits and pieces of information about her Iife I have observed her tell have been scaled down and received lightly. Iulia is probably accurate in responding 'everybody' to this question as she is frequently asked questions about her life and experiences but the depth of her responses is important to understanding her relationship with her co-workers and 
clients. It reveals that she trusts less of her private self to those she is not close to.

Iulia's 'everybody' response to statement \#31, "Iulia tells these people when they are doing a good job," conflicts with researcher observations. I have observed her over sixty hours, in many situations, and the only time I have heard her tell someone they were doing a good job was to patients whose dental profile improved from one visit to the next. This occurred less than half the time as many patients do not do a good job cleaning their teeth between dental visits. Further, Iulia claims she tries to scare patients into taking better care of their teeth which contradicts telling them they are doing a good job. In this instance, Iulia's perception of her interactions is different from what I observed.

There were four instances where the researcher noted Iulia carrying on types of interactions that she did not identify as part of her repertoire. Two of these, statements \#3 and \#4, had to do with joking and teasing. Iulia believes herself incapable of doing either in English and describes the humor she does express as irony (Appendix E, 20). Iulia does not tell jokes and is unable to understand many that are told to her. Those she does understand she does not find funny. However, Iulia constantly sees and expresses humor in human behavior. She is extremely pleasant, finding a lot to laugh about with her 
patients and often with the doctors. The statements were phrased in such a way that they hid a distinction between expressing humor and telling jokes.

In statement \#18, "Iulia reminds these people of upcoming events," the researcher was thinking of Iulia's reminding patients of their next appointments. This is a part of the patient visits recorded in observations but was interpreted differently by Iulia. The statement should be disregarded. Finally, "Iulia rebukes these people," statement \#19, is rare and has been noted elsewhere in the thesis as exceptional behavior. Iulia either sees these incidents differently or forgets them.

As mentioned before, the researcher did not identify housekeepers and mechanics as part of Iulia's network, nor did the researcher observe interactions with these participants. Iulia classified types and natures of interactions with them as general and the same as those given above for 'everybody' without additions. It is likely that Iulia does ask these people questions to be polite because she has little opportunity to know them well since she seldom comes into contact with them.

Iulia also has little contact with supervisors and managers. The manager at the clinic is a very busy man (see discussion of structure taxonomy below) who runs the administrative side of the business. He has little contact with dental personnel who are overseen by specialized 
supervisors. Hygiene supervisors divide their time between clinics. As a floating employee, Iulia's time is divided among different clinics and she rarely sees her supervisor. Iulia mainly interacts with the key types of people already identified in her communication network: doctors, hygienists, assistants, and patients. Among these groups, she carries on the greatest variety of interactions with patients, with whom she spends the majority of her time.

Iulia readily described the occupation structure at the clinic (Appendix E). She distinguished finer categories of employees than have been possible to know as an outside observer. These will be discussed in the order they appear in the tables from top to bottom and left to right.

There are two groups of dentists (Table V), associates and 'others' whom Iulia was unable to name. These 'other' dentists will be referred to as non-associate dentists. The Technical Director is an associate dentist and in charge of both groups of dentists. The associate dentists have power over the non-associate dentists. There are many types of dentists but three main ones at the clinic. These are 1) General-- the main kind, those who refer patients to specialist dentists "if the patient has something special" (Iulia/researcher phone conversation $7 / 12 / 92) ; 2$ ) Pedodontists-- those who specialize in working with children; and 3) Periodontists-- those who specialize in 
TABLE V

DENTISTS

\begin{tabular}{|c|c|c|c|c|c|c|}
\hline \multicolumn{7}{|c|}{ TECHNICAL DIRECTOR } \\
\hline \multicolumn{3}{|c|}{ ASSOCIATE DENTISTS } & \multicolumn{4}{|c|}{ NON-ASSOCIATE DENTISTS } \\
\hline $\begin{array}{l}\text { GENERAL } \\
\text { those who } \\
\text { refer } \\
\text { patients to } \\
\text { specialist } \\
\text { dentists }\end{array}$ & $\begin{array}{l}\text { PEDO- } \\
\text { DONTISTS } \\
\text { those who } \\
\text { work with } \\
\text { children }\end{array}$ & $\begin{array}{l}\text { PERIO- } \\
\text { DONTISTS } \\
\text { those who } \\
\text { work on } \\
\text { patients } \\
\text { with gum } \\
\text { disease }\end{array}$ & $\begin{array}{l}\text { ORTHO- } \\
\text { DONTISTS } \\
\text { those who } \\
\text { work with } \\
\text { braces }\end{array}$ & $\begin{array}{l}\text { ORAL } \\
\text { SURGEONS } \\
\text { 'maxilal facial,' } \\
\text { those who } \\
\text { operate on the } \\
\text { jaw, mandibles } \\
\text { and parts of the } \\
\text { mouth }\end{array}$ & $\begin{array}{l}\text { ENDO- } \\
\text { DONTISTS } \\
\text { those who } \\
\text { perform root } \\
\text { canals }\end{array}$ & $\begin{array}{l}\text { PROSTETIC } \\
\text { DENTISTS } \\
\text { those who } \\
\text { work with } \\
\text { dentures and } \\
\text { gum disease }\end{array}$ \\
\hline
\end{tabular}


patients with gum disease. Some other types of dentists are included and described in the table.

All dentists have high status regardless of their associate status. The dentists do not have a role in hiring and firing clinic staff and have little to do with the system at the clinic. Iulia describes them as separate and says they do not care about others. In fact, they have one large office at the back of the clinic which is rarely entered by non-dentist personnel. Thus, dentists are physically as well as structurally separate from all other personnel and patients at the clinic.

The dentists are in charge of themselves and all other personnel fall under Dental Administration. Iulia made finer distinctions of personnel who fall under Dental Administration, in particular, the hygienist and dental assistant categories (Table VI). Iulia has expanded functions certification which allows her to administer nitric oxide and anesthetics. Her certification also allows her to give sutures and fillings (silver and composite) but these are not recognized in this state. Hygienists without this additional certification cannot perform these procedures. Dental Assistants were the most finely categorized group.

Dental Aides clean instruments. This last group used to be called instrument cleaners and the work was included 
TABLE VI

DENTAL ADMINISTRATION

\begin{tabular}{|c|c|c|c|c|c|c|}
\hline \multicolumn{7}{|c|}{ DENTAL ADMINISTRATION } \\
\hline \multicolumn{3}{|c|}{ HYGIENE SUPERVISORS } & \multicolumn{4}{|c|}{ DENTAL ASSISTANT SUPERVISORS } \\
\hline $\begin{array}{l}\text { HYGIENISTS } \\
\text { clean teeth only }\end{array}$ & $\begin{array}{l}\text { EFDA HYGIENISTS } \\
\text { clean teeth, administer } \\
\text { nitric oxide and } \\
\text { anesthetics, give } \\
\text { sutures and fillings } \\
\text { (silver and composite) }\end{array}$ & $\begin{array}{l}\text { OHAP } \\
\text { ASSISTANTS } \\
\text { assist dentists in } \\
\text { surgery }\end{array}$ & $\begin{array}{l}\text { DENTAL } \\
\text { ASSISTANTS } \\
\text { LEVEL } 1 \text { take } \\
\text { patient dental pictures } \\
\text { only }\end{array}$ & $\begin{array}{l}\text { DENTAL } \\
\text { ASSISTANTS } \\
\text { LEVEL } 2 \\
\text { take dental patient } \\
\text { pictures and assist in } \\
\text { surgery }\end{array}$ & $\begin{array}{l}\text { EFDA DENTAL } \\
\text { ASSISTANTS take } \\
\text { patient dental } \\
\text { pictures and } \\
\text { impressions of } \\
\text { teeth. }\end{array}$ & $\begin{array}{l}\text { DENTAL AIDES } \\
\text { 'instrument } \\
\text { cleaners,' clean } \\
\text { instruments, wash } \\
\text { dishes' }\end{array}$ \\
\hline
\end{tabular}


in other assistant job descriptions. The dental assistant union has successfully worked to change the job specifications and title of the position. The certification each assistant and hygienist holds is well known, common but unspoken knowledge.

The supervisors' job has recently changed. Previously the supervisor was in charge of hiring and firing staff, managing staff, and doing administrative work. The supervisor did and does supervise staff at three clinics and works 1 to 2 days at each. In the past there was a lead hygienist and a lead dental assistant to act as supervisor in the supervisor's absence. Economic conditions have eliminated the lead hygienist position and force the supervisors to work part time as hygienists and dental assistants when there is a shortage of these personnel. Iulia's supervisor prefers to work solely as a supervisor and occasionally changes schedules with Iulia to avoid hygiene work.

Table VII below gives a visual picture of the many jobs the clinic's manager performs. In addition to the manager's function in relation to the listed people, he keeps clinic records and is in charge of purchasing office supplies.

I examined the interview transcripts (Appendix E) for categories and classifications Iulia makes in organizing information at work. There were two clear categories Iulia distinguished at length: kinds of people she likes to work 
TABLE VII

DENTAL ADMINISTRATION II

\begin{tabular}{|c|c|c|c|c|}
\hline \multicolumn{5}{|c|}{ DENTAL ADMINISTRATION II } \\
\hline \multicolumn{5}{|c|}{ MANAGER } \\
\hline $\begin{array}{l}\text { TEMPORARY } \\
\text { PERSONNEL } \\
\text { manager hires to } \\
\text { cater parties, work } \\
\text { the front desk when } \\
\text { shorthanded }\end{array}$ & $\begin{array}{l}\text { PATIENTS } \\
\text { manager responds } \\
\text { to patient } \\
\text { complaints; works } \\
\text { to improve patient } \\
\text { relations }\end{array}$ & $\begin{array}{l}\text { MECHANICS } \\
\text { manager is } \\
\text { responsible for } \\
\text { calling mechanics to } \\
\text { repair broken } \\
\text { administrative and } \\
\text { dental equipment }\end{array}$ & $\begin{array}{l}\text { HOUSEKEEPERS } \\
\text { manager } \\
\text { responsible for } \\
\text { hiring and firing } \\
\text { housekeeping } \\
\text { staff/company and } \\
\text { making sure they } \\
\text { are doing a } \\
\text { satisfactory job }\end{array}$ & $\begin{array}{l}\text { FRONT DESK } \\
\text { PERSONNEL } \\
\text { manager hires, } \\
\text { fires, and } \\
\text { prepares } \\
\text { schedules for this } \\
\text { group and acts as } \\
\text { job and personnel } \\
\text { supervisor. }\end{array}$ \\
\hline
\end{tabular}


with and kinds of people who are difficult to work with. Iulia describes kinds of people she likes to work with as nice, open, talkative, and not demanding. These people can be patients and/or colleagues. She thinks patients who talk a lot are most interesting but is careful to adjust to them if they do not want to talk:

some of them are nice but you can feel that when you start, if they want to talk it's okay, if not then not asking so. (Appendix $E, 9 f$ )

Iulia further classifies patients as those who take care of their teeth and those who don't (Appendix E, 11) and:

There are cases, you know, they don't listen to you or they come second time and the same kind of problems or stuff like that or they are demanding or they are complaining about your colleagues or, you know, things, there are things. (Appendix $E$, 21a)

Iulia does not care for patients who complain about her colleagues.

Iulia finds it difficult to work with doctors who are 'picky.' These doctors ask her 'specialty' questions (5d). Iulia describes conversations with doctors as very delicate and says in these interactions "the best thing to do is to be very delicate..." (5h). She never interferes or contradicts a doctor. Iulia related a time she was advising a dentist of her findings and mentioned the patient was 12 years old. The dentist became angry and told her he knew how old the patient was. A few of these isolated events were all that Iulia required to know to be careful in her dealings with the dentists. 
My interpretations of data throughout the course of my observations may have caused me to categorize the types and natures of interactions and to base my questions on those categories. To reduce this effect, Iulia was given ample time to add examples and stories to her answers. I did not narrowly follow my prepared questions, but instead I diverged when Iulia did and came back to the focus of the interview when appropriate. This lengthened the interview considerably. The validity of these results has been accepted where they are in agreement with past results and was further explored or explained through subsequent questions when Iulia's perceptions differed from mine.

Researcher limitations were illustrated in Iulia's identification of housekeepers and mechanics in her communication network. The researcher did not observe or identify these participants. A variety of research techniques are necessary in order to record as accurate an account of the situation in focus as possible.

Iulia defines herself primarily in terms of her morals and values. She believes all people are or should be 'the same.' She fights feelings within herself that contradict this, seeing these as a personal battle and her 'sin,'

Well, everybody is special, you know, you cannot categorize... if somebody is open to people it's it's valuing everybody, that way supposed to be... (Appendix E, 12a \& 12C) 
These morals and values are a result of many influences. I have learned Iulia is a devout Baptist and have seen religious influence in her frequent references to God's presence in her life. Her family history of having lived as highly placed government officials then as prisoner, outcasts, and finally immigrants has brought Iulia close to her family and has taught her that one's station in life neither lowers nor elevates one's worth. The influence of the communist regime she lived under remains with Iulia despite her desire to leave it behind. This is seen most obviously in her hesitancy to announce her pregnancy but in more subtle ways as well. Iulia worked up until the day she gave birth because she fears imminent destitution, keeping breadlines and low wages in mind. Occasionally Iulia's language reveals her ties too; for instance, Iulia speaks in terms of duty when asked if she likes her work or if she is happy in her marriage. Iulia sees personal happiness as less important than doing one's duty for the good of the family and society. Her own character and trust in her beliefs and values aid her in integrating and in moving across the line between American and Romanian culture and her personal and private self.

\section{SUMMARY}

Since qualitative research is not scientifically and mathematically measurable, all three of the analyses 
discussed in this chapter were necessary for validating researcher observations of the work environment. Each analysis was used to examine a different layer of the situation observed. The results of the discourse analysis revealed learning strategies Iulia uses that have contributed to her success as a language learner. These results also show her work environment is linguistically limited by context and may eventually contribute to Iulia's fossilizing as an English language learner. The results of the event/network analysis were useful for identifying the people a hygienist interacts with at work. The detailed record provided presents a number of examples of situations and discourse that could be useful to ESP educators in preparing simulated activities for future NNS hygienist training. The results of the componential analysis demonstrate the way Iulia organizes her knowledge and experience of the work environment. I attempted to explain this organization by eliciting her opinions, values, and beliefs. What the results of these analyses mean in terms of communicative competence for a NNS hygienist in the particular setting studied, the relation of ESP to ESL, and the applicability of this study to teaching ESP are discussed in Chapter VI. 
CHAPTER VI

\section{DISCUSSION}

In order to define what it means for a NNS to be communicatively competent in a specific professional environment, I examined a NNS professional in her work setting. Through interviews and observations, I clarified ambiguous points in the discourse, event/network, and componential analyses; gained Iulia's perspective of her work and the people she interacts with; and described the environment and those interactants. In this chapter, I summarize information about Iulia and her work culture, and I discuss the results of the analyses, interviews, and observations in relation to the three research questions I proposed in Chapter I.

\section{THE NNS PROFILE}

Iulia has succeeded in assimilating to her life in America in many ways. For example, she believes conformity will enable her to improve her financial status in this country. She conforms through silence in not speaking out against things she believes are wrong, such as dentist recommending unnecessary procedures. Such situations make 
her feel she is compromising her values but her need to survive financially and socially is greater and she adjusts. Success for Iulia means giving up a way of life, adopting the larger cultural norms (asking how you are and not meaning it) and remaining silent when these conflict with inner feelings. Iulia likes working for the clinic because she agrees with the company's philosophy,

the goal is to take care, to prevent, conserve, yes, not to do a lot of extensive work which is expensive and gives profit. The best is to do the best treatment (Appendix $E, 6 \mathrm{C}$ ).

Since the company's overall philosophy is in agreement with her own, Iulia rarely finds herself in compromising situations and this has influenced her efforts to gain permanent employment at the clinic.

I have presented a rich description of Iulia's strength and character to provide researchers and teachers significant insight into the characteristics, strengths, strategies, and skills that contribute to a learner's success. To do this, Iulia's domestic and cultural struggles have remained as much in focus during this study as the research questions having to do with skills a NNS needs to function professionally in a foreign work culture. She retains cultural beliefs that a woman is subservient to a man as long as the man loves and cares for the woman. When this is no longer the case, the woman is free of her 
subservient role. Iulia has remained in a marriage that is not working and only after four years of struggle in it is she beginning to believe there is really nothing more she can do to make it work. Her determination to make her marriage work is due to her beliefs about a marriage partner's responsibility and dedication to the relationship. The society Iulia is in holds less stringent views of the obligations of marriage partners in general (as evidenced by the ease and frequency of obtaining divorce). Trent and South (1989) gathered statistical data on divorce rates in 66 countries and found the rate in the United States to be one of the highest in their samples. They attributed this to four major factors: "socioeconomic development, the female labor participation rate, the sex ratio, and dominant religion" (p. 391).

Iulia is told by many familiar with her situation that she should leave her marriage, yet these are values she does not adopt. On the other hand, she can verbalize these situations, watch how her husband cannot adjust and see too that he has been unemployed for well over two years. Iulia does not see it as her position to support the family but finds she is doing just that because her husband refuses to see the world from any perspective but his own and is unable to integrate into this culture. Trying not to judge or change Iulia's marriage has been both difficult and painful. 
However, in contrasting her to her husband, one can clearly see the bicultural person Iulia has become. By day she is a successful business woman, serving her clients and communicating with colleagues, supervisors and patients in her second language and culture. By night she is a Romanian woman, relaxing with her family (husband, parents, and siblings) in a large garden after a traditional meal primarily of potatoes and several kinds of meat. The conversation is sparse and spoken in Romanian.

Iulia does not have the same level of confidence in her English language abilities as she does in her values and beliefs. She sees herself as a more confident speaker of Romanian and speaks more loudly and naturally in that language. She can hear her mistakes when she speaks English and becomes frustrated when she is unable to successfully communicate her meaning.

Iulia is an active language learner, refusing to allow meanings to go by unless she understands them. She attempts to incorporate new terms into her vocabulary. For instance, I used 'interact,' 'interactant,' and 'interaction' when explaining the discourse analysis to Iulia. Soon 'interfere' and 'interference' began appearing in her dialogue where 'interact' and 'interaction' would have been more appropriate: "I didn't have a lot of interference with, you know, activities and stuff like that with older 
people..." (Appendix E, 14a). In another example, "I don't feel complexed and I don't feel inferior" (Appendix E, 10f), Iulia used 'complexed' for 'compromised.' She is attempting more difficult and unfamiliar vocabulary she has heard people use or found in the dictionary herself. Iulia's errors often go unchecked by her interlocutors, but eventually she begins using her new terms accurately.

Iulia does not appear to be slowing down in her language development. There are at least two explanations for this. Iulia studied Latin, French, Italian, and Russian before she began learning English. It is entirely possible that along with acquiring these languages she acquired an aptitude for learning languages and automatically uses the language learning strategies that have proven successful for her in any second or foreign language situation (see pp. 7179). The second explanation is that Iulia puts herself in linguistic situations for which she does not have the necessary language skills to cope. She is forced to improve quickly. She cites the two most difficult of these instances as the time she entered her dental assistant training program and the time she began working professionally as a hygienist. In the first instance, Iulia could not understand the lectures or the conversation around her. She found common, everyday language more difficult to acquire than the medical terminology based on Germanic roots 
which she could guess at with relative success. In the second instance, Iulia came in contact with a variety of accents, status relations, and styles of speaking and she was again forced to work hard in order to understand and even more so to reduce her accent in order to be comprehensible to a greater number of listeners. Iulia's skills and perseverance will not be found in all language learners but the strategies she uses, vocabulary development, clarification requests, repetition, and selfexpansion might be key to teaching second language learners.

PROFILE OF THE DENTAL CULTURE

The dental culture is characterized by stability and group orientedness, strict schedules, pressures (patient quota), and common rights and benefits. There is a clear division of labor at the clinic. Jobs do not overlap and the only way employees can move up in status and monetary earnings is by furthering their education. The two occupation classifications that most nearly overlap in function are the dental hygienist and the dental assistant positions. Both work directly with patients and require a fair amount of dental knowledge. The dental hygienists have two years more education than the assistants and earn more than twice as much money. The hygienists work in private rooms but share the breakroom and dressing room. The dental 
assistant area is shared by all the assistants and is more public than the hygienists' rooms. The hygienists walk through the assistant area between patient visits to put away used instruments and pick up new ones. Hygienists also have more interaction with the doctors. All hygienists and assistants at the clinic are women. Names rather than titles are used when these two groups address each other or when others address them. Every hygienist and assistant knows the job title of every other hygienist or assistant, but this knowledge is not stated unless an error is made by an outside observer. Only then do hygienists and assistants make the distinction. Tension between the two groups exists in their complaints about each other. The hygienists would like to retain the distinction of their occupation and greater earning power while the assistants would like to minimize the gap. Iulia falls somewhere in between the two. As mentioned before, she was once a dental assistant and sympathizes with their grievances but supports the hygienists by not volunteering information to the assistants regarding how much she earns. She says this information is best kept from them in order not to aggravate them more. She tries to ease hostilities by helping the assistants with their work when she can. Until recently, the hygienists did not have a union but the assistants did. The power of the union to fight for better wages and working conditions for 
the assistants may have posed a threat to the hygienists and influenced the inception of a hygiene union which in turn may have upset the assistants in stripping them of any opportunity to achieve more equivalent status and pay. Iulia summarizes the sentiments of the two groups towards each other:

the assistants hate hygienists usually that's where and probably vice versa, the hygienists feel superior to but I don't have that feeling. (Appendix E, 8b)

It is enough for the hygienists and assistants to identify with one group or another but not to distinguish their qualifications within their group unless specifically asked about their certification. Among the hygienists, EFDA certification has limited recognition in this state and additional certification does add earning power, higher status, or significantly alter hygienists' job specifications.

The relation of an individual to the culture raises complex issues that when identified and explained may simplify the transition for new-comers to the work setting: "the acquisition of culture is often accomplished by conflict and struggle; and conformity with cultural rules and norms is frequently associated with frustration and tension" (Trudgill, 1983: 100). Iulia was frustrated by her initial inability to communicate and by the initial tensions 
she experienced as she was learning the norms of her cultural environment. More studies like this one are needed in order to reveal a common core of American work culture in order to prepare a number of NNSs to communicate in a variety of American work environments. Adequate descriptions and classifications of the language roles and features in specific situations may eventually provide the field of language education a means of defining communicative competence in those situations and perhaps a general consensus on what it means to be communicatively competent in ESP. Language educators will then be better prepared to bridge the gap between learner needs and employer expectation.

QUESTIONS

This study began with three questions.

Question 1

What characteristics of a specific setting need to be identified and taught to non-native speakers in order for them to function and communicate in their professional fields?

The results of this study are based on observations of one NNS hygienist and the characteristics of her situation cannot be generalized to a large population. However, in 
analyzing Iulia's communicative needs in her work situation, I was able to identify many general characteristics of a work situation an educator needs to be aware of when teaching ESP. These might best be presented as a series of questions ESP educators might ask themselves: 1) Who will the learners communicate with? Most? On what topics? 2) What are some of the cultural norms of the society that are likely to be unfamiliar to students (responsibility, evaluation)? 3) What is the culture of the specific field? 4) How is talking to a doctor different from talking to a patient? 5) What structures and vocabulary are used most frequently in the setting? 6) What is the philosophy of the business or field and how can it be conveyed to students? 7) What learning strategies are students most comfortable using and which ones should they learn to help them repair communication breakdowns in their work situations?

I found identifying the participants in the hygienists' network to be the first step in determining important characteristics of the work situation. Analyzing the types of conversations the hygienists hold with these different people revealed patterns of communication. When patterns are established, such as making requests of doctors and colleagues, instructors can teach the patterns in relation to the appropriate interactants the NNS hygienist will 
communicate with. Types of conversations held with the greatest variety of interactants should be identified and practiced more than those used infrequently and with fewer interactants.

Another characteristic of communication in the hygienists' work situation teachers need to be aware of is the limitation of language by the context of the situation. Topics often relate to dental issues. Medical vocabulary is used with medical professionals while simplified medical language and discussions of current events are used with patients. The results of this data would suggest when learning English, medical personnel who deal most frequently with patients need to be prepared to communicate with patients on general, current topics. However, the current context of topics does limit the number of grammatical structures an instructor would need to teach.

The philosophy of the dental clinic in this study is to provide a service to the patients. Competition in the American work environment requires businesses provide good service to their clients in order to ensure clients return. An instructor may emphasize the idea of providing a service in developing learners' awareness of patients' communicative needs. In this way, the instructor would prepare students to succeed in their occupations and meet the needs of the business at the same time. 
Question 2

How can professional language educators best meet the needs of the ESP learners and the desires of the business community simultaneously?

Identifying the characteristics of a setting, such as the interactants, nature of address, topics of conversations, and status relations and the philosophy of a business, such as 'providing a service to patients' will help educators set course goals to meet the needs of both the learners and the business community. Educators can use their knowledge of the fields their students will be entering to simulate role-plays and present problem solving activities students will find authentic and purposeful. A language educator trained or partially trained in her students' specified field will be able to go so far as to train students as well as teach them the language competencies they will need.

Language educators interested in teaching ESP may find this study useful for recognizing the rich variety of life and work experience their students bring to the classroom. Educators can be better prepared to work with such students knowing in advance the many responsibilities and obstacles the students face outside the classroom. The picture presented of Iulia's work culture and the interactants in 
her setting may give educators an understanding of what NNS students in dental programs will need to do with language in their professions. Thus, this is the first step in providing a means for setting and achieving educational goals in ESP.

\section{Question 3}

Are the language competencies, functions, and settings so different between ESP and ESL that ESP needs to be heralded as a separate discipline?

I began my research by focusing on this question. A tentative response is given in two parts below and is based on results and experience gained in conducting this study. Although it will remain an important philosophical question, distinguishing the difference between ESP and ESL is perhaps not so critical to the outcome of this study.

The competencies and functions of language are not so different as seen by the variety of non-medical people hygienists spend the greater part of their day conversing with. They must be able to communicate with these people on a variety of spontaneous, non-medical topics. Iulia achieved the competence to meet her communicative needs through time, her own perseverance, and occupational experience outside of her profession (as mentioned before). The process does not have to be as difficult as it was for 
Iulia: language educators can aid learners in transitioning into a new field in a second language and culture.

The ESP setting is considerably different from the academic environment ESI learners are prepared for. Richards (1989) suggests the focus of attention in ESP should be the environment. Widdowson (1983) says a primary means of addressing or bringing into focus the environment is through problem-solving activities or simulating situations the learner will encounter. The data and analyses in this study should provide language educators a solid beginning in meeting personal needs of the learners and organizational goals of the business when teaching in an ESP setting.

\section{LIMITATIONS}

The main limitations in this study were in collecting the data. I was not always able to hear Iulia when she spoke because of her soft voice, other conversations carried on nearby, and the ever present noise from the radio. Also, I was not always able to follow Iulia around the clinic during field observations and, as a result, I was unable to record interactions that took place outside of her room. A third limitation to the data and results of this study is that Iulia is employed at two clinics and in private practice through a temporary placement agency. I was only 
given permission to observe her at one clinic. The interactions that take place in her other two work environments may differ from those where I observed. Another limitation in field observation and data collection occurred when I interviewed the NS hygienist. These observations took place towards the end of my data collection when employees at the clinic were becoming weary of my presence. Greetings were less enthusiastic and the NS hygienist postponed allowing me to observe her twice. I shortened my observations at this point and feel I did not gain adequate insight into the differences of communication for NNS hygienists as compared to NS hygienists.

Data collected for the discourse analysis is limited to three samples. It is difficult to draw conclusive results from such a small sampling. Data collected for the event/network analysis was collected on one day only. Many factors could have affected the data and results such as the volume of work on that day, other co-workers present, and whether or not Iulia was tired. In other words, it might not have been a typical day. Finally, my own inexperience in conducting a componential analysis affected the data that was collected. I questioned Iulia about her perception of status relations even after it was clear she did not want to discuss or admit them if they existed. If I were to conduct the interview again, I would question Iulia more about 
patients and ask her to relate stories about them to support and give depth to her responses.

\section{SUMMARY}

Finding ways to meet the needs and goals of learners and businesses hiring these learners should be of great concern to ESP educators. I have identified speech participants in a specific work environment, communicative events common to the situation, many of the linguistic skills NNS workers need to communicate in their situations, and characteristics of the setting which may be useful for familiarizing educators with the dental field. The data and information in this study may be useful for educators studying, selling, or designing ESP courses for learners in the dental field.

Much more work needs to be done in specialized areas of language education. Non-verbal communication was only briefly addressed in this study, but could easily constitute a study by itself. The research and analyses used in this study could be broadened to a larger sample population of NNS hygienists in order for conclusions to be generalized. Finally, more discourse data need to be gathered and analyzed where variables such as topic and setting remain constant while discourse participants have variable status 
in order to determine whether or not status affects learners' uses of language learning strategies. 
Birdwhistell, R.L. (1955) . Background to kinesics. ETC: A Review of General Semantics, 13, 10-18.

Blom, J.P., \& Gumperz, J.J. (1986). Social meaning in linguistic structures: Code-switching in Norway. In J.J. Gumperz \& D. Hymes (Eds.), Directions in sociolinguistics (pp. 407-434). New York: Basil Blackwell, Inc.

Brown, H.D. (1987). Principles of language learning and teaching. Englewood Cliffs, NJ: Prentice Hall.

Brown, G., \& Yule, G. (1984). Discourse analysis. Cambridge: Cambridge University Press.

Campbell, R., \& Wales, R. (1970). The study of language acquisition. In $J$. Lyons (Ed.). New horizons in linguistics (pp. 31-59). New York: Penguin.

Canale, M., \& Swain, M. (1980). Theoretical bases of communicative approaches to second language teaching and testing. Applied Linguistics, 1, 1-47.

Canale, M. (1983). From communicative competence to communicative language pedagogy. In $J$. Richards \& $R$. Schmidt (Eds.), Language \& Communication (pp. 2-28). New York: Longman.

Candlin, C. (1974). Dentist-patient communication skills. England: Lancaster University, Department of Linguistics.

Candlin, C., et al. (1977a). Doctor speech functions in casualty consultations: some quantified characteristics of discourse in a regulated setting. In G. Nickel (Ed.), proceedings of the Third AILA World Congress. Stuttgart: Hochschulverlag.

Chomsky, N. (1965). Aspects of the theory of syntax. Cambridge, MA: MIT Press.

Christy, N.P. (1979a). English is our second language. New England Journal of Medicine, 300, 979-981. 
Christy, N.P. (1979b). Medspeak. New England Journal of Medicine, 301, 508 .

Dobbert, M.L. (1982). Ethnographic research: Theory and application for modern schools and societies. New York: Praeger.

Dreger, E. (1990). University faculty reactions to non -native speakers. Unpublished manuscript.

Drobnic, K. (1978, October). Outside Iinguistics: ESP as historical necessity. Paper presented at the 1978 ORTESOL conference, Portland, OR.

Dubois, B.L. (1988). Citation in biomedical journal articles. English for Specific purposes, 7, 181-193.

Ellis, R. (1985) . Understanding second language acquisition. Oxford: oxford University Press.

Faerch, C. \& Kasper, G. (1984). Two ways of defining communication strategies. Language Learning, 34, 4563 .

Frelick, A., \& van Naerssen, M. (1982, May). Professional cultural orientation in ESP. Paper presented at the annual convention of teachers to speakers of other languages, Honolulu, HI.

Gage, J., \& Prince, D. (1982). Vocational English: Preparing for a first job. TESOL Quarterly, 16, 349358 .

Gray-Richards, B. \& Kitlry, R. (1983, March). English for the health sciences: Special projects report. Vancouver, B.C.: Vancouver community college.

Gumperz, J.J., \& Hymes, D. (Eds.). (1986). Directions in sociolinguistics. New York: Basil Blackwell.

Howard, R. (1988). Review of English in Medicine. English for Specific Purposes, 7, 61-72.

Hutchinson, T., \& Waters, A. (1987). English for specific purposes: A learning-centred approach. Cambridge: Cambridge University Press. 
Hymes, D. (Ed.). (1974). Language in culture and society: A reader in linquistics and anthropology. New York: Harper \& Row.

Hymes, D. (1986). Models of the interaction of language and social Iife. In J.J. Gumperz \& D. Hymes (Eds.), Directions in sociolinguistics (pp. 35-71). New York: Basil Blackwell.

Johns, A.M. (1986). The language of business. Annual Review of Applied Linguistics, 2, 3-17.

Kachru, Y. (1985). Culture and interpretation: Discourse in non-native English. TESL Studies, $\underline{6}$, $74-87$.

Long, M.H. (1983). Native speaker/non-native speaker conversation and the negotiation of comprehensible input. Applied Linguistics, 4, 126-141.

Maher, J. (1986). The development of English as an international language of medicine. Applied Linguistics, I, 206-218.

Maher, J. (1986). English for medical purposes state of the art article. Language Teaching, 19, 112-145.

Munby, J. (1978). Communicative syllabus design. Cambridge: Cambridge University Press.

Rey, A. (1977). Accent and employability: Language attitudes. Language Sciences, 47, 7-13.

Richards, K. (1989). Pride and prejudice: The relationship between ESP and training. English for Specific Purposes, 8, 207-222.

Sauvignon, S.J. (1983). Communicative competence: Theory and classroom practice. Reading, MA: AddisonWesley Publishing Company.

Schiffrin, F. (1990). Conversation analysis. Annual Review of Applied Linguistics, 11, 3-16.

Selinker, L., Trimble, L., \& Trimble, M. (1976). Presuppositional rhetorical information in EST discourse. TESOL Quarterly, 10, 281-290. 
Spradley, James, (1970). You owe yourself a drunk: An ethnography of urban nomads. Boston: Little, Brown.

Spradley, James, (1979). The ethnographic interview. New York: Holt, Rinehart, and Winston.

Spradley, James, (1980). Participant observation. New York: Holt, Rinehart, and Winston.

Speaking Proficiency English Assessment Kit (SPEAK) Test. (1982). Educational Testing Service, Princeton, NJ.

Swain, M. (1985). Communicative competence: Some roles of comprehensible input and comprehensible output in its development. In S. Gass \& C. Madden (Eds.), Input in Second Lanquage Acquisition (pp. 235-253). Rowley, MA: Newbury House.

Swales, J. (1987). Communicative language teaching in ESP contexts. Annual Review of Applied Linguistics, 8, 48-56.

Tarone, E. (1980). Communication strategies, foreigner talk, and repair in interlanguage. Lanquage Learning, 30, 417-431.

Trent, K. and South, S. (1989). Structural determinants of the divorce rate: A cross-societal analysis. Journal of Marriage and the Family, 51, 391-404.

Tripp, D. (1986, April). Teachers' journals: An illustrated rationale for teacher/researcher partnership in curriculum research. Paper presented at the annual meeting of the American educational research association, San Francisco, CA.

Trudgill, P. (1983). Sociolinguistics: An introduction to lanquage and society. New York: Penguin.

van Ek, (1975). The threshold level. Strasbourg: Council of Europe.

van Naerssen, M. (1978, August). Improving English medical recordings by foreign medical graduates. Paper presented at the conference of the Association Internationale de Linguistique Applique, Montreal, Quebec, Canada. 
van Naerssen, M. (1979, November). Relating to the communication concerns of foreign medical colleagues. Paper presented at the annual convention of Society for Computer Medicine, Atlanta, GA.

van Naerssen, M. (1981). ESL in medicine: A matter of Iife and death. TESOL Quarterly, 12, 193-203.

Watson-Gegeo, K.A. (1988). Ethnography in ESL: Defining the essentials. TESOL Quarterly, 22, 575-592.

Widdowson, H.G. (1983) . Learning purpose and language use. Oxford: Oxford University Press.

Yamamoto, N. (1991). Effects of setting on Japanese ESL students interaction patterns. Unpublished master's thesis, Portland state University, Portland, oR. 
APPENDIX A

SPEAK TEST 


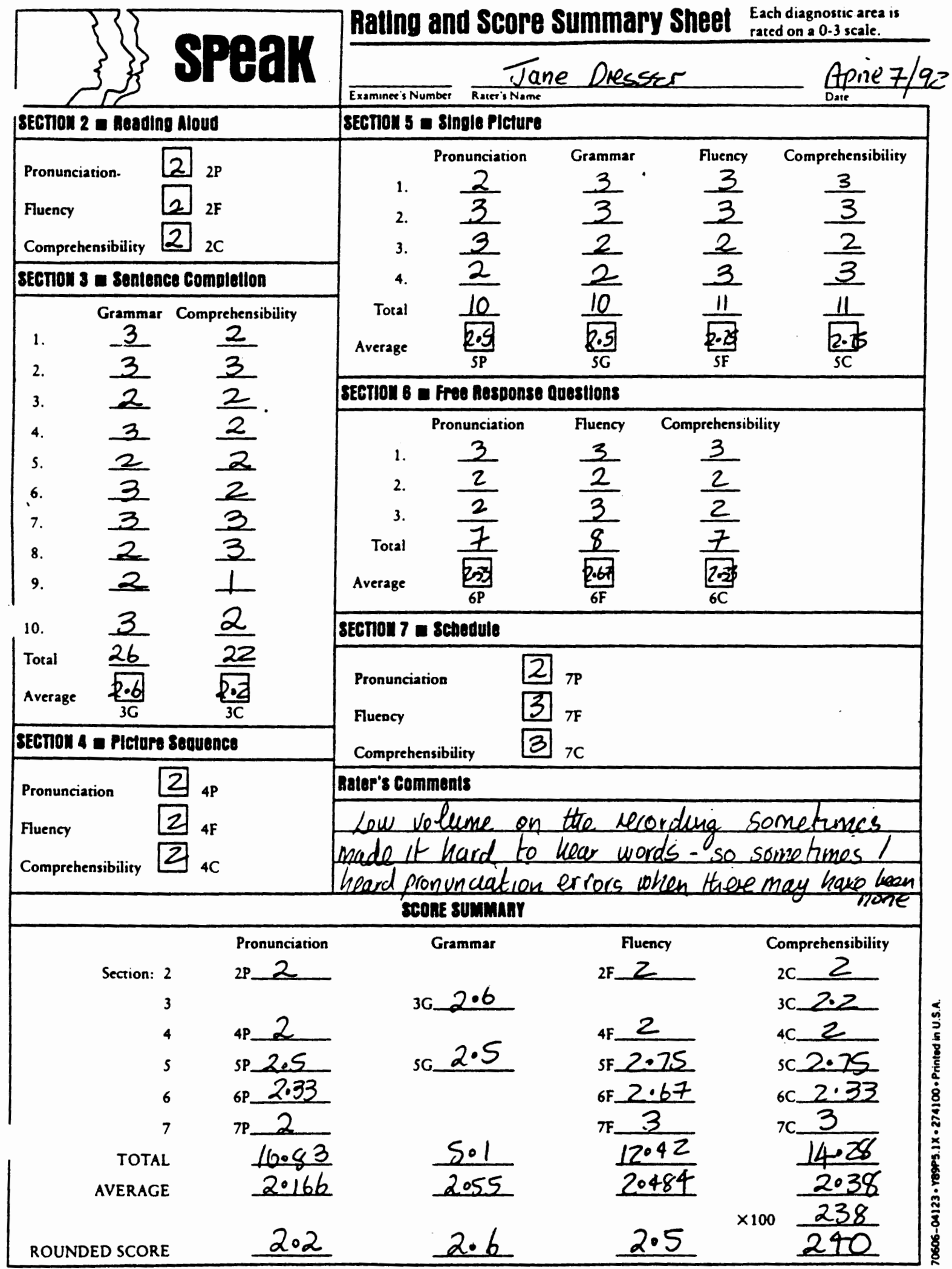


APPENDIX B

PATIENT CONSENT FORM 
We have in the dental department a researcher who is conducting an in-depth study of the job of a dental hygienist. This researcher may be present when you are being seen by a hygienist. If you have any objection to this non-medical person being present during your appointment, please inform the receptionist.

(adapted from Candlin, C., et al, (1977a) Doctor speech functions in casualty consultations: some quantified characteristics of discourse in a regulated setting). 
APPENDIX C

EVENT/NETWORK DATA

1 
$7: 28$

$7: 30$

$7: 32$

(1)

Interactants:

Nature of address:

Equality:

Territory:

$7: 33$

$7: 37$

$7: 38$

(2)

Interactants:

Nature of Address:

Equality

Territory:

$7: 39$

$7: 41$

$7: 44 \quad I, H$

(3)

Interactants:

Nature of Address:

Equality:

Territory:

$7: 46$

$7: 48$

$7: 49$

$7: 50$

$7: 50$

$-8: 26$

I,H
Iulia arrives, changes clothes

Iulia goes to her room, turns on light, puts down bag.

Asks $H$ in Room 1 for big gloves.

$I, H$ (from Room 1)

Request Iulia wants the large gloves she has been keeping in room 1 since that is where she usually works.

Equal, I believe, Iulia and this $\mathrm{H}$ are friends, talk a lot though it is technically the H's room and this may make it unequal.

H's.

Iulia goes to central room to set-up tray. Iulia brings tray to room

I, H Iulia says 'no' to hygienist, then Iulia leaves room.

I, $H$ (may be $D A)$

Rebuke. Person is looking through Iulia's charts without asking, Iulia tells her they are from the day before.

Unequal, think Iulia is annoyed that the person did not ask.

Room 6, Iulia's territory, does seem to be a factor.

Iulia returns with more trays.

Iulia leaves room again, possibly in search of $E_{1}$; whom I have requested to meet.

Iulia returns, talks to new $H$ who is in her room, counts her patients, wonders allowed why she has so many new ones again.

Question. H asks Iulia whose charts are in the room.

Equal, I think.

Iulia's (borrowed but hers for the day)

Iulia leaves room to get $\mathrm{P} 1$.

I, P Iulia returns with $\mathrm{P} 1$.

Iulia leaves to get PI's chart.

Iulia returns.

I, P Iulia asks PI questions about his medical

history and charts as P1

answers. When done with medical history and examining chart, Iulia puts on her gloves and mask, looks for blue/red pen, lowers PI's chair, checks to see he is comfortable. 


\section{7:55 Iulia begins probing. \\ 8:01 When she finishes probing, Iulia calls the doctor, then begins cleaning to save time (i.e., rather than wait for doctor). \\ 8:02 DA brings PI's photographs. Iulia thanks her. \\ 8:04 Iulia cleans PI's teeth, wants PI to let her know if he feels uncomfortable at anytime.}

(4)

Interactants:

Nature of Address:

Equality:

Territory:

(5)

Interactants:

Nature of Address:

Equality:

Territory:

$8: 06-8: 12$

$8: 08$

(6)

Interactants:

Nature of Address:

Equality:

Territory:

$8: 12$

$8: 12$

(7)
$I, D A$

Statement. DA brings PI's pictures to Iulia, working together. Iulia thanks her, asks $D A$ if she is doing pictures today, no, just helping out.

Equal, but then Iulia has been a DA and perhaps identifies with them more than other Hs.

Iulia's.

$I, P 1$

Back and Forth question/answer, small talk. P1 asked if he should set his glasses down, Iulia as always said, "No" (because they offer the P1 protection should she drop an instrument). Iulia asked questions about P1's medical history, asked him to sign off that there were no changes from the original and tells him what she is going to do and the course of the exam. Iulia tries to make small talk but $P 1$ is not participating, Iulia asks why and he tells her she needs to speak louder. Small talk Iulia introduces centers around the Blazers. Iulia tells PI to let her know if he is uncomfortable during the exam. Iulia telis $P 1$ he is brushing well but not enough because his gums are bleeding. So a compliment followed by a reprimand.

Equal

Iulia's

I, D, P1

Doctor arrives, addresses me, "So you haven't left yet?"

D looks at Pl's mouth, at pictures, back at mouth.

\section{$I, P 1, D$}

Iulia to P1, D to P1, Iulia to D Doctor checks PI's mouth, comfort level, gives advice, particularly to pay attention to Iulia's advice on cleaning in order to arrest gum disease, Doctor thanks P1.

Seems relatively equal, but probably is not since Iulia waits while the $D$ checks $P 1$ giving him the authority.

Iulia's room, doctor has higher status in the clinic.

D writes in chart and leaves. Iulia continues cleaning Pl's teeth.

$I, P I$ 
Nature of Address:

Equality

Territory:

$8: 18$

$8: 25$

$8: 26$

$8: 31$

$8: 31-8: 34$

$8: 35 \quad I, R$

$8: 37-8: 44$

$9: 18$

$9: 20$

$-9: 38$

(8)

Interactants:

Nature of Address:

Equality:

Territory:

$9: 38$
Advice. Iulia tells P1 what she is doing, the action she is going to take for the purpose of giving comfort.

Unequal, Iulia higher status as she is the one doing the work, the one with the knowledge.

Iulia's.

Iulia begins polishing Pl's teeth, rinses his mouth.

Iulia checks her work, shows him how she wants him to floss, brush, discusses his next appointment being in six months, gives him a tooth brush, completes his charts while PI waits.

Iulia and PI go to front desk to see about making an appointment. Iulia never lets me come to these things but later in the day she tells me the reason she usually accompanies the Ps to the front is because they never get her instructions right on what appointment to schedule, possibly because they don't speak dentalese. Worth sitting up front for awhile one day, that's for sure.

Iulia comes back. The last patient went quickly because he was missing quite a few teeth, the molars... Iulia said he didn't have a lot of stuff and besides, she is becoming better and better. She said the last patient had very, very mild gum decay. Iulia charts.

Iulia talking to me and cleaning room. Asked her what she would do if I wasn't here, she said do her charts, set up for the next patient, see if the dental assistants needed help with taking blood pressure. She said she would fill the time, they are supposed to. Iulia setting up the room talking to me. Iulia gone to see what has become of the P2. Iulia talking to other hygienists. 9:34 Iulia's light goes on.

$I, H$ in room, third $H$ joins conversation.

Gossip. Discussing H's vacation plans.

Unequal.

First $H$ 's room, $H$ sitting in front of her charts, Iulia leaning against a wall.

Iulia comes back, says they were talking about going to hygiene school. 
$9: 39$

$9: 42$

$9: 53$

$9: 54$

$9: 59$

10:02 I, P2

$10: 05$

$10: 06$

$10: 08$

$$
I, \mathrm{P} 2
$$

$10: 11$

$10: 13 \quad I$

(9)

Interactants:

Nature of Address:

Equality:

Territory:

$10: 15$

$10: 17$

$10: 19$

(10)

Interactants:

Nature of Address: $I$, mom

Iulia leaves again to see what is up with P2, she is supposed to do a new patient in 30 minutes.

Iulia back, tells me the $\mathrm{P} 2$ is 3 years old, now the $\mathrm{P} 2$ is getting pictures (if they can). Iulia has wanted me to see her with a child because she says she is good with them. She gets out a tooth brush and has toys ready. Iulia goes to see what is keeping P2, was talking to me before that. I, P2, mom and another child return.

Iulia advises mom she is going to have the doctor give the P2 an exam.

Iulia shows P2 what the polish instrument feels like on his finger and begins polishing. Polishes P2's teeth. Iulia rinses P2's teeth. Iulia's next patient has arrived. She continues to rinse, they are having fun. Iulia checks P2's teeth again and is now waiting for the Doctor.

Iulia has P2 choose two toys and tell her what they are. Iulia teasing him. Iulia goes to see about getting Doctor who doesn't know he will be examining a child (i.e., to apprise him of the lack of patience).

I Iulia comes back and says the Doctor will be here soon.

\section{I,P2 (3 years old), mom, child,DA}

Comforting, Information exchange. Iulia to P2, Iulia to mom, mom to Iulia, $D A$ to $P 2, D A$ to mom. Iulia asks mom questions about her child's teeth mostly. Iulia tries to make P2 comfortable and does a very good job, she talks mostly to the P2. There is talk of making another appointment too. Unequal, Iulia is higher status as she is the expert.

Iulia's.

\section{Doctor $W_{1}^{1}$ i arrives.} $I, P 2, D$, mom

All looking in P2's mouth. Mom was concerned about an uneven surface. Iulia removed whatever it was. Doctor writing in chart.

\section{I,P2,mom,child,doctor}

Information exchange, joking, recommending. $D$ to $P 2, D$ to mom, Iulia to $D$ $D$ enquires about moms concerns, mom goes on about a chip on P2's tooth 
and sons liking to chew. $D$ jokes with $P 2$. D recommends a possible filling for next time, should keep an eye on it. Iulia and D talk about P2, D wants to know if $P 2$ is taking fluoride, $D$ says he is going to write a prescription for fluoride, mom says her husband has very bad teeth and she is afraid her children have inherited them.

Equality: Unequal. Doctor highest status.

Territory: Iulia's

$10: 20$

Doctor leaves.

$10: 21$

$10: 22$

$10: 23$

$I$, mom

Doctor comes back, writes prescription for

fluoride for P2. He tells mom how to give it and when to give pills.

$10: 23 \quad I$, mom

Iulia and doctor leave.

Iulia comes back, writes in chart, mom is waiting for the prescription, Iulia tells her the child needs to be seen again in six months.

$10: 24$ Iulia goes up front with the P2.

$10: 30$ $I$

$10: 31$ I, P3

Iulia goes to get next $P$.

Both return, can hear Iulia asking the $\mathrm{P} 3$ if it is okay if I observe, the answer is yes (I have yet to be refused).

10:31 I,P3 Iulia asks P3 questions and writes in his chart.

$-10: 36$

$10: 36 \quad$ I, P3

(11)

Interactants:

Iulia tells P3 what she is going to do-Probe, calls doctor to do exam and begins cleaning his teeth

Nature of Address: $\quad$ Questioning, Iulia to P3. Iulia asks about how P3's medical history is, if it has changed, what his orthodontic history is. P3 had cancer removed when he was 7 years old, but has no complications. Iulia asks if there are any specific problems he is having with his teeth now, $P 3$ has an ache that began last night. P3 has allergies, they discuss. Once cleaning begins there is little talking. Iulia is concentrating on her work.

Equality:

Territory:

Unequal. Iulia higher status because of her knowledge.

Iulia's.

$\begin{array}{lll}10: 37 & \text { I } & \text { Writes in chart, puts on gloves, mask, } \\ \text { goggles, lowers chair } & \\ \text { Iulia turns on Iights, begins probing. In } & \\ & \text { response to P3's complaint, Iulia telis him } \\ & \text { his gums are irritated because he is not } \\ \text { flossing (she says that to everybody). } & \text { Iulia calls doctor } \\ 10: 40 & \text { Iulia begins scraping P3's teeth. } \\ 10: 42 & \text { Iulia rinsing. Doctor arrives. }\end{array}$


(12)

Interactants:

Nature of Address:

Equality:

Territory:

$10: 56$

$11: 04 \quad I$

(13)

Interactants:

Nature of Address:
Equality:

Territory:

$11: 07$

$11: 09$

$11: 13$

$11: 17$

$11: 19$

$11: 20$

$11: 23$

$11: 24$
$D, P 3, I$

Question, retell, request, directing, advising/recommending. $D$ to $P 3$, Iulia to $D, D$ to Iulia, $P 3$ to $D$ Doctor asks $P 3$ what is giving him trouble? Iulia retells what $P 3$ told her. $D$ wants to know if $P 3$ is using floss. Asks Iulia to get him a cold lotion. D talks to P3 about using a toothpick, says it is better than nothing. $D$ directs $P 3$ to help him out during the exam. D tells Iulia what to write and Iulia writes in P3's chart. D tells Iulia what he thinks about what he thinks the ache is, asks Iulia if she found any pockets. D recommends $P 3$ come back in six months.

Unequal, D highest status.

Iulia's.

Doctor gone. A Iittle talking between Iulia \& P3 while she is cleaning.

Iulia rinsing, she advises $P 3$ she is going to polish next.

\section{$I, P 3$}

Informing, responding, instructing, advising, questioning. Iulia to $P 3$ and $P 3$ to Iulia. Iulia tells the P3 what she is going to do. P3 tells her how he feels about it, "hates this part" (the polishing). Iulia gives P3 instructions on how to make her job easier for both of them. Iulia tells him to floss, wants to know if P3 wants a six month or year appointment next time. Iulia asks P3 to wait so she can give him her papers and he can make the appointment up front, she sends him off by himself.

Unequal. Iulia higher status.

Iulia's.

Iulia just about done with polishing, her light just went off again, the next patient is here.

P3 leaves, Iulia puts pictures away, cleans from the last patient.

Iulia takes her tray and cold stuff to the back room.

Iulia is back, she explains to me there was a cancellation and they gave Iulia another patient, a difficult one. She has a half hour and told me the DA is good, but slow. she is setting up her room. Iulia finishes setting up her room, puts away the chart from the last patient with pictures in the envelope.

Iulia leaves room.

Iulia returns with the new $\mathrm{P} 4$, a young boy, nervous.

$I$, parent

Iulia left to talk to the boys father. 
$11: 26$

$11: 28$

$11: 29$

$11: 31$

$11: 39$

11:40

(14)

Interactants:

Nature of Address:

Equality:

Territory:

$11: 43$

$11: 47$

(15)

Interactants:

Nature of Address:

Equality:

Territory:

$11: 50$

$11: 51$

(16)

Interactants:

Nature of Address:
Iulia returns with a frown on her face. Iulia begins examining the P4's teeth. Iulia calls doctor. Iulia begins cleaning. Iulia calls doctor again, the last call did not take.

Iulia begins polishing.

$I, P 4, D A$

Questioning, making small talk, joking, informing. Iulia tried to make small talk then went to talk to the boy's father. When Iulia came back, she asked him about how he cares for his teeth. DA came in with pictures and laughed about her breath smelling like alcohol because of something she sprayed on her mouth. Iulia tells P4 the pictures tell her how he is taking or not taking care of his mouth, she says the pictures don't lie. She then informs him what she is going to do in the exam.

Unequal. Iulia higher status, boy will hardly talk, has not been taking care of his teeth and knows Iulia knows it. Iulia is disgusted with the boys personal hygiene and that of the father (this was revealed later in $Q \& A$ between she and I. Iulia said the child and father smelled bad, she doesn't understand how the parents could let their child be seen by the doctor-any doctor when they are so dirty).

Iulia's and the waiting room.

The doctor arrives

Doctor is writing in chart.

$I, P 4, D$

Joking, questioning/answering, informing, clarifying. Iulia to $D$, Iulia to $P 4, D$ to P4, D to Iulia. Iulia and the doctor joke but I can't hear what it is about. Doctor looks at P4's mouth, tells Iulia what he finds and asks her if P4 has an orthodontist through Kaiser. He recommends one early because the P4 has so many problems with alignment. Doctor instructs Iulia to chart, "give a little red ' $x$ ' to $T \& J$ " (dentalese). Doctor informs Iulia the problem is definitely not with crowding since P4 has plenty of space. Doctor and Iulia discuss which orthodontist the child should see, Doctor instructs Iulia again and she has to clarify his meaning.

Unequal but less so than most doctor visits.

Iulia's, not a factor.

Doctor leaves.

Iulia is done polishing, she works on P4's charts, P4 is waiting to leave.

\section{I,P4}

Instructing, reprimanding. Iulia to P4. Iulia tells the P4 what he needs to do to care for his teeth and makes him promise to do so. Iulia tells P4 he must wait while she finishes writing in his chart, when she finishes she tells him they can go. 
Equality:

Territory:

$11: 53$

$11: 55$

$11: 59$

$12: 02-12: 04$

(17)

Interactants:

Nature of Address:
Equality:

Territory:

$12: 08$

$12: 22$

(18)

Interactants:

Nature of Address:
Equality:

Territory:

$12: 25$

$12: 26$
Unequal, Iulia asks all the questions and gives all the advice.

Unequal-due to age more though.

P4 and Iulia go up front, Iulia to talk to parent and schedule the next appointment for the P4.

Iulia is back, clears room, takes the tray to the back.

Iulia begins setting up for next $P$. Iulia keeps an open pack of instruments in case one of her packages is short an instrument? No, I found this out because a pack was incompleteshe said she had a previous one that was incomplete earlier and that is why it happened. She said this happens when they change who works sterilizing instruments in back and she says it is very frustrating. Iulia goes to get next P5.

\section{I,PS}

Questioning/answering, information exchange. Iulia to P5, P5 to Iulia. Iulia asks P5 if it is okay if I watch. P5 tells Iulia about her injured knee and tells her she hates getting her teeth cleaned more than having work done on them because she hates the feel of the polish. Iulia asked about P5's medical history and had to ask P5 to spell the name of the inflammatory drug she was taking. Iulia asked P5 about her dental habits. P5's knee is hurting her and Iulia asks her about it again, P5 says there is nothing to do. P5 states that her teeth have changed since she had children, much harder to keep them in shape and efforts don't seem to help.

Unequal

Iulia's.

Iulia begins exam and cleaning. Iulia begins polishing.

$I, P 5$

Advising, reminding. Iulia to P5 and PS to Iulia. Iulia tells P5 it is time for her favorite part, the polishing. She says the ends justify the means, that's the way she looks at it. Iulia gives P5 advice as always. Though the woman's teeth look good, Iulia tells her what to do. Iulia reminds P5 when her next appointments are and wishes her good luck with her leg, and have a nice weekend.

Unequal

Iulia's.

Iulia finishes polishing. Iulia checks her work. 
$12: 28$

$12: 50$

$1: 40$

$1: 44$

$1: 45$

(19)

Interactants:

Nature of Address:
P5 leave (no doctor visit). Iulia works on charts, cleans and sets up room till...?

Lunch time.

Lunch time:

Doctors were in lunch room for awhile, a bunch of hygienists were here today, I even met $E$ | . The topic of discussion for awhile was the union (this will be ideal for an event analysis). Iulia hardly partook in the conversations at all. At one point they were talking about women being past due a month, having to induce labor and producing really big babies. they laughed and thought they shouldn't be talking about it in front of Iulia. Iulia said she didn't know what they were talking about. Group was a heck of a lot of fun today, lots of laughter, talk seemed very clean to me (by clean I mean devoid of gossip).

Later I asked Iulia about the union discussion in the lunch room. She said all these women were against the union, only the woman whose room Iulia is working in is for it, nobody likes her, they make jokes about her all the time. Also the woman who locks everything is for it but she is part of the 'family'. Iulia thinks it is sad the way $S$ I is ( $\mathrm{S}$ ) is the one nobody likes) because she is missing out. Iulia says $S$ | tattles on everyone, speaks in a loud voice all the time even when asking patients personal questions. Also, Iulia said SH is missing work a lot lately (reason why Iulia is working today in fact) she had some injury to her foot, I've noticed she has put on weight.

P6 \& Iulia here, Iulia asks if okay that I'm here.

P6 did not have pictures taken. Iulia examines his mouth and comments on what she sees as well as asks his questions. Lots of talk back and forth.

Iulia starts cleaning. Iulia found one side cleaner than the other. P6 thought it might be because he is right handed. Iulia thought this was interesting.

\section{$I, P 6, R$}

Questioning, seeking/giving information, teasing, informing, instructing. Iulia to P6, P6 to Iulia, P6 to R, R to P6. Iulia asked the P6 if it would be okay 
Equality:

Territory:

(20)

Interactants:

Nature of Address:

Equality:

Territory:

$2: 02$

$2: 06$

$2: 07$

$2: 12$

$2: 13$

$2: 15$

$2: 34$

$2: 35$

$2: 35-2: 40$

$2: 40$ to have me observe. The P6 said yes and wanted to know what my research was about so I told him. Iulia asked P6 what the hygienist did for him last time, she asked about his dental habits, told him what he needs to do, he mimicked her and they laughed. Iulia told him what she was going to do, instructed him to help her (open please, bite,...).

Equal Exam differs from others in that P6 teases Iulia, puts them on more equal footing though Iulia is still the expert, P6 turns her advice into nagging since he has heard it all before, hasn't paid attention in the past and probably will lag again in his efforts.

Iulia's.

I,P6

Making small talk, requesting information, explaining (imparting

information), advising. Iulia asks P6 about feelings re: Blazers. P6 wants to know how sums look, Iulia says something, P6 doesn't understand, asks her to explain, she elaborates. Explains salivary ducts producing and depositing in spots. Iulia says there is bleeding, means he is not taking good enough care of his teeth. Iulia tells him what and how to take care of his teeth, P6 claims he doesn't floss because his gums bleed so Iulia goes into the standard explanation that they bleed because he doesn't floss regularly. Unequal, P6 looks to Iulia as the expert.

Iulia's

Iulia begins the polishing, advises P6 to clean molars better. This P6 doesn't like the taste of the polish-interesting day-this is the third $\mathrm{P} 6$ who has commented on it. Iulia rinses P6's mouth.

Iulia gives P6 tooth brush, tells him when next appointment should be (six months), he gets pictures and a doctor visit but neither this time.

P6 leaves, compliments Iulia, says he hopes he gets her next time. El| (supervisor) overhears.

P6 back to ask Iulia another question, he is a bit strange according to me and I think Iulia thinks so too. will check (yes). Iulia and I talking, I go to restroom, when I come back Iulia is on the phone in back, room is clean, Iulia sets up, we chat, she asks me to help her husband again, please. Iulia goes to get her patient. New P7 has allergies-amazing. Iulia leaves (for where? To do what?) Iulia asking P7's history, dental care, about changes. P7 and I chatted while Iulia was gone, P7 mentioned how smart I am, think she 
$2: 43$

(21)

Interactants:

Nature of Address:

Equality:

Territory:

$2: 48$

$2: 57$

$3: 00$

$3: 06$

$3: 07$

$3: 18$

$3: 20$

(22)

Interactants:

Nature of Address: felt less because of my education. She is very soft spoken.

Iulia begins exam and cleaning, P7 is a diabetic.

I,P7

Questioning, informing, asking for help, promising. Iulia briefly questions P7. $P 7$ wants to know if she should take her glasses off. Didn't hear the entire conversation but did hear Iulia say, "That's why you are here, to have your teeth professionally cleaned." Iulia tells P7 she is going to move the chair to clean the lower teeth. P7 compliments Iulia on her English, Iulia says some things that lower her status (i.e., she doesn't know how to spell the words and says battle is easy to get confused with bottle, it is like fight and faithwhich is which). Neither the P7 nor I understand but don't ask Iulia to clarify to save her face (this isn't good in that we are protecting her and she is not being forced to improve). P7 asks Iulia what paste she should use, says she switches all the time because she doesn't know. Iulia tells her the tartar control story. P7 tells Iulia her gums bleed when she flosses (surprise, surprise-my comment to myself), Iulia tells her that is because she does not floss regularly, the gums are irritated from the dirt collecting there. P7 promises to pick up some floss today.

Iulia is definitely higher status but slips a bit there.

Iulia's.

E I I peeked. Made me feel good, belonging, accepted.

Iulia begins polishing.

Iulia rinses. This $\mathrm{P7}$ has also been a prophy only meaning no pictures and no exam. Iulia writes up rest of chart, they chat and P7 leaves.

Next patient has been here awhile, Iulia says she likes to go up front with the patient to see they get what they need. Am listening to Iulia tell patients the same thing but differently. Asked if that was because she got tired, she said no, if she feels they understand, she doesn't waste words. Asked Iulia if she got bored. She said no, the patients were so interesting and she told me one of her patients from yesterday told her she had cancer and was crying. Iulia goes to get P8. Iulia returns with $\mathrm{P} 8$.

$I, P 8$

Questioning, answering. Iulia to P8, P8 to Iulia. Iulia asks the P8: Do you have a partial? Are you allergic to penicillin? Do you have higher blood pressure than normal today/lately? Asks him to sign off that there are no 
Equality:

Territory:

$3: 25$

$3: 27$

$3: 29$

$3: 30$

$3: 33$

$3: 34$

(23)

Interactants:

Nature of Address:

Equality:

Territory:

$3: 38$

(24)

Interactants:

Nature of Address:

Equality:

Territory:

$3: 51$

$3: 53$

$3: 54$ changes to his medical history since last time-this is to protect herself. Asks P8 how many times a week he brushes/flosses, P8 answers 2 times a day and 3 times a week, respectively. Iulia tells P8 what she is going to do. P8 asks where Iulia is from.

Unequal, Iulia higher status.

Iulia's.

Iulia is going to probe in order to compare with other times.

Iulia goes to get a mask-guess she is out. Iulia returns, putting stuff away. Iulia begins probe.

Iulia calls doctor for exam, begins cleaning, tells $\mathrm{P} 8$ to tell her if she does something he doesn't like.

Doctor here for exam, looks at pictures, checks chart.

$I, P 8, D$

Informing, questioning, thanking. D to P8, Iulia to D, Iulia to P8. Iulia tells the P8 she will let the doctor have his turn. Doctor asks P8 if he is ready for a break from Iulia. Doctor looks at P8's pictures to see if the ones taken today differ at all from the ones before, doesn't see anything and looks in the P8's mouth. Doctor says, "I just can't find anything to do." Iulia says, "that's good news, now I'm going to finish. Thank you doctor." No response. P8 says, "Thank you doctor." Doctor says, "You betcha." Unequal, doctor definitely higher status.

Iulia's.

Doctor done and gone. Iulia continues with the cleaning.

I,P8

Making small talk. Iulia asks P8 how he feels about the blazers.

Equal

Iulia's.

Iulia begins polishing.

Iulia rinses.

Iulia checks spots-she missed some and wants

to get them. Iulia gives P8 advice. Tells

him to use salt water for the pain. P8 wants to know what it does, Iulia says she is not sure how to tell him (how to explain or whether she even knows is not clear-I do not interrupt to clarify and P8 does not press her). 
Iulia gives P8 tooth brush, turns of light, tells P8 to floss more often, tells him he has recession.

$3: 57$

Iulia tells P8 what to do to stop the recession and to come back in six months. Iulia writes in charts. $P 8$ wants to talk. He has son with a croatian wife.

$3: 59$

P8 leaves after Iulia tells him to take paper up front to make appointment. Usually Iulia goes up front with Ps but she says she is felling lazy. I am done for the day, Iulia does not have any more patients. Ask her how she will spend the day, she says she will finish charts and clean her room. 
APPENDIX D

DISCOURSE TRANSCRIPTS 


\title{
DATA CODING
}

\author{
* stress on preceding syllable \\ -- speaker quit speaking without clear verbal \\ completion of thought \\ - speaker quit speaking with clear verbal completion \\ of thought \\ i replaces letters in names of people and places to \\ protect the identity of the speakers \\ ( ( ) contains number of words in Iulia's turn \\ / brief break in flow of speech (not countable) \\ (.) pause lasting less than one second \\ (.1) pause lasting between 1 and 2 seconds \\ (.2) pause lasting between 2 and 3 seconds and coded as \\ a long initial pause. A number is added for each \\ additional pause of one second \\ I Iulia \\ P patient \\ $\mathrm{H}$ hygienist (referred to as $\mathrm{H1}, \mathrm{H} 2$, etc. when more \\ than one hygienist is present) \\ D doctor/dentist \\ R researcher \\ DA dental assistant
}


Researcher and Iulia at Iulia's home discussing Iulia's English/Hygiene school history. No one else was home at time of interview, no interruptions occurred, interview took about 45 minutes. Interview took place following administration of the SPEAK test, lulia fairly relaxed with the casual conversation following the test.

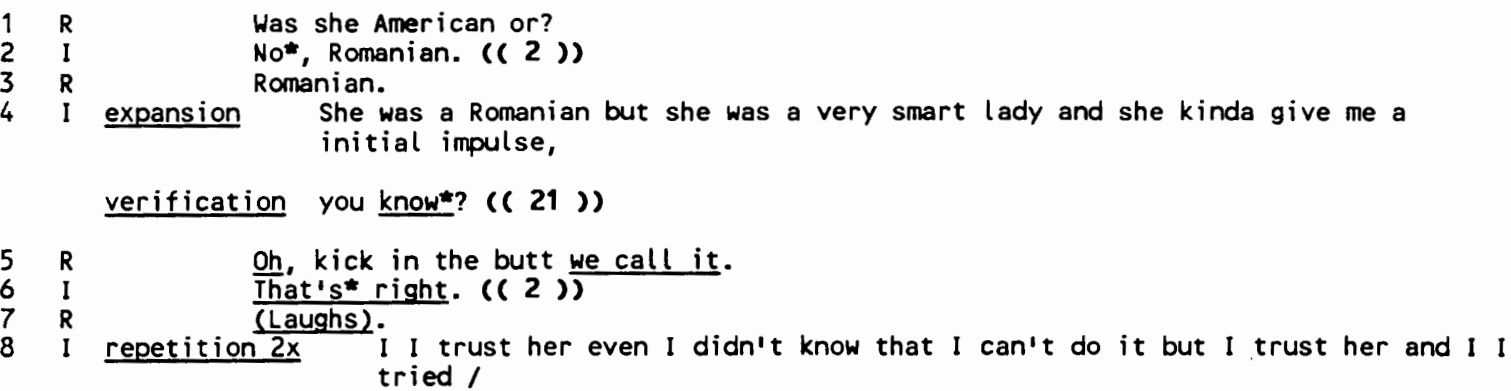
so she was the one who / (breathes out) uh give me a list what can I do / become a nurse, becone a technician dental technician, become a hygienist

self-expansion I didn't know what hygiene at that time anything / or dental assistant

and I thought of this one is the easiest / one and shortest and (.) I un try it / so she sent me to the school. ( $(83))$

$\begin{array}{ll}9 & R \\ 10 & I \\ 11 & R \\ 12 & I\end{array}$
$13 R$

$12 \mathrm{a}$

$14 \mathrm{R}$

$15 \mathrm{I}$

$16 R$

17 I

$18 R$

19 I

$20 \mathrm{R}$

19a I

20a R

$19 \mathrm{~b} I$

20b R

19c I

$21 \mathrm{R}$

$22 I$

21a $R$

23 I

$24 R$

25 I

$26 R$

25a !

To P-- ?

expansion To Pl| Sll. (( 3 ))

And how long (unintelligible).

And I have a cousin who help me I didn't drive I didn't have car I didn't know the city I didn't know anything around so she took my hand and we went there / they told us

long initial pause $\quad$ (.3) and was like a ad adventure / exactly like adventure

(.) talk with the instructor they give me the test

(.) the test was like (breathes out) (.2) I remember was some dis(word unintelligible) stuff and I

repetition I think I did good with that fast and because I have this / the work

self-expansion (.) I worked with her with my hand and / wasn't so hard but the written part (.) written written

repetition understanding I think was uh kind of-- $((106))$

(Laughs) $\underline{\text { Oh. }}$.

Not strong yeah. (( 3$)$ )

How long had you been at MII HII'?

long initial pause (breaths out) $(.2)$. ( ( 0$)$ )

Three months six months?

clarification for dental assistant? ( 3 ))

No, no, for French and--

false-start No I didn't I 1 -- ( 5 ))

You you-.

expansion I started-- ( ( 2 ))

Enrolled but you didn't go--

I- - ( 1 ( ))

oh, oh, okay okay.

self-expansion I just enroll and then I just-- $\left(\left(\begin{array}{l}7 \\ )\end{array}\right)\right.$

Cause shé was saying--

Yes. ( ( 1 ) )

Do something practical.

Yes. ( ( 1$)$

Okay.

You In fact I was asking her to / sign for me for financially and she say, "No* I'm not going to do that go ahead and do something else." ( 29 ))

Oh.

You don't need French you don't need Spanish at this time 

Hmm.

So the director (breathes out) was accepting me at that time. ( 9 )) What was her name?

repetition Uhm LI| R II, LI| RII, Dr. LII R I

long initial pause $\quad$ (.2) I don't know why she accepted me cause I didn't deserve to enter school but I / I don't know what happened something happened anyway so / she accepted me with the condition to (.) learn English in Portland with the school

long initial pause $\quad(.2)$ (breaths out) so we $f i x$ some exam for (.) English as a second language and that exam went

self-expansion after / I don't know a few days I had something few days week ten days I don't remember how long /

repetition how long I have but I have to I remember I learn I study a lot at home from my Romanian school I

self-expansion study grammar / all kinds of grammar / and (breaths out)

long initial pause (.4) I think I pass that test and my score was like (.3) the last one for the years term something

self-expansion like that I think was something with the ENNL dealing with the ENNL/ level so they send me to do some ENL and unfortunately I couldn't find classes

self-expansion / the classes were conflicting with my classes and I was going back to the director and crying I

repetition was crying to her (unintelligible). (( 181$)$ )

(4 minutes 50 on dictaphone)

I don't know how I told her but I remember that she told her it's okay / don't do that (.2) uhm

repetition (.2) Let's start it / like that and if you can (.) if you can (.) uhm (.2) keep (.) with / you drop so don't lose your money but I didn't know exactly what that means and-- ( 51 ))

$30 \mathrm{R}$

Yeah.

26 I repetition And that and uh I I start it /

repair and she give me the courage to start / I was scared by the books I was scared about ever everything / because I didn't know anything about American school * I didn't know anything about / the system

repetition $I *$ I have

indication-diff / even hard time you know / finding my locker and my / se- how how you call that? the

repetition combination- ( $(64))$

$31 R$ repair Combination.

$26 \mathrm{~b} I$ The combinations so somebody was helping me with that everything

/ they were so nice around but I have / tears all the time in my eyes I remember that / (breathes out) everyday (.2)

and I started school and-- ( 34 )

$32 \mathrm{R} \quad(.2)$ How long did that take you?

33 I long initial pause (.2) That was one year and I know I have some

long initial pause $\quad(.2)$ I uhm (.2) I was asking a friend no I was asking neighbor to help me with some English like I

self-expansion was (unintel!igible) and asked/(breathes out) and to help me to translate I just to understand better to save some time because 1 had a lot to read* and I writing the words* I didn't know so

/ he was nice but he was leaving soon he left soon and he give me his sister

(breathes out) and his sister say, "Why* are* you going to school if you don't know English?" (laughs) so-- ((96)) 
$34 \mathrm{R}$

This* was it* I I had to do it by myself so I was coming home and / and uhm $\frac{1}{(.3)}$ take the repetition dictionary and find each word and I was I I wrote the word in the book you know- - ( 39 ))

$36 R$ The Book?

37 I expansion English book

repetition (.) so I did that / a lot a lot / and

repetition $2 x$ / my was lucky very lucky because there / there are / system of grading was in my advantage / cause

indication-diff of the / how you call that test? scanttron test or -. (( 38 ))

verification

$38 R$ Multiple choice.

39 I repetition Yeah multiple choice. (( 3 ))

$40 \mathrm{R}$ Uh huh.

41 I You know it's easier / then / to write / everything until / so it was easier

long initial pause $\quad(.2)$ and uh I had a few few good grades but I had a few bad grades first and I remember a teacher /

repetition one of instructor was telling me go ahead and talk with your advisor because she was sure* that I cannot / survive

repair (.) but / part partly I didn't understand partly I didn't want to go. (( 68 ))

$42 R$ To the advisor (laughs).

43 I repetition (laughs) Io the advisor-- ( 3 ))

$44 \mathrm{R}$ Uh huh.

45 I You know (.2) I realized in fact later that what she wanted me to do

long initial pause $\quad(.2)$ the second time I got very good grades for that class and she long initial pause I remember wrote something

repetition (unintelligible) or something like that or something she couldn't imagine that I can have such a

/ and the other teacher / they were very nice but they

repetition / I was a curiosity I'm sure that I was a curiosity because they they didn't not

I the only director was trusting some way that 1 can do something but nobody else (.2) is trusting that I can do it so they accept me because the director said that (laughs) I think-- ( 105$)$ )

(4 minutes 50 on dictaphone) 
Iulia working in room 6, has been cleaning patient's teeth. Buzzed doctor to come examine patient. Patient is female, mid-thirties. Doctor arrives to examine patient. Background noise in room number 5 makes dialogue difficult to hear at times. Radio playing near by does not help either. Researcher is present but trying not to participate in exchange.

Dr. All will be here. (( 5 ))

Hello.

(.1) Hi. ( 1 ) )

Good evening.

Didn't see anything. ( 3 ))

(.) Didn't see anything, huh, that's really nice to hear.

(laughs) It sure* it is. (laughs)

You probably like it better than we* do.

P Ah yes (laughs). I certainly do because I do not like needles or drills or any (unintelligible)--

10 D Can't say as I blame you there.

11 I (.3) Unm (unintelligible)--

12 D Okay.

(background talking can't hear)

13 P I'm so glad I remember (.) No, I didn't.

14 I long initial pause (.10) Is this clear like that with (unintelligible). (( 6$)$ )

15 P Snintelligible).

16 I But I think the stains (unintelligible). (( 5 ))

$17 \mathrm{P}$ No oh.

18 I So. ( ( 1 ) )

19 P Okay (unintelligible).

20 I Did you have that all the time? (unintelligible). ( 7 ))

21 P Well lately its been darker--

22 I Kay its inside its not (word unintelligible). (( 6 ))

$23 \mathrm{P}(.6)$ As long as its not dying on me or something like that

24 I Well that could be too* (.) sometime it does. ( 8 ))

25 D (.1) See, which one we talking about here?

26 I No, no. (.1) (unintelligible). ( ( 2 ))

27 D Take a shot there in that tooth when you were younger*?

$28 \mathrm{P}$ (.1) Uh, I don't know.

29 D Little, little drop there or anything like that*?

$30 \mathrm{P}$ Uhm, I' don't know, I can kind of (.2) my brother you know when your little-.

31 D Oh, okay.

30a $\quad \mathrm{P} \quad$ But I don't remember either their getting loose or anything like that.

32 D Well the reason I ask is cause if you you look at this is all what we're looking at so this is the tooth we're talking about if you notice in this one you can see the stark line going down here where the nerve tissue is, where if you look at this one you're real hard pressed to see it we might want to shoot for--

33 I No, we have. ( 3 ))

34 D Oh we got one--

35 I Yeah. ( ( 1 ) )

$34 a$ Okay, let's see what we've got there.

36 P I just had braces (unintelligible).

37 I (unintelligible).

$38 \mathrm{P}$ They had to move my teeth quite a bit when I had braces cause I was real buck tooth.

39 Dell, you know you look at this one its the same kind of thing you just you don't see any nerve tissue in there that's (.) uhm (.1) at this point in time I don't know that it would do you all that much good to do a root canal or anything like that.

$40 \mathrm{P}$ Oh I don't (unintelligible) (laughs).

41 D Okay, well--

42 (laughs) I I uh it doesn't give me any problems or anything I just kind of noticed that-43 D sunintelligible) discolored like that.

$44 \mathrm{P}$ The only reason I even noticed here you know know that there's anything to that is my sister-in-law had problems with her front teeth, she's had them capped and--

450 Uh huh.

44a Uh, one of them was real real dark and she said that $/$ it and that was--

46 D Kay.

$44 b$ P Or that--

47 D Well well something that can be done there if you were interested uh would be there's a a

$48 \mathrm{P}$ Oh.

$49 \mathrm{D}$ Kind of / the best thing that that they look like to me is false fingernails.

$50 \mathrm{P}$ Oh. 
51 D And uhm what you do is you actually go in you you shave off some of your / take an impression the mold would be sent to the lab and they make that and $i$ ts bonded on there but the thing is its an aesthetic procedure its its not something that's covered as far as insurance policies but it can be done.

52 If will this tooth get much darker if I don't get it done?

$53 \mathrm{D} U \mathrm{~h} *$, probably not.

$54 \mathrm{P}$ Well, then I won't worry about it, I'm not that vain.

55 D It's uh, okay it's pretty (unintelligible).

$56 \mathrm{P} I$ just $k$ ind of noticed, yeah $\mathrm{hm}$ yeah (laughs).

$57 D$ Yeah. (.5) Isn't that something that / you know if you do get to the point you say "Gee, you know, this is a little darker and I don't like that" or something like that that's the sort of thing you put in (unintelligible).

58 P Oh, okay.

59 D Its uh all in all a real easy sort of thing you know we got one of the guys here that really likes to do them and has been doing quite a few of them I suppose it's probably (unintelligible) and uh I I just couldn't believe the difference--

( 50 on the dictaphone)

$60 \mathrm{P} \mathrm{Hmm}$.

59a $D$ (unintelligible)--

$61 \mathrm{P} \mathrm{Hmm}$.

$59 \mathrm{~b} D \quad$ And uh--

62 P The only other thing I can think of that / that / that would do (.1) is this one right--

63 D Oxay.

$62 a$ P And I've got that (word unintelligible) and stuff and that would make it smooth like the others. That's all. But it its not anything that (.1) I'm not vain as far as that so uh I just serious.

64 D (unintelligible) serious just something that at any time you want and uh-.

$65 P$ And if it gets black like my sister-in-law's--

66 D Yep. Okay.

65a P (laughs) Then 1 'll do it. (laughs)

67 D Okay (.1) Okay (.2) and if I read the chart right your a daily flosser is that correct?

$68 \mathrm{P}$ More or less (laughs).

69 D Hopefully more than less.

70 P Um hm.

71 D Okay. (.2) Uh, you hate needles and drills and stuff like that that's probably the best thing you can do as far as staying out of the dentist chair.

$72 P$ (unintelligible).

73 D The only addition I would say I want to do is (unintelligible) is (unintelligible).

74 P I thought that I thought that one guy had said that after (unintelligible).

75 D well no, the crowns--

$76 \mathrm{P}$ Oh.

75a D Because that's an aesthetic thing / but but the rest is worked topically and uh (unintelligible) thing and kids.

77 P Oh

$78 \mathrm{D}$ (.5) This one right here is a very bad tooth. We're starting to show some new work right now but you don't need to replace it (unintelligible) I would say probably in the next four or five years. Uh (.10) okay (unintelligible) you look great, I don't see any problems at all.

79 P Great. (.) Well, all of those are about thirty, some years old and that's (unintelligible).

80 D They've served you well then.

81 P They have. (.6) I haven't had a filling since I was / about eighteen. I'm lucky.

82 I Lucky one of them too. ( 5 ))

$83 R$ (laughs) Looks that way. I don't have any.

$84 \mathrm{P}$ Huh, how old are you?

85 R Uh, twenty-six.

$86 \mathrm{P}$ My sister was twenty-one before she had her first one. She's got more now and when I had my kids when I got pregnant that's when I worried / about it / but I didn't get any new cavities til I was thirty so I lucked out but my little sister's didn't, so.

$87 R$ (.2) We didn't take care of our teeth very well, it was just it was just the good water we had when we were growing up--

$88 \mathrm{P}$ Yeah.

87a R So.

89 P My grandmother had every tooth in her head when she died but they were all real dark uh stained from fluoride in the water minerals and stuff that were in the water. (unintelligible).

90 D Okay, how's that.

91 I Thank you doctor. (( 3 ))

92 D Your welcome. 
93 P Thank you.

94 I This is yours. ( 3 ))

$95 \mathrm{P}$ Oh great. (.3) Its so narrow (.2) its shaped funny (laughs) tiny.

96 I Yeah, I think so because (word unintelligible) normally and there-- (( 9 ))

$97 \mathrm{P}$ Oh good (laughs) I thought maybe they were new / new style. (.1)

98 I The-- ( 1 ( ))

$99 \mathrm{P}$ (unintelligible) this is really narrow.

100 I No, they're not let me show it to you. Okay? (( 10$)$ )

$101 \mathrm{P}$ Oh I see (laughs). Still narrow.

102 I Well, but its good / you know its good that now its narrow its not the best part. You don't have to have (unintelligible)? (( 22 ))

$103 \mathrm{P}$ Oh. Okay.

104 I So, you are doctor say you can uh in few months if you in November so pretty sure-- (( 18$)$ )

$105 \mathrm{P}$ Sure what?

106 I Come in November again? ( 4 ))

$107 \mathrm{P}$ Sure (laughs).

108 I false start Uhm and I ask if they will change my mind (.2) if

\section{false start (.1) soon but}

$$
\text { long initial pause (.3) if you don't come-- (( } 17) \text { ) }
$$

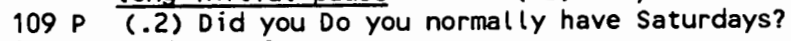

110 I Yeah. ( 1 ))

$111 \mathrm{P}$ That's terrific. I mean I wish I could put all my doctor's appointments on Saturdays / I know that's not very nice for the doctors but / sure great for / spending them at work.

112 I long initial pause $\quad(.2)$ Do you- - ( $(2))$

113 p (.1) Thank you very much.

114 I Uh Let's go up to the front desk. I'm not sure that they will help us uhm we'll (unintelligible). (( 18 ))

(61 on the dictaphone) 
Dialogue takes place in Breakroom during lunch hour. Lunch hour is from 12:50 to 1:50 p.m. Iulia sitting on couch as usual, tired, trying to relax. Eats her lunch out of a bag. Hygienist sitting at table near the window also eating a lunch she brought from home. Another hygienist comes in, eating and standing, walking around.

$1 \quad R$ So Iulia will you have Monday off? You work six days this week?

2 I avoidance

3 R Five. Oh.

(.22) tape off

4 I Yeah nobody hire me (laughs) because / I didn't know English well they didn't trust me (.2) I have (unintelligible) but-- ( 17$)$ )

5 H1 But Kaiser did.

6 I repair Uh no uh-- (( 3$))$

7 H1 (Laughs).

6a I self-expansion Somebody in Gresham / who have / desperate they are doing was desperate took me for a half day or you know few hours Saturdays

self-expansion / and I keep that for one year and I was working nother place / nother assisting - $((38))$

8 H1 Yes wh huh.

6b I avoidance And*.- ( ( 1 ( ))

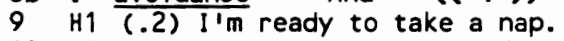

10 H2 You could go to your car for a nap.

11 H1 I did*.

12 H2 When you were assisting were you going to school too? Oh.

13 I And working too.

long initial pause (.2) so I was working six days and going to school for ten credits (unintelligible). (( 16 ))

14 H2 How about through hygiene school though?

15 I expansion And when I was at the hygiene school I was working too.

repetition $2 x$ / I I have all all the time I was working all the time I was working Saturdays, Sundays.self-expansion ( 30$)$ )

$16 \mathrm{H} 2$ That'd be hard.

15 a I And afternoons I was working Dr. WI| 12 to 8 . (( 10$)$ )

$17 \mathrm{H} 2 \mathrm{Hm}(.) \mathrm{hm}$.

18 I (Laughs).

19 H2 What school'd you go to*? Hygiene school*?

20 I (Unintelligibie).

21 H2 okay, I couldn't remember.

22 I long initial pause (.2) And dental school I was at harder than other school I could

long initial pause see some other students I didn't know hardly (word unintelligible). ( 20 ))

$23 \mathrm{H} 2 \mathrm{Um} \mathrm{hm}$ (unintelligible).

24 I She she's so nice*. ( ( 4 ))

25 H2 What does she do?

26 I She come to $S ! !($.$) for the hygiene. ( 7$ ))

27 H2 She what?

28 H1 She's going to $S$ !' campus.

29 I repetition for hygiene. ( $(2))$

30 H2 Oh I guess okay no no I don't know her then no was someone else I was thinking of.

31 I But she is not complaining anytime you know very she's relax she's

32 H2 Sure.

$33 R$ That's apple.

$34 \mathrm{H} 2$ Yeah there its hard (.2) I thought.

35 HI Is your family still in Rumania, Iulia?

36 I Part, but my (.1) oldest family's there. ( ( 6 ))

37 h1 Um hm.

38 H2 Dad still has his job?

39 I Yeah (.1) still have them. (( 4 ))

$40 \mathrm{H}$ (.2) Good Sunintell igible).

41 I Unintelligible).

$42 R$ (.4) Is this your dad?

(Everyone talking at once, can't hear) 
43 I (Unintelligible).

(50 in the dictaphone)

44 H2 Do they uhm count the time that he was laid off as time worked? / Who knows (.) I mean he can still retire in two more years no matter what.

45 I Yes. ( $(1))$

46 H2 Yeah.

(.4 lots of background noise, can't hear)

47 I You know, I'm sure that he can go up like that because he have (unintelligible). ((14))

48 H2 Doesn't sound like he wants to quit.

49 I long initial pause $\quad$ (.3) But he wants to go to Rumania. ( 7 ))

$50 \mathrm{H} 2 \mathrm{Um}$. (.3) It wouldn't be hard to get back out, would it?

51 I $(.2)$ I think he says he wants to go forever there I guess uhm-- ( 13 ))

52 H2 Well I mean just to visit it wouldn't be hard?

53 I Nah not at this time. (( 5$)$ )

54 H2 (.2) That's good.

55 I He's dreaming to go there. ( 5 ))

56 H2 I'll bet he misses it.

57 I Yeah. (.27) I was looking for one*, I'm use the one. (.7) Is your husband home? How is your mom*?

( $(18))$

58 H2 My mom and dad‡?

59 I SUnintelligible).

$60 \mathrm{H}$ Uhm Yeah my husband has to work al! weekend but he works graveyard so he's sleeping. (.3) So, (.2) I didn't think he'd want to stay awake all day course with $\underline{K}$ II.

61 I So when are you (.) working this (unintelligible)? (( 6 ))

$62 \mathrm{H} 2$ On Wednesdays he is and on Mondays his mom takes her.

63 I long initial pause $\quad$ (3) So only one days next week. (( 6 ))

$64 \mathrm{H} 2$ (.2) And that's a hard day (laughs).

65 I clarification Hard day for her*? ( 4 ))

$66 \mathrm{H} 2$ For him*. (.2) For him after being up all night and then staying awake and keeping her all day.

$67 \mathrm{R}$ (.10) (unintelligible) there's a lot of (word unintelligible) to and I would uh go all day long take a one / two hour nap and go to work.

$68 \mathrm{HI}$ (Sighs).

$69 R$ Get up and go all day long five days in a row and then when I had two days off / I never woke up.

$70 \mathrm{H} 2 \mathrm{Hmm}$.

71 R Til I had to go back to work (laughs)--

$72 \mathrm{H} 2 \mathrm{Um} \mathrm{hm}$.

71 a $R$ Start all over again.

73 I (Unintelligible).

74 H2 Sounds awful.

$75 R$ Oh it was fun, at the time I was young and I didn't have / well to do it now / I didn't have family and any kind of responsibility. (.4) Has your husband always worked graveyard?

76 H2 (.1) He worked rotating shifts for thirteen years (.2) which was (.1) every single week it changed (.2) and that was awful and (.) so he he kind of he will lay down and sleep whenever any time of day but this is getting harder now (.) he's ready to switch to days.

$77 \mathrm{R}$ (.2) He has a choice? (Someone brushing their teeth in background).

$78 \mathrm{H} 2$ (.1) Not at this point (laughs). (.2) Hopefully something will come up or else he's going to start looking for something else.

$79 \mathrm{R}$ (.3) And what does he do?

80 H2 Well, he works at $P$ ! (false start) $P|| C|| P||$ right now (.) but he worked at $R-\cdots M-.$. and he quit there a year before they shut down (.1) or laid off.

( 50 on the dictaphone) 
APPENDIX E

COMPONENTIAL ANALYSIS TRANSCRIPTS 
1. What part of your job is easiest?

I don't have any parts are easy (laughs)

everythings hard.

2. Hardest?

Everything is of same importance for me so I don't thinks its easier or probably harder.

2a. Is there anything you find more difficult or hard?

Well, probably the communication is the hard

part, you know, because its giving me more

frustration, I don't understand all, all, things

like that but not not the work itself, I don't

think so.

3. What do you like best about your work?

you are coming with such a hard question today.

3a. I thought they were easy.

This is not easy to answer. What's what's what you say? What's

4. What do you like most about your job?

Well, I like everything, you know, it's funny but I like working with patients all the time.

4a. I know, you said that.

Yeah, it's such a nice variety.

5. Are some people easier to work with than others? oh yes, of course.

5a. What kind? Like who?

Like who? Well, nice people, open people, people who likes to talk, people who doesn't don't demand so much, you know.

5b. Are you thinking of patients?

Yeah, patients patients and uhm colleagues too, doctors.

5c. Are there some doctors who are harder to work with? Yeah, there are some doctors picky and they just overcontrol you, well they just want to want you to be correct and they ask you so many questions and they uhm

5d. What kind of questions do they ask? 
What kind of questions? Well, specialties specialty questions what they think about this

5e. Do they ask your opinion? sometimes, yeah. Well sometimes it's harder when they don't ask you and you just

5f. It's hard not to say? Yeah.

5g. What happens if you say and they didn't ask? I have to say very delicate because I don't know if you was there one time when I say uh I say, you know, I supposed to make a treatment plan for the patient and uh some doctors view that okay some doctors don't but its your duty to make a diagnose some somehow and present it to the doctor and you know there are delicate things like medication, treatment and stuff like that and you don't know what to say about this tooth to come out or to stay there and one time I say, well, this patient is twelve years old and $I$ don't know if this tooth it's okay to stay there or, I try to make a treatment plan and he say, "I* know* that* I* know* that* was twelve years old!" and so like he interpret like I was telling him, you know, not doing my job.

5h. So the best thing to do is to ask? The best thing to do is to be very delicate but not with everybody. Some of them are nice, expect you to present your notes like at school. sometimes they appreciate, sometimes they don't care about your uhm and depends which school are they coming from I'm sure

5i. And can they change anything?

Yeah, because they have the last word, they have to do the diagnost

5j. So then does that relieve you from responsibility? No*, you know why? No, because you should see I mean if he doesn't see it you should tell him, you know, it's kind of cooperation somehow. Like I have when I when I have the patient I have to make the uh prechart so I have to record all the decays, all the structures, everything and sometime you cannot see the decay and uh and, you know, they have to see it but you have to do it 
you have to be prepared, you have to see it what's going on so you are not the one to tell the patient you have that you have that but you can tell the patient, "I am seeing something here like a shadow it's not in a good shape" or something but I am not the last one who decide on that. This is a delicate.

5k. And if you know it's decay then you still say something like--

Yeah, I don't supposed to tell, "Hey this is--"

51. Well what if you think a tooth needs to come out and the doctor doesn't?

oh no no, I don't have to interfere with that.

5m. You don't even think that?

Not, you know $I$, if $I$ if if $I$ see the tooth to come out and probably I should report that to other doctor or something but its not, no it's too big contradiction, no will be in trouble, legal, legal usually they are good.

5n. You would be in trouble legally for saying something like that?

No, no, I not be in trouble legally. The doctor who doesn't see that it's emergent, he will be in trouble.

50. So he has more responsibility?

Yeah, he has he has the most responsibility.

6. Is there anything about your job you don't like? No, I don't have anything I don't like it. No, this is the truth, I like it and I don't know if I don't know if this is very deep deep deep deep or is because I train myself to be like that. I did the school I start working, it's pleasing me a lot and I'm not saying I hate that. Probably I can say when I'm working private $I$ hate to be under a lot of stress and I hate to interfere with bad manners, bad doctors, bad, you know, they are forcing the people to have their teeth or something like that, that's that thing I don't like it. But other way working, no I like it, I like everything.

6a. Well it's kind of asking you to compromise your values. 
Yes, yes, yes, yes and that happen very often.

6b. In private practice?

In private practice. So that's a difference between the place I am working which is more conservative patient, you know, denture and den teeth, conservative.

6c. Uh, huh, that's the clinic?

Yes, and I like it, their philosophy it's a lot better to me. What, it seems to be, the goal is to take care, to prevent, conserve, yes, not to do a lot of extensive work which is expensive and gives profit. The best is to do the best treatment.

7. Thinking about the clinic, and a work day at the clinic, can you list all the people, like the type of people you talk to? Patients being a group and hygienist being another group, just everybody.

So, there are so many other groups. Assistant groups, and there are lot of assistants (unintelligible) -that are working with doctors directly and there are OHAP assistants-the one who are doing the $x$-rays and uh take blood pressure and so there are two categories, front desk ladies, uhm doctors, what else? Housekeeper, and there are some mechanics too, their changing the specialty the chair, you know, broken stuff, equipment, the equipment.

7a. How often do they come?

You know how often do you have problems? So they can come weekly.

7b. And the supervisor--

Hygiene supervisor, assistant's supervisor, manager

8. Well, who would you say you spend the most time talking to?

Talk with everybody. I'm talking with everybody.

8a. Okay, but if you compare it with you would spend more time talking with the hygienist than you would with the mechanic--

Well because their frequency, they are seen and it's less but I'm talking with everybody like if there are hygienists and assistants they knew 
that I am coming from the assistant position, I don't have any mentalities or, you know. There is a there is a in some places the hygienists and and and assistants they have a

8b. Division?

Yeah, division and they kind of, the assistants hate hygienists usually that's where probably vice versa, the hygienists feel superior to but I don't have that feeling.

8c. Because you were--

Because I was assistant and I don't remember having such a big conflict with the hygienists, except a few of them. Yeah, I didn't have conflict but I kind of hated them, they were too superior, presenting too superior and I'm not like that, I try to be nice.

8d. Do all the hygienists help the assistant out? Oh--

8e. I know they're supposed to. Well, you know, it's nice to do it but they are

not doing it. The assistants are kind of complaining a lot about that. You know, it's nice even you are not doing a lot of things, but the fact that you are supporting them and you are trying to do you know just take a blood pressure take a picture when you are not busy it's nice for them but the hygienists kind of. And my biggest excuse is that I am pregnant at this time and I don't know how it will be--

8f. Well, it's just towards the end. Yeah, well, I hope I will change because I like to in my way I like to do something. And I was doing a few times but not-- so when $I$ have a minute when I have a minute $I$ just like to relax a little, I need to.

8g. When you help the assistants do you generally work on your patient?

No.

8h. Or it doesn't matter?

Doesn't matter. I'm working on mine, I'm working on others when I don't have patient, I help with that, clean instruments. 
8i. So the instrument sterilizer-Yeah

8j. Is that a dental assistant?

It's a aide for some clinics, used to be assistant, I used to clean instruments but now the modern way they have a person who is dealing with instruments.

9. Well, what do you talk about with dental assistants? Everything.

9a. Everything*. What do you talk about with dental hygienists?

You know, many times I am asking them questions,

you know, what to do if this is, and I like to

ask them because they feel very good and they are

answering me and they are, you know, feel

flattering, and it's nice when you treat them

like that. And I'm kinda young, you know,

compared to them.

9b. New?

New, professional at this profession. And there are many things and I like to ask them.

9c. Do you fell like they ever feel superior to you? No, they are very nice, a very nice group there.

9d. What about the dentists?

The dentists? Well, same thing, I'm asking and I'm asking questions and uhm well, we are talking so many times, everyone is asking me, especially at $R_{1} \mid$, they are crazy, you know, they, you know, I am not used to such attention, Everybody's asking me, everybody, everybody, all day, you know, you have to make something, hey, I'm feeling like that I'm feeling like that, sometimes you say feel bad just to tell something different because I was feeling good.

9e. What do you talk about with patients?

Talk about with patients? Well when I talk about patients $I$ am talking in front of them.

9f. No, with them.

With the patients, all kind of things, all kind of things. Regarding their medical history, this is mandatory question, there is a change or 
something in your medical history, discuss if there are problems, after that dental problems, what kind of problems do you have, what's bothering you, what's complaining, what do you complain about? Okay, after that I am telling them what I am going to do the charts, you know, perio charts, dental charts, I explain them why I am doing, what I am planning, and after that educational stuff, instructional stuff, brushing in a circular motion and brushing back teeth better and reach that, the vertical and this area, floss, go deep, under the gum, use a perio aide, use a floss threader, use, you know, all kind of instruction you have to be up with all kind of instructions and so there is a lot of variety, plus, plus all questions, how is your weekend, and and stuff like that. some are so interesting, tell you everything, I can find so many things and it's easier for me to do for patient, some of them are nice but you can feel that when you start, if they want to talk it's okay, if not then not asking so.

9g. And what do you talk to housekeepers about? Well, just, hello, how are you, how's your weekend, what are you going to do? and stuff like that. She's talking a lot.

9h. She talks a lot?

Well, if she's asked first, and she's telling about her mother and her children.

10. How do you see yourself in relation to these people? Higher or lower status?

Well, I feel very spoiled, I feel very spoiled, they give me a lot more attention than I expected and I kind of feel good and I hope I have good response to that when somebody giving me attention or try to be nice and respond the same way. So, they were surprising me so many times with their-

10a. Who's that?

Everybody around. Talking mostly about $R$ || they are so family oriented.

10b. The co-workers?

Yes, everybody around. And it's this spirit. 
10c. So would you say you are equal to other hygienists? Um I don't know if I am equal, you know, I don't have enough experience. I don't have a lot of experience like they do. I don't feel like a ten year hygienist. I feel like one who start and try to improve all the time and is under their observation and probably this-- anyway, I'm not equal with them, I don't feel myself equal with them.

10d. How about with the dental assistants?

Well, like I told you I'm trying to be nice with them all the time because I know the mentality which I don't like it and I try to be nice with them.

10e. Are you equal to patients?

No, I don't think I am equal to patients. I am there to give a service and it's it's different. it's my work so I am in different position.

10f. Is it a higher or lower position?

I think it's a special position and I cannot position. I don't want to say, you know I have all kind of patients with all kind of background. I don't feel complexed and $I$ don't feel inferior and I don't feel superior but I'm, I feel like I'm doing a service to them, I'm doing myself that way and I like having all kind of patients, I learn a lot from.

11. Uhm, you said that patients were the most interesting part of your job because they were so different. Well, given that they are different, can you classify types of patients?

Yeah, probably the easiest one is patients who care about their teeth and patients who doesn't don't care about their teeth, you know (laughs)? So this is my first interference, patients who care, patients who don't care. And I don't like to categorize them socially, you know, just I don't care about that so much, don't view that way.

11a. Well, how about by age?

Yeah, there is but I'm I'm so pleased with old patients lets say with very nice teeth, taking care, so, age can be a factor in their uhm 
ability let's say to against taking good care but cannot be

11b. So age is against them?

Yeah, but I don't think that it's against them because of the exception that I have.

11c. So you think if they work harder at it?

Yeah, they they can do, depends on them. Everybody's interest

11d. Are male patients different from female patients? I cannot say that. No, I didn't follow that, some of them take very good nice care, some of them don't. And it's nice when you have family, you know, sometimes both of them are nice and clean, and sometimes the wife is worse and sometimes the husband is worse, and it's very interesting, you know, you expect, you think, anticipate a little bit and it's surprising.

12. Are any patients easier to talk to than others? Yeah. A lot.

12a. What kind of patients?

Well, everybody is special, you know, you cannot categorize. Just depends on the personality and education and you know.

12b. How does education play a factor?

Well if education, ha, this is hard, you catch me here.

12c. I didn't mean to catch you.

You know, education-- when I'm talking about education I'm thinking about family, you know, what they they the moral values they have, you know, somebody doesn't care about people, even is very educated is not talking with you is not interested in your conversation but if somebody is open to people it's it's valuing everybody that way supposed to be, it's easy to talk with and probably I am making a lot of confusion here with education and

12d. And morals and values?

And morals and but I think I consider educated person person with values more than, you know, colleges and stuff like that. 
12e. And why do you do that?

Because I feel it is that way. I hope I am not confusing you.

13. Are there any kinds of patients you don't like? I should say bad smelling mouth uhm kind of irritated me but I am not saying I don't like it I am just, you know, you know, there are some accidents or something like that, you can't give them an excuse but sometimes when it's a bad odor kind of thinking hey what kind of people are you. And I'm not supposed to do that but I am doing it this is my weakness.

13a. Well, maybe you're doing it inside but I don't think anybody can see this.

I'm not mani I'm not expressing that

13b. Manifesting.

Yeah, manifesting but I am feeling, you know, and plus the battle always giving me a bad time so I have to be, you know, this is one of my one of my weakness point.

14. How do Romanians treat older people? How do you treat older people?

You know, how do I treat older people? At work you mean?

14a. No, in general.

You know my closer older people are my relatives and I love them a lot, you know, they are not older, they are so special, you know, I don't see them older, I don't want to see them old, it's hard to see them old and and uh uhm I saw thinking about other people I know they have a special wisdom, very special to me, I didn't have a lot of interference with, you know, activities and stuff like that with older people but they are special, I think. And plus we have a different mentality about sickness and illness and stuff like that. So people older people follow relation not same in my culture they have more ability than other people.

14b. How should they be treated? Who?

14c. Older people. Nice, patient, sometimes patiently. 
14d. Maybe I'm not thinking that old.

Yeah, the difference talking about teeth or talking in general, they are nice. You know depends on everybody, everybody is nice before, some of them are prepared, are strong, nice to do it, some of them are very different, you know, panicky, thinking about death and stuff like that which is bothering me, everybody.

14e. Do you treat those two groups the same? I don't know. Yeah, I'm not dealing with old people for so long times. The only old people are my parents but I don't consider them old. They are sixty-five they are strong, too strong to die yet. You know, I was telling you before how (unintelligible) of course I was sick before but there are people who can do many things and they just pay others to do them, things and I think that's humiliating and put them down somehow. In a In a In an environment where everybody's expecting get sick, you know, and it's depressing and it's not the life, it's not the way to do it. I just I had hard time adjusting with that philosophy that I can't I hope myself to do like things until I die, nobody will take care of me and my everything.

14f. As your parents get older who will take care of them? Well, they will take care of them and I will take care of them but I'm sure that they will take care of them because they don't accept idea of that, you know, going somewhere and have service because I am not, I don't have to talk now because you don't know what happened. There are so many of them and other kind of things strokes and but even so. When you have something to do and you have a reason to do something it's keeping you strong like my one of my grandmother all the time was saying that she cannot die if she has something started to do and she was doing crochet and nice work and she all the time she have something start because that was keeping her. She died in a few hours, you know, she don't have, in fact, she didn't wake up, you know, she went to bed and in the morning she didn't wake up. This is kind of bless blessing. 
15. Let's go back. What are other people allowed to do in your room? Like what are dental assistants allowed to do in your room?

A lot. They can do everything.

15a. How about another hygienist?

Take instrument (both laugh). They steal

instruments.

15b. Is that allowed?

Well, depends, they can come and borrow things.

15c. Does that mean they don't have to ask?

Well, they are asking but if I'm not there they can take and tell you later. Hey, yeah stealing instruments is a big problem but, you know, it's stealing in a way when you put back, it's nice to put them back.

15d. It must be really nice having me there observing because I

act like a watch dog. I've never seen anybody take your instruments.

Yeah, because uhm not really instruments but there are some materials, like tape, (unintelligible), and stuff like. Some hygienists are more organized and keep it up and they're not coming in there when I am there probably because they are thinking that this is not my room and I think uhm is not my room so its not my instruments. I only took my instruments at top and use some and refill some common stuff but not delicate stuff so just because of my position.

15e. So then you're saying they don't take your instruments so much because they're not yours?

Usually the instruments the instruments the hygiene instruments you don't supposed to take it because everybody have their own way to sharpen. There is a rule there is a general rule but everybody has own way own power own angle everything so it's not nice to take somebody else's instruments and sharp them. That's a crime. So everybody has own instruments and I am using the on-call instruments. I have my instruments but I don't like them and I using the on-call at $\mathrm{R}$ ! . The other clinic I have my own 
and I sharpen them, keep them the way I want. So everybody has own instruments and own style instruments. Yes. Some of them are using universal some of them are using some specific, some of them are using scalers, different kind of, difference in which color they come in difference in what they are trying to do or what they like to do.

15f. What are dental assistants allowed to do in your room? clean probably.

15g. Do they do that?

Well, some of them are doing, some of them are nice, some of them don't. They don't supposed to do that but they can do that.

15h. So, are you there when they do that? Well, if I'm with a patient at the front desk explaining treatment plans, something like that, they can come and take my instruments away. There there is not, this doesn't happen so often because--

15i. Their busy?

Yeah, they are busy and they don't like to do it but they are cleanings for them like the hygienist is busy with something else they come and clean the room. They they can do that or you can ask them to do that for you.

15j. Oh, that's okay?

Yes, of course they can refuse you but--

16. Okay, language, language. Do Romanians compliment each other?

They're supposed to.

16a. Their supposed to. Do they do it the same way Americans do?

No, not like Americans, not like here all the time thank you and stuff like that, no. Not so much smiling not so much wasting words, you know. But we are we are complimenting each other, but not like here not like her.

16b. And what is the proper response when someone compliments 
you?

You know, the proper response is well, it's not need to say that, you don't say thank you, you don't appreciate, you kind of you kind of say, "Oh, for nothing" you know like in spanish.

16c. Oh, so there's an expression, yeah, niente in Italian.

Yeah, yeah, like I was doing that not for a compliment you know what I mean. And when it's just for you I don't need your compliment. There are many ways so we are not I have very hard time adjusting with "Thank you" when someone is complimenting me.

16d. Do you feel uncomfortable when someone is complimenting you?

sometimes, yes. sometimes.

16f. Why do you hear your mistakes?

Yeah, I hear, and is not only I hear my mistakes, I know when I sometimes I know when I am saying like and sometimes I want to say so much and I can't you know.

16g. Why? What's happening?

What's happening? It's not coming. It's not coming so fast, you know, I cannot put every word in the right position so fast to match with my feeling also, you know? so that way I don't feel like I express everything so I don't feel accurate.

16h. Do you ever hear in your head what you want to say, it's there but it won't come out?

Yeah. That that's happens lots of times. You want to say something and you cannot find the right words and the right expression, you know, to match like I said. so, that's frustration and it's dumb feeling and many patients are kind of complimenting me in my accent and, you know, I don't realize how heavy is my accent sometime I don't realize because just I open my mouth and they shoo can see that can feel that and I'm telling everybody that I want to change my accent but I can't and many of them are saying, "No, it's very nice accent." some of them I trust, some of them I don't. 
16i. It is a nice accent and they are hard to lose. But you are

a lot more clear than you were a year ago. Do you speak more loudly in Romanian than in English?

Yes. Unfortunately (laughs). I am speaking at home all the time Romanian. Speaking with my parents, my husband, sometimes I am speaking with my patients too.

16j. In Romanian?

Well, I'm recommending usually, combining words (laughs) and I realize sometime and I change them fast.

16k. Well, I was thinking about that. I thought you might speak

louder in Romanian but then I thought the people you speak Romanian to are your family. So is it--

Louder? You know, I am more relaxed more relaxed

talking and I remember I have a speech class and they were asking me to read a poem in my language and in English and they had the comments about $\underline{I}$ was more comfortable and more sure of things in my language than in English. The language sounds more natural in my native.

17. What part about communicating in English is easiest? I'm thinking about reading, writing, grammar, speaking and listening.

Probably talking is the easiest because, you know, you can adjust to whoever and they can help you. It's hard to write, impossible almost. I need to write. And probably because I have, I don't have enough training for that and uh--

17a. Is that in Romanian too?

No*, No*. No I can I used to be good and I probably still am but in English it's im*possible especially business type letters, resumes and stuff like that. Even writing composition and stuff like that.

18. Who do you find most easy to talk to? Easiest person? I cannot answer the easiest person.

18a. Can you answer the most difficult person? No, I can't you know because it depends. If the patient it's nice is open but if the person is 
nervous and demanding then it's hard to talk like this, you know what I mean?

19. Uhm, sometimes you ask patients to spell words for you, like medical terms, do you see any change in the patient? Is there any change in the relationship? Does it matter?

Oh, uhm if I feel inferior asking that? You know, I'm not asking a lot but usually some medications usually the medication. I don't think so because they are spelling bad many times. They don't I find many times bad spelling, the medication is hard to remember that some letter some other words some German words and stuff like that. So I don't feel compromising myself asking for.

19a. And you don't see that they change at all either? No, I don't think so, well, they are sin then.

19b. Do they sin when they're not able to understand you because of your accent or not getting your meaning across?

Well, I try to explain and I give up if they don't. I say okay okay let's try different. Many patients don't know the medication. Coming back to that. They don't know the name, they don't know the dosage, they don't know the stuff so I have to document that too. They don't know the name.

19c. Do you think they have any expectations of you? oh, some of them. Some of them like, some of them expect me to write the right word and I supposed to have a book with me all the time to check that because nobody knows the spelling of there are so many of them.

20. Who do you joke with?

If I joke? Well, other person I know very well and usually I am not joking. I have uh different kind of irony? Irony stuff I cannot joke because I don't know your jokes. But I can be ironic. So they call that humor sometimes. And I am joking at patients at times, joking with some doctors.

21a. Some?

Some. Not everybody. Not with everybody. You know when the patients are impossible. There are 
cases, you know, they don't listen to you or they come second time and the same kind of problems or stuff like that or they are demanding or they are complaining about your colleagues or, you know, things there are things. I can tell the doctors, you know, to make a picture, just explain, hey, this patient is demanding that and wants that or many patients want absolute things. They want to have a certain treatment which is not possible, technically, maintain teeth which are submolar and stuff like that, abscessed or

21b. And they want to keep-They want to keep them and there are things like so I'm going to talk with the doctors before just to give them a picture, as a case. And mostly they agree with me sometimes they are indulgent to the patient and giving them circumstances. circumstance?

21c. Yeah, I understand that but by indulgent do you mean they are nice to the patients or to let them keep maybe two teeth?

Nice presenting what the situation is. But I'm talking about manners to present.

21d. And they have the case there so they know, yeah. When you're sad who do you share that with?

Well, I'm not I try to mask that if it's possible. Uhm--

21e. Why? Why do you mask it?

Because I don't think that it's nice to tell everybody about your sadness and your weakness. I don't like it but sometimes they are asking me because of my face, it's not masked enough. I try, I not telling the truth always.

21f. About how you feel?

Yes, you know the details and the deepness.

21g. Is that typical Romanian behavior?

Um, I'm like that. If I have a problem it's my problem.

21h. How about when you are happy?

I like to tell everybody I'm happy. I don't know if I'm telling or I don't think they appreciate so much. 
21g. They don't appreciate the sadness?

No, the real happiness. You know like I'm

telling somebody my sister was accepted to the

grad school, "Oh really* really* give me that

instrument" or something like that, you know,

superficial stuff. So.

21h. Oh, when it's really a great thing.

Yeah, yeah and $I$ kind of I have that experience a few times and I-- this happen.

21i. And you could have said, "My mother died" and they would have said, "Really, give me that instrument." Uhm, they are not polite, they are more uhm I don't know how to say but they are more a lot more superficial than my feelings and my mentality is so when I'm asking somebody how are you--

21j. You want to know.

They are not answering me, "Fine thanks: they are answering nice, I'm talking about Romanians, but here everybody is, "Fine, thanks." so, "Fine, thanks."

21k. Why do you suppose they do that?

Well, because they are not enough time.

22. Are the clinic's employees different to work with than other patients?

Well, I feel we have more in common. At least the benefits (laughs). At least we know our rights. Yeah, we are interfering the medical, the dental. I'm not good at teasing, I don't know how to tease in English. 